\title{
Preparedness for HIV/AIDS service delivery: The 2005 Kenya health workers survey
}

National AIDS and STD Control Programme

Ministry of Health Kenya

Follow this and additional works at: https://knowledgecommons.popcouncil.org/departments_sbsr-hiv

Part of the Family, Life Course, and Society Commons, Gender and Sexuality Commons, and the International Public Health Commons

How does access to this work benefit you? Let us know!

\section{Recommended Citation}

National AIDS and STD Control Programme and Ministry of Health Kenya. 2006. "Preparedness for HIV/ AIDS service delivery: The 2005 Kenya health workers survey." Nairobi: NASCOP. 



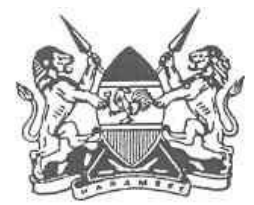

Ministry of Health

Republic of Kenya

\section{PREPAREDNESS FOR HIV/AIDS SERVICE DELIVERY}

\section{THE 2005 KENYA HEALTH WORKERS SURVEY}

\section{(C) Kenya Ministry of Health 2006}

National AIDS and STD Control Programme (NASCOP)

Kenya Ministry of Health

PO Box $19361-00200$

Nairobi, Kenya

Tel: + 254202729549 or 2729502

Fax: +254202710518

Email: headnascop@aidskenya.org

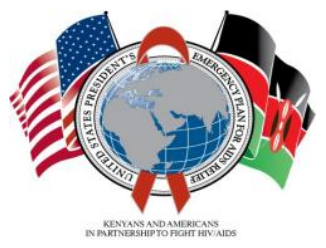

(2) Population Council 


\section{Acknowledgements}

We wish to acknowledge the Kenya Ministry of Health and its administrative structures represented by the District Medical Officers (DMOs), the District Health Management Teams (DHMTs), the District AIDS and STD Control Officers (DASCOs), and others who facilitated this important study. We also wish to thank all the health workers who sacrificed their time to answer the extensive questions in the research. We thank the National AIDS and STD Control Program (NASCOP) under the able leadership of Dr. I. Mohamed, for overseeing fieldwork implementation. Recognition is also given to Population Council (Horizons) and to the Centers for Disease Control and Prevention (CDC) for providing technical assistance. We also wish to thank the field teams who worked tirelessly to conduct the interviews. Special appreciation is directed at the fieldwork supervisors specifically Ms. Mary Annuncieta, Ms. Magdalene Cherop, Mr. Daniel Kongai, Mr. Sahal Mohammed, Mr. Cornellius Mutangili, Ms. Patricia Oluoch, Ms. Naomi Shiyonga, and Mr. John Wanyungu. We would like to thank Mr. Scott Geibel for his assistance with data entry and management. Appreciation is also extended to Mr. Wafula Wabwile, and the NASCOP data entry team for their role in data entry and cleaning. Acknowledgement is extended to the reviewers of this report including Ms. Magdalene Cherop, Ms. Annie Mwangi, Ms. Jane Awuor Ogunde, Mr. Wilson Liambila, Ms. Ellen Weiss, Dr. Naomi Rutenberg and Dr. Reinhard Kaiser.

The main investigators at NASCOP were Dr. Isaiah Tanui, Mr. Godffrey Baltazar, Mr. John Wanyungu and Mr. Meshak Ndolo. At CDC-Kenya, the main investigators were Dr. Lawrence Marum and Dr. Mary Mwangi. At Horizons/Population Council, the main investigators were Dr. Karusa Kiragu (Horizons/PATH) and Ms. Susan Kaai (Horizons/Population Council).

The study received financial support from the U. S. Presidential Emergency Plan for AIDS Relief (PEPFAR) Program in Kenya. It was funded by Centers for Disease Control and Prevention (CDC) through the NASCOP-CDC Cooperative Agreement No. U62/CCU020906-03-1 and through a CDC contract to Population Council (Horizons) No. S500-4-m-1619. The opinions expressed herein are those of the authors and do not necessarily reflect the views of the Centers for Disease Control and Prevention or Population Council. 


\section{Table of Contents}

ACKNOWLEDGEMENTS ........................................................................................................................... ii

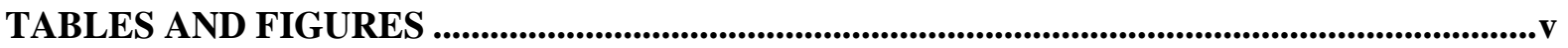

ABBREVIATIONS AND ACRONYMS ........................................................................................ vii

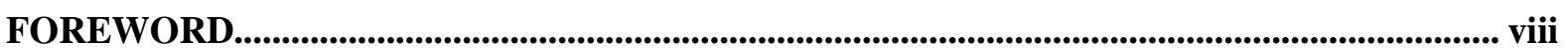

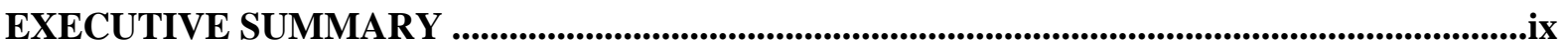

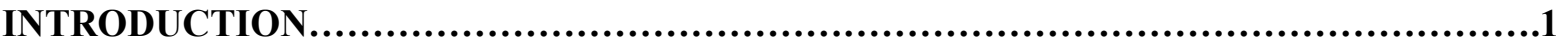

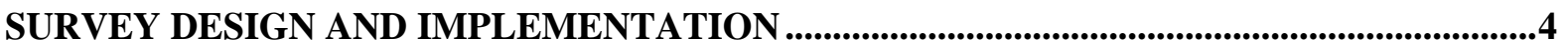

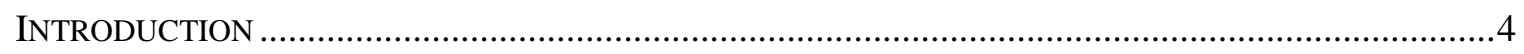

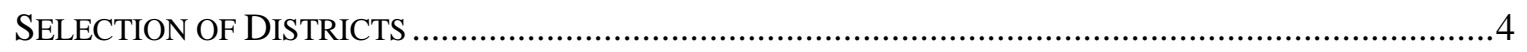

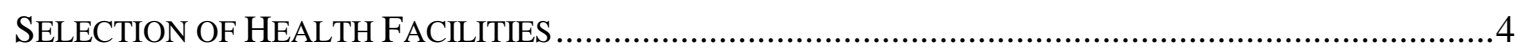

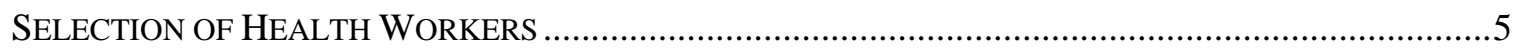

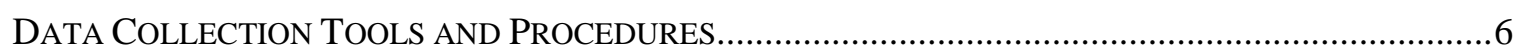

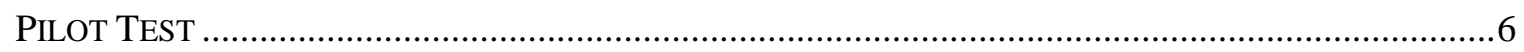

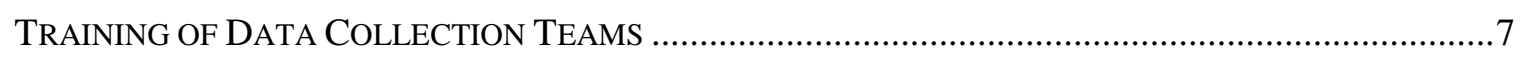

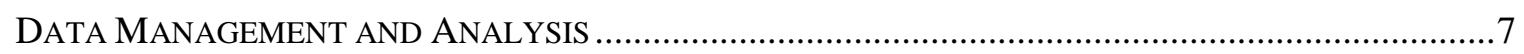

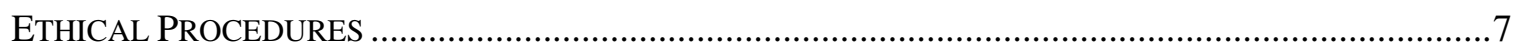

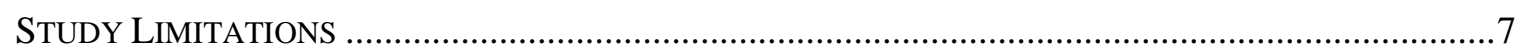

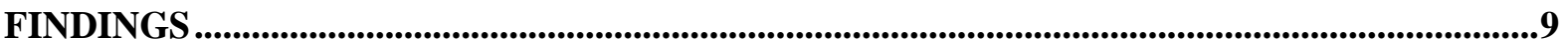

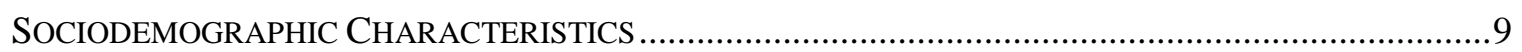

HIV TeSting In CliniCAL SETtings: KnOwledge, Attitudes, AND PRACTICES .......................11

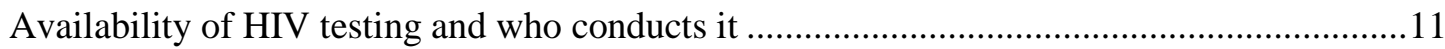

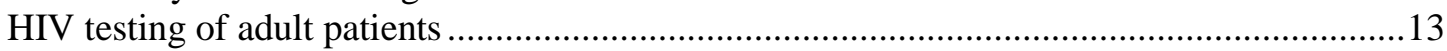

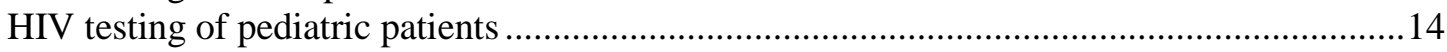

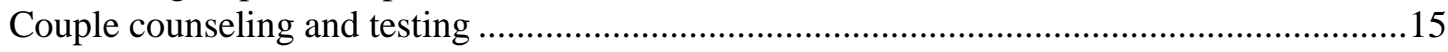

Testing patients without their knowledge ………...............................................................16

Management's support of HIV testing at health facility ........................................................17

Perceived confidence in HIV testing and counseling and training needs ...............................19

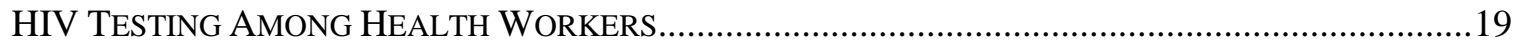

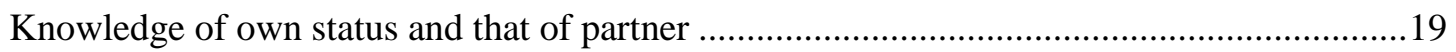

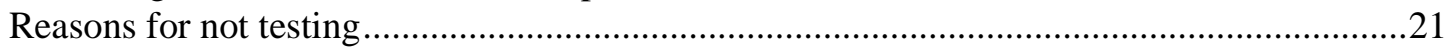

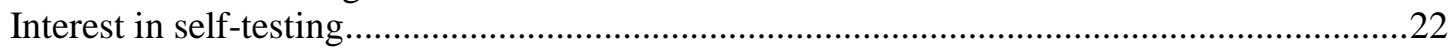

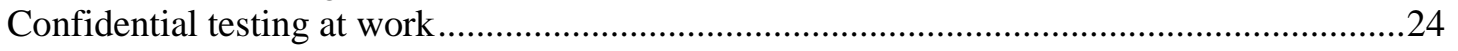

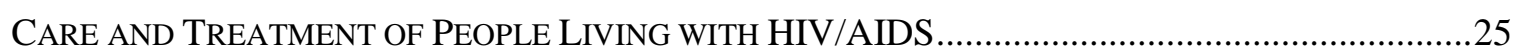

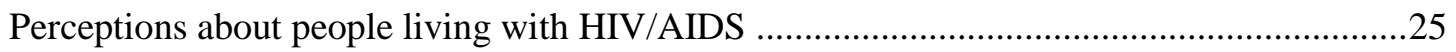

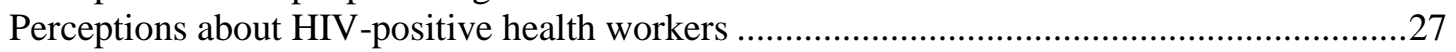


KNOWLEDGE AND PERCEIVEd COMPETENCE In THE CARE AND MANAGEMENT OF

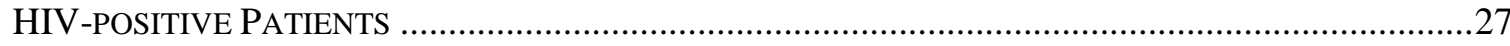

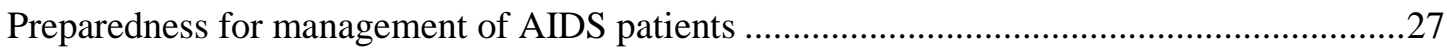

Perceived competence in the delivery of HIV/AIDS services .................................................30

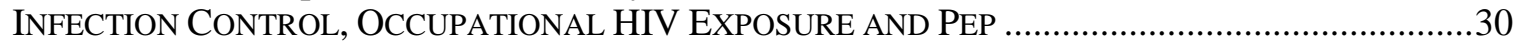

Perceptions about availability of infection control items...........................................................

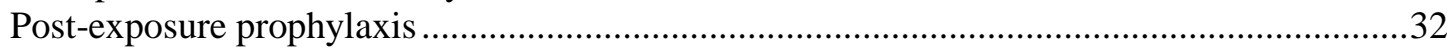

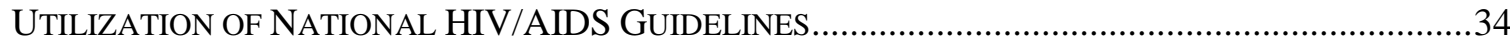

PERCEPTION OF HIV PREVENTION MESSAGES AND KNOWLEDGE OF HIV TRANSMISSION ...........36

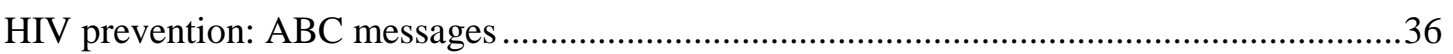

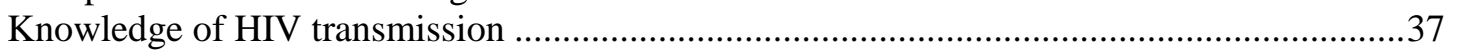

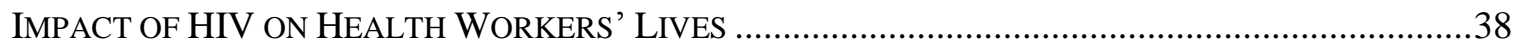

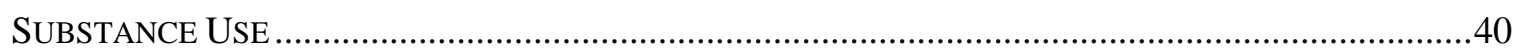

SUMMARY OF FINDINGS AND STUDY RECOMMENDATIONS .........................................43

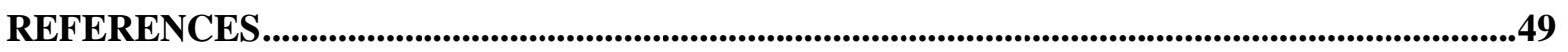

\section{APPENDICES}

APPENDIX I: DISTRICTS AND HEALTH FACILITIES IN THE KENYA HEALTH

WORKERS SURVEY

APPENDIX II: KENYA HEALTH WORKER SURVEY DATA COLLECTION AND

MANAGEMENT TEAM

APPENDIX III: KENYA HEALTH WORKER SURVEY — INDIVIDUAL QUESTIONNAIRE ... 


\section{Tables and Figures}

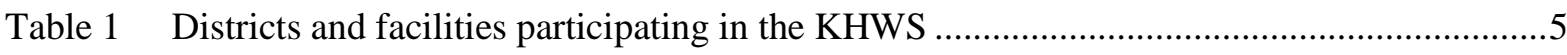

Table 2 Sociodemographic characteristics of respondents ......................................................... 9

Table 3 Percent distribution of selected respondent characteristics by sex .....................................10

Table 4 Percent of health workers who know what "couple counseling" is.....................................16

Table 5 Health workers who feel it is acceptable to test a patient for HIV without their knowledge.

Table 6 Percent of health workers who report low confidence in specific aspects of HIV testing and percent of health workers who request additional training

Table 7 Percent of health workers who have ever been tested for HIV, who tested in the past year, and whose partner has been tested

Table 8 Percent of health workers who would be interested in self-testing among all respondents and by past HIV testing status

Table 9 Percent of health workers who feel they can get a confidential HIV test at work among those who say testing available at their facility

Table 10 Percent of doctors, clinical officers and nurses who provide AIDS care and referral, percent who have been trained in AIDS patient management, and percent feel adequately prepared among those trained

Table 11 Percent of health workers who say the supply of selected infection control items is adequate, mean number of items available, and percent of health workers who are aware of written infection guidelines in their facility

Table 12 Percent of health workers who claim to know what PEP is, who accurately know what it is, who believe PEP is available at their facility, and who have experienced possible occupational exposure to HIV

Table 13 Percent of health workers who know that male or female condoms are effective in preventing the transmission of HIV

Table 14 Percent of health workers who know about couple discordance and vertical transmission of HIV

Table 15 Percent of health workers who report familial HIV burden

Table 16 Percent of health workers who have ever drunk alcohol and have got "really drunk" in the last one month.

Figure 1 Percent of health workers reporting various locations for HIV testing in their facilities ....11

Figure 2 Percent of health workers who conduct HIV testing and counseling and who have been trained by type of training they have received

Figure 3 Percent of health workers who had ever ordered an HIV test for an adult patient by cadre

Figure 4 Percent of health workers who followed recommended procedures in their last adult HIV test

Figure 5 Percent of health workers who followed recommended procedures in their last pediatric HIV test

Figure 6 Percent of health workers who say management encourages HIV testing of listed categories of individuals 
Figure 7 Health workers' reasons for never having been tested for HIV

Figure 8 Percent of doctors, clinical officers, and nurses who have been trained in the | specified area

Figure 9 Percent distribution of doctors, clinical officers and nurses who report feeling "low competence" in the listed areas .30

Figure 10 Average number of GOK HIV/AIDS guidelines read by cadre . .35

Figure 11 Percent who have read specific GOK HIV/AIDS guidelines .35

Figure 12 Percent of health workers who have ever been tested for HIV by intoxication preceding month 


\section{Abbreviations and Acronyms}

$\begin{array}{ll}\text { ABC } & \text { Abstinence, being faithful, condom use } \\ \text { AIDS } & \text { Acquired immunodeficiency syndrome } \\ \text { ANC } & \text { Ante-natal care } \\ \text { ART } & \text { Antiretroviral therapy } \\ \text { ARV } & \text { Antiretrovirals } \\ \text { CDC } & \text { Centers for Disease Control and Prevention } \\ \text { CT } & \text { Counseling and testing } \\ \text { DASCO } & \text { District AIDS and STD Coordinator } \\ \text { DHMT } & \text { District Health Management Team } \\ \text { DMOH } & \text { District Medical Officer of Health } \\ \text { DTC } & \text { Diagnostic testing and counseling } \\ \text { DfID } & \text { Department for International Development } \\ \text { FGD } & \text { Focus group discussion } \\ \text { GOK } & \text { Government of Kenya } \\ \text { HIV } & \text { Human immunodeficiency virus } \\ \text { KDHS } & \text { Kenya Demographic and Health Survey } \\ \text { KHWS } & \text { Kenya Health Worker Survey } \\ \text { KSPA } & \text { Kenya Service Provision Assessment } \\ \text { NASCOP } & \text { National AIDS and STD Control Program } \\ \text { NCST } & \text { National Council for Science and Technology } \\ \text { NEP } & \text { North Eastern Province } \\ \text { NGO } & \text { Non-governmental organization } \\ \text { NUD*IST } & \text { Non-numerical unstructured data indexing, searching and theorizing software } \\ \text { MOH } & \text { Ministry of Health } \\ \text { OI } & \text { Opportunistic infection } \\ \text { PEP } & \text { Post-exposure prophylaxis } \\ \text { PEPFAR } & \text { President's Emergency Plan for AIDS Relief } \\ \text { PLHIV } & \text { People living with HIV } \\ \text { PMCT } & \text { Prevention of mother-to-child transmission } \\ \text { QSR N6 } & \text { QSR International qualitative research software } \\ \text { STD } & \text { Sexually transmitted disease } \\ \text { STI } & \text { Sexually transmitted infection } \\ \text { TB } & \text { Tuberculosis } \\ \text { VCT } & \text { Voluntary counseling and testing } \\ & \end{array}$




\section{Foreword}

HIV/AIDS continues to pose major challenges to the health sector in Kenya. However recent years have seen an increase in resources to fight the epidemic, and major advances in treatment and care. Antiretroviral therapy is now affordable and widely available to many Kenyans. But to access care and treatment, individuals must first undergo HIV testing. The 2003 Kenya Demographic and Health Survey (KDHS) documents that nearly 90 percent of Kenyans do not know their HIV status. To increase the opportunities individuals may have to learn their HIV status, the Ministry of Health has developed guidelines for HIV testing in clinical settings. Launched in 2004, these guidelines encourage health workers to offer HIV testing to patients who would benefit from this service, in order to facilitate access to treatment.

The 2005 Kenya Health Workers Survey is the first attempt to examine the preparedness of the health system to implement these guidelines, and to provide comprehensive AIDS management. This includes availing HIV testing in clinical settings to both adult and pediatric patients, and providing treatment for HIV disease. The survey also examines the working environment in health care facilities, with an emphasis on HIV infection control and access to post-exposure prophylaxis for health workers themselves.

The research reveals a large unmet need for capacity building, with many health workers expressing a need for training in HIV counseling and testing so that they can effectively conduct DTC. The study shows that many health care providers are involved in the management of AIDS patients without the benefit of relevant training. The data also reveal that most providers feel at great risk of occupational HIV infection because they lack adequate supplies of basic infection control items such as water and soap. The constant risk of occupational exposure raises the need for routine HIV testing for health workers; indeed the study participants express keen interest in HIV self-testing, were such an option available in Kenya.

It is our hope that the findings of this survey will contribute to efforts to improve access to AIDS treatment among Kenyans, beginning with encouraging HIV testing and counseling in clinical settings. It is anticipated that the findings will also inform the training programs for providers, especially those in AIDS patient management. It is also hoped that the study will inform interventions aimed at improving the occupational environment and welfare of health workers. We thank all those who supported and participated in this research.

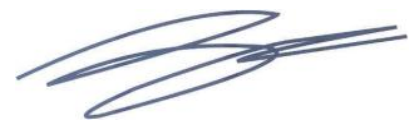

Dr. James Nyikal, MBS

Director of Medical Services 


\section{Executive Summary}

The 2005 Kenya Health Workers Survey (KHWS), the first survey of its kind in the country, interviewed 1,897 health workers in order to determine their readiness to provide HIV/AIDS services in the country. In particular, the study wanted to assess the preparedness of the health system to provide diagnostic testing and counseling (DTC) as part of routine patient management. The survey was conducted between May and June 2005, and covered 27 districts in all eight provinces, including Nairobi. The fieldwork was conducted by 35 trained interviewers and gathered data from health workers in 247 public, private, and faith-based health facilities. The facilities included hospitals, health centers, dispensaries, and maternity homes. The survey used the same sampling frame as that used in the Kenya Service Provision Assessment (KSPA), and provides an opportunity to assess service delivery for HIV/AIDS at the national and provincial level from the providers' perspectives. The study also included 24 focus group discussions with health workers and district management teams, in order to further investigate the issues being addressed.

The research focused on health care providers who are involved in HIV testing and counseling of patients, as well as those who are involved in direct management of AIDS patients. Thus the sample comprised medical doctors $(n=86)$, clinical officers $(n=171)$, registered and enrolled nurses $(n=$ 397 and $n=841$ respectively), laboratory staff $(n=167)$, voluntary counseling and testing (VCT) counselors $(n=131)$, social workers $(n=33)$, and "other" $(n=70$; these are providers who reported multiple roles). Because DTC is largely conducted in hospitals, these were over-sampled to allow adequate sample sizes for in-depth analysis. However, the data were weighted to reflect the national distribution of health worker categories. All the findings are based on weighted data and are summarized below:

\section{Demographic Characteristics}

Of the 1,897 respondents in the study, the majority (62 percent) are female, documenting that health care service delivery in Kenya is largely provided by women. Female health workers outnumber males in all provinces except North Eastern Province (NEP) where 73 percent of providers are male. The data also show that 82 percent of the country's doctors, 70 percent of the laboratory staff, and 65 percent of the clinical officers are male. On the other hand, three quarters of the nurses, 63 percent of the VCT counselors, and 59 percent of the social workers are women. The data also show that enrolled nurses comprise the largest single cadre, making up 44 percent of the health workers in the study. The mean age of the survey respondents was 38 years, and 75 percent were currently married. Among those married, 12 percent of males and six percent of females were in polygamous unions. Respondents had worked at their current post for a median of six years.

\section{Facilities}

Seventy-two percent of the health workers in the survey were working in hospitals, 15 percent in health centers, and 10 percent in dispensaries. About 80 percent of the respondents were employed in public facilities, eight percent in faith-based facilities, and 12 percent in other private facilities. 


\section{Key Findings}

\section{HIV testing practice}

The majority of health workers (88 percent) were employed in facilities where HIV testing was available.

- About 49 percent of the study sample said they conduct HIV testing or counseling, suggesting that the remaining 51 percent could provide this service were appropriate structures in place. Among those who provide HIV testing or counseling, a quarter said they had not been trained in the procedure. Doctors and clinical officers, who provide the bulk of provider-initiated HIV testing, were the least likely to have been trained, with 40 percent or more untrained.

- Of those who had received training in counseling or testing, 50 percent received prevention of mother-to-child transmission (PMCT) training, 36 percent received VCT training, and 18 percent received DTC training (multiple responses possible).

- Over 70 percent of all respondents expressed a need for further training in counseling and testing, with the greatest demand being for training in couple counseling (requested by 90 percent of the health workers).

- One in five health workers felt it was appropriate to test patients without the patient's knowledge, including 40 percent of doctors and 25 percent of nurses. The main justification for testing patients in these circumstances was to obtain a better diagnosis, to know how to medically manage the patient, and in situations where the patient was unconscious.

\section{Recommendations}

There is a need to enable those health workers who are currently not conducting counseling and testing to do so. As indicated in the Guidelines for HIV Testing in Clinical Settings (NASCOP, 2004), health workers should be trained to routinely offer and appropriately recommend HIV testing for their patients. It may be particularly important to expand the proportion of nurses who can undertake this task, since nurses comprise the majority of health care workers. HIV disease can present with a variety of symptoms, including relatively minor ones such as lymphadenopathy and limited weight loss. Symptoms may be rather unspecific, such as respiratory infections or diarrhea. Health workers need to be trained to offer HIV testing, so that patients can receive comprehensive care early enough in the disease process when treatment has a higher probability of success. Earlier knowledge of status will also allow HIV-infected persons to modify their behavior sooner, hence avert infection to partners.

There is also a need to ensure that those already offering counseling and testing are themselves adequately trained. This may be particularly important for doctors and clinical officers, since they are the most likely to order HIV tests and are presently the least likely to have appropriate training. Refresher training to ensure continuous skills improvement is necessary, as there is great demand for it by nearly all respondents in the study. As new information, policies and HIV-related technologies become available, (for example early infant diagnosis), there is need to ensure health workers are up to date and adequately prepared. However, participants for capacity building should be selected judiciously, since training often comes with material benefits that could attract inappropriate candidates.

The roles and responsibilities for HIV counseling and testing should be better defined. This is particularly important because as DTC expands, more and more health workers, including laboratory staff, VCT counselors, and social workers, may be increasingly faced with situations where they might be expected or believe it is appropriate for them to order an HIV test. The recently launched DTC guidelines are not clear on which cadres of health workers are "allowed" to order HIV tests. As DTC scales up, there may be a need to clarify which health workers can order or conduct counseling and testing and which ones cannot. 


\section{Perceived competence in care and management of HIV}

Analysis pertaining to management of AIDS patients was confined to doctors, clinical officers, and nurses $(n=1,494)$. The data revealed a large unmet need for training.

- While 80 percent of these medical personnel had taken care of AIDS patients at their current facility, only 33 percent said they had been trained on AIDS patient management, and only 39 percent felt adequately prepared to carry out this task.

- Two thirds of doctors, clinical officers and nurses said ARVs were available in their facilities, and 16 percent also prescribed these drugs. However, 40 to 50 percent of these personnel did not feel adequately prepared to assess patient readiness for antiretrovirals (ARVs), or to provide adherence counseling.

- Even among those who had received some type of training in AIDS patient management, four out of ten still felt inadequately prepared.

\section{Recommendations}

As is the case with HIV testing in clinical settings, there is also a large unmet need for training in AIDS patient management among Kenyan health workers. This need is likely to become more acute as treatment becomes more available country-wide. And as more patients receive treatment, drug-related problems are likely to surface, for example the emergence of drug-resistant viruses. Although the study did not disaggregate training needs by type of patient, there is need to train health workers in the management of pediatric patients given the low percentage of infected children on therapy, and given the Ministry of Health's commitment to expand pediatric AIDS management.

\section{Utilization of national HIV/AIDS guidelines}

Analysis pertaining to the utilization of national HIV/AIDS guidelines was also confined to doctors, clinical officers, and nurses. Of the eight national HIV/AIDS guidelines that these cadres should have read, the providers had read an average of four. The recently launched DTC guidelines were yet to be read by 74 percent of doctors, clinical officers and nurses.

\section{Recommendations}

An effective dissemination strategy is required to increase health workers' access to national HIV/AIDS guidelines. However, availing the guidelines may not be sufficient. There should be seminars, continuing education sessions, or other opportunities to discuss the guidelines once they arrive at health facilities, in order to enable uniform interpretation and application.

\section{Stigma against people living with HIV (PLHIV)}

All health workers were asked about stigma towards PLHIV.

- In general, health workers felt that AIDS patients were not stigmatized; in fact four out of every ten respondents felt that these patients were treated better than other patients due to increased resources directed at the disease.

- However, focus group discussions (FGDs) suggested some underlying stigma, with AIDS patients sometimes placed at the back of the wards or in less visible areas.

- One in ten providers, including 15 percent of medical doctors, felt that health workers should "have the right to refuse to care for AIDS patients." 


\section{Recommendations}

There is still a need to address stigma among health workers, and address its root causes. Due to understaffing and other constraints in their work environment, health care personnel may be under constant pressure and may not be aware of their negative behaviors. At the same time, when examined in the context of the poor infection control environment in health facilities (see below), it may not be surprising that a certain amount of fear remains, with health workers apprehensive about being infected. Thus efforts to reduce stigma should be coupled with tangible improvements in infection control. In addition, strong efforts should be made to sensitize health workers about confidentiality, violations of patient rights, and upholding the dignity of patients. There may also be a need to develop supportive structures so that patients and others who identify stigmatizing behavior can seek assistance.

\section{Infection control supplies}

Kenyan health workers have adequate supplies of important infection control items but not others:

- About 75 percent of all the health workers interviewed report having sufficient supplies of gloves and sharps disposal containers, and 67 percent report an adequate supply of disinfectant.

- Only 57 percent reported having an adequate supply of running water, and 63 percent an adequate supply of soap.

- Only a third of participants said there were written guidelines about infection control at their facility. Enrolled nurses (27 percent) were the least likely to report presence of these guidelines at their facility and social workers (68 percent) the most likely.

\section{$\underline{\text { Recommendations }}$}

The data suggest a severe need to greatly improve infection control supplies, guidelines, and the general environment in Kenyan health facilities. Simple running water and soap are greatly needed. Guidelines for infection control should be widely disseminated and conspicuously displayed. The problem appears to be widespread, and is particularly urgent in public sector facilities. In addition, wide regional disparities indicate the need to focus more attention on the most problematic provinces.

\section{Knowledge about post-exposure prophylaxis}

Many health workers were uninformed about post-exposure prophylaxis (PEP):

- 41 percent of all the respondents in the survey said they do not know what PEP is. Enrolled nurses were the most likely to say they did not know what PEP was (51 percent), while nearly all doctors (98 percent) said they knew what it was.

- Among those who said they knew what PEP was, one in five could not accurately describe it. Thus only half of providers can be said to have functional knowledge about PEP (i.e., have heard of it and can accurately describe it). Again, enrolled nurses were the least likely to have functional knowledge (36 percent) and medical doctors the most likely (88 percent).

\section{Recommendations}

There is a compelling need to inform health workers about PEP, so that they are clear on what it is, how it works and how it can help them. In particular, there is need to address the wide gap in knowledge among different cadres of health workers, as PEP can be life-saving for all health workers. Information should go beyond general awareness and should be functional enough that health workers can accurately assess when they need PEP and when they do not. There is also a need to make it widely available, and to ensure that health workers know when/where it can be found. 


\section{Exposure to HIV at work}

Nearly one in five of the study sample had had an event where they felt they may have been exposed to HIV at work in the previous 12 months, and half of these had multiple exposures during this time period. Doctors (24 percent) were the most likely to report an accident at work where they could have been exposed to HIV, followed by laboratory staff (19 percent), and by registered and enrolled nurses (17 percent each).

- Among all health workers who knew what PEP was, said it was available in their facility, and reported an incident of potential HIV exposure in the previous 12 months, only 46 percent sought this service.

- About two thirds of those who did not seek PEP said it was because of lack of sufficient information (40 percent) and fear of the process (28 percent).

Recommendations: There is need to reduce the information, social and psychological barriers hindering health workers from seeking PEP. Information about the PEP provision process, including the HIV test, should be availed so that health workers know what to expect. Structures to ensure confidentiality and reduce stigma should be strengthened, so that health workers are not subjected to knowing glances and "physical diagnosis" by colleagues. Because health care personnel can be exposed to HIV multiple times in a given period, they should not feel hindered from seeking appropriate care.

\section{Health workers' awareness of their HIV status}

Many health workers had been tested for HIV.

- Nearly two thirds of the health workers in the study had taken an HIV test, and half of those with partners said that the partner had also been tested. However, this suggests that a third of health workers have never taken the HIV test, and about half the partners of the study respondents had not been tested.

- When asked why they had never been tested for HIV, four out of ten of untested health workers said "no particular reason," a third said they did not feel at risk, and a third said they were "planning to go for the test."

- Nearly three out of four health workers would be interested in HIV self-testing were this service available.

\section{$\underline{\text { Recommendations }}$}

While many have been tested, there is still a need to continue promoting HIV testing among health workers, particularly those who have not been tested or were tested over a year ago. There is also a need to promote partner HIV status awareness, and to make couple counseling and testing available for health workers. This is particularly important in light of the high rates of HIV discordance among couples in Kenya. There is a major need to reduce the apathy toward HIV status awareness particularly among the large proportion of never-testers who state "no particular reason" as the explanation for having never tested. A positive attitude towards knowing their own HIV status is likely to empower health workers to encourage patients to agree to HIV testing - the study results also show that health workers who are aware of their HIV status are also better at providing HIV testing services to their patients. Thus HIV testing among health workers could also boost their confidence in delivering this service.

The data also reveal considerable interest in HIV self-testing. Therefore, a feasibility study exploring this option may be useful. Such a study would need to weigh the ethical and psychological costs and benefits of making this new technology available. In addition, the 
current VCT or DTC guidelines are not clear on self-testing. The findings in this report suggest the need to review these guidelines to provide direction on self-testing.

\section{Personal HIV burden among health workers}

Many health workers in Kenya have been personally affected by HIV.

- Nearly 40 percent had an immediate family member who was HIV-positive or who had died of AIDS; Nyanza Province had the highest proportion, 60 percent.

- Two out of every ten health workers were caring for an HIV-positive immediate family member at the time of the survey. In Nyanza and Western provinces, 40 percent and 32 percent of health workers respectively, were caring for such a family member.

\section{Recommendations}

There is need to recognize that health workers are also personally affected by HIV, and their burden of care does not end at the health facility. Resources to help them recognize stresses associated with this burden, and access to coping strategies such as support groups, discounted medical care services, and similar cost-reducing initiatives, can lessen the strain they experience at home. Workplace programs to "care for the caregiver" can begin to address the challenges faced by health workers who are infected or may be dealing with HIV infection among multiple members of their family.

\section{Attitudes toward condoms}

- More than one in five health workers do not believe that male condoms are effective in preventing HIV.

- More than a third of health workers do not believe that female condoms are effective in preventing HIV.

\section{Recommendations}

As in the rest of Kenyan society, there continues to be a diverse opinion about condoms among health workers. Because provider attitudes and beliefs are likely to affect how they promote condoms, there is a need to educate health workers and to help them disentangle the inconsistent messages about these important means of HIV prevention. Many providers may need the skills to counsel patients about condoms even if they are disapproving or skeptical of them. DTC rollouts may provide an important vehicle for addressing knowledge deficiencies and values conflict.

\section{Alcohol and drug use}

Four in ten health workers have ever drunk alcohol, and 20 percent of ever-drinkers had been intoxicated the month preceding the study. Male providers were more likely to report alcohol use than female providers.

\section{Recommendations}

Further study of alcohol and substance abuse is needed among health workers, in order to determine whether it is a significant problem, and if so, how it can be addressed. Such a study should include addictive substances available in the health care facilities such as methanol and similar mood-altering products. Such a study should also investigate the gender dynamics of alcohol use and HIV risk perception. The finding that one in five health workers self- 
reported being drank in the preceding month may also be indicative of individuals with a drinking problem, and may be worth investigating further. This may be particularly relevant given the acquiescence bias associated with responses to such questions. 



\section{Introduction}

\section{Background}

Kenya is now acknowledged as one of the few countries that have succeeded in changing the course of the HIV/AIDS epidemic. According to UNAIDS, nationwide HIV prevalence presently stands at 6.1 percent among adults ages 15-49 years (UNAIDS 2006). HIV surveillance data over the last 15 years provide strong evidence that there has also been a decline in incidence - the number of new cases appears to have peaked at 200,000 annually in the early 1990s, and fell to 86,000 in 2003. The sad news however is that AIDS-related deaths now exceed new infections, and an estimated 150,000 adults died in 2003 (Ministry of Health 2005).

Almost nine out of ten Kenyan adults do not know their HIV status (Central Bureau of Statistics 2004). According to the 2003 Kenya Demographic and Health Survey (KDHS), only 14 percent of men and 13 percent of women ages 15-49 have ever tested for HIV. The KDHS also found that 7 percent of all cohabiting couples in Kenya are discordant, that is, one partner is HIV-positive and the other is not. Uptake of couple counseling in the nation's more than 800 voluntary counseling and testing (VCT) centers continues to be low despite massive national campaigns.

The expansion of HIV services in Kenya, including VCT and prevention of mother-to-child transmission (PMCT) programs, has enabled more Kenyans to learn their status. However, this leaves out many individuals who could benefit from HIV testing and counseling, such as hospital patients. Patients who present to a health care facility could learn their status as part of a diagnostic assessment, enabling health care personnel to provide a more accurate clinical evaluation and accelerate access to comprehensive treatment and care. This is particularly relevant because up to 60 percent of all medical ward hospital beds in Kenya are thought to be occupied by HIV-infected patients (NASCOP 2004). Such provider-initiated testing and counseling, referred to as "diagnostic testing and counseling" (DTC), provides an opportunity to interrupt the cycle of HIV transmission to the partners and children of patients, thereby boosting HIV prevention efforts.

In 2004, the Ministry of Health (MOH) launched the publication, "Guidelines for HIV Testing in Clinical Settings" (NASCOP/Ministry of Health 2004). These guidelines aim to assist health workers in providing high quality HIV testing and counseling in clinical settings, and increase the opportunities for individuals to learn their HIV status (Box 1).

In order to assess the preparedness of health workers to provide DTC, a national survey in public and private health care facilities was conducted. The survey also provided an opportunity to assess HIVrelated service delivery in the country, to examine the occupational risk environment among health workers, and to assess how HIV has affected them in their personal lives.

\section{Overview of the Survey and Objectives}

This report describes the findings of the national Kenya Health Workers Survey (KHWS).

Researchers interviewed 1,897 health workers in 247 health facilities in all eight provinces of Kenya, including Nairobi, in May and June 2005. The study included public, faith-based, and private hospitals, health centers, dispensaries, and maternity homes. Health workers who work directly with patients and are involved in HIV testing were selected to participate in the survey: doctors, clinical officers, nurses, laboratory staff, social workers, and VCT counselors. Focus group discussions were 


\section{Box 1 Diagnostic Testing and Counseling}

In Kenya, there are six types of HIV testing categories:

1. VCT, initiated by a client seeking to learn his/her status

2. Routine testing and counseling, provided as part of a standard screening package (e.g., PMCT)

3. Diagnostic HIV testing and counseling (DTC), provided to patients as part of the diagnostic work-up for patients

4. Required HIV testing (e.g., in certain restricted settings such as military recruitment)

5. Blood and tissue donation testing

6. HIV testing for medical research and surveillance

With the exception of required testing mandated by a court of law, all HIV testing must be performed with informed consent. In addition, with the exception of testing for research and surveillance, which have their own special requirements, all persons tested for HIV must be offered their results and receive appropriate post-test information.

DTC is the procedure whereby a health worker requests, as part of other investigative tests, HIV testing of a patient with symptoms that could be attributable to HIV. Thus DTC is conducted in the context of medical care. When symptoms suggestive of HIV, such as tuberculosis, are present, DTC is performed routinely as a basic standard of care. The main purpose of DTC is to identify HIV in patients so that they can receive comprehensive care.

DTC uses an opt-out approach, that is, it is assumed that patients with symptoms of HIV desire a diagnosis, therapy, and care. This therefore implies consent for diagnostic testing, including for HIV. HIV testing should therefore not be treated differently from other noninvasive tests such as sputum or urinalysis or other blood tests. However, the HIV test must be conducted with informed consent; patients must be informed that the test is being done and have a right to decline.

Source: NASCOP/Ministry of Health: Guidelines for HIV Testing in Clinical Settings, 2004

also conducted with health care providers and district health management teams. The specific objectives of the survey were to:

HIV testing and counseling

- Determine health workers' perceived competencies, perceptions, and practices pertaining to HIV testing and counseling of patients; examine perceived barriers and how these can be addressed

- Document health workers' awareness of their own HIV status

- Explore health workers' interest in HIV self-testing

HIV/AIDS treatment and care

- Determine health workers' perceived competence in providing HIV/AIDS treatment and care

- Assess the attitudes of health workers toward HIV-infected persons and patients 
Impact of HIV on health workers

- Document the perceptions and experiences of health workers in relation to infection control and occupational exposure to HIV

- Determine health workers' knowledge and uptake of post-exposure prophylaxis (PEP) and barriers to its use

- Investigate the psychosocial burden of HIV/AIDS on health workers

- Assess health workers' use of alcohol and other drugs

\section{Collaborating Organizations}

The 2005 KHWS was implemented by NASCOP, in collaboration with the Horizons Program of the Population Council and the Centers for Disease Control and Prevention (CDC-Kenya). Financial support for the survey was provided by CDC-Kenya under the President's Emergency Plan for AIDS Relief (PEPFAR). 


\section{Survey Design and Implementation}

\section{Introduction}

The KHWS was designed to be a nationally representative cross-sectional survey of health workers in the country. It was based on the 2004 Kenya Service Provision Assessment (KSPA) sampling frame. The KSPA sampling frame contains the universe of public, private, and faith-based health facilities nationwide, categorized by province, district, and facility type (NCPAD et al. 2004).

\section{Selection of Districts}

The KHWS sample was calculated to enable 95 percent confidence and 80 percent power for selected indicators. A sample size of 1,700 was estimated as sufficient for the desired estimates, and since 1,897 respondents were interviewed, the survey exceeded this requirement. For logistical and fiscal manageability, health facilities were selected from 27 districts, including Nairobi. These were randomly selected from the eight provinces proportionate to the number of districts in each province (Table 1).

\section{Selection of Health Facilities}

According to the most recent Health Sector Status Report (Government of Kenya and World Health Organization, 2005), Kenya has 4,634 health facilities. These include 260 hospitals (6 percent), 578 health centers (12 percent), 3,514 dispensaries ( 75 percent), 214 maternity/nursing homes ( 5 percent), and 68 other health facilities ( 2 percent). This national distribution was used to determine the number of each facility type that would participate in the KHWS. A total of 247 health facilities, were randomly selected from the KSPA sampling frame to mirror the national distribution of facilities (Table 1, also see Appendix 1). They included public and private facilities. Since the KHWS focused on clinic-based health workers, stand-alone VCT facilities $(\mathrm{n}=54)$ were excluded from the sampling frame. In addition, facilities classified as "other" $(n=68)$ were also excluded to avoid ambiguity. This reduced the number of facilities in the sampling frame to 4,512 .

The proportion of hospitals and dispensaries to be included in the survey was reassessed owing to logistical challenges of reaching a very large number of dispensaries and the fact that DTC is less likely to occur in such facilities. Thus, although dispensaries make up 78 percent of all health facilities in Kenya, they comprised about 37 percent of the sample. Similarly, hospitals where most DTC occurs were doubled, to make up 12 percent of the sample (see Appendix 1 for list of facilities).

The study aimed at covering the entire country, including North Eastern Province (NEP). The NEP is normally excluded from most surveys due to its sparse population, low level of security, and difficulty in accessing most of the province. Rather than omit the province entirely however, the KHWS selected NEP's largest and most populated district, Garissa, to participate in the study. The eight sampled health facilities included the provincial hospital, which contributed 47 percent of the 83 health workers interviewed. Thus the results for NEP may not be representative of the province, and should be interpreted with caution. 
Table 1 Districts and facilities participating in the KHWS

\begin{tabular}{lcccc}
\hline Province & $\begin{array}{c}\text { Number of } \\
\text { districts }{ }^{1} \text { in the } \\
\text { province }\end{array}$ & $\begin{array}{c}\text { Number of } \\
\text { districts in the } \\
\text { KHWS sample }\end{array}$ & $\begin{array}{c}\text { Number of } \\
\text { health facilities } \\
\text { nationwide }\end{array}$ & $\begin{array}{c}\text { Number of health } \\
\text { facilities in KHWS } \\
\text { sample }^{2}\end{array}$ \\
\hline Rift Valley & 19 & 7 & 1,346 & 73 \\
Eastern & 13 & 4 & 891 & 54 \\
Nyanza & 13 & 5 & 588 & 23 \\
Central & 8 & 3 & 535 & 30 \\
Coast & 7 & 3 & 521 & 22 \\
Nairobi & 1 & 1 & 361 & 12 \\
Western & 8 & 3 & 311 & 25 \\
N. Eastern & 4 & 1 & 81 & 8 \\
Total & 4 & $\mathbf{2 7}$ & $\mathbf{4 , 6 3 4}$ & $\mathbf{2 4 7}$ \\
\hline
\end{tabular}

${ }^{1}$ At the time of fieldwork, new districts were being demarcated, a process that had not been concluded. The KHWS used the most reliable figures.

${ }^{2}$ The numerical distribution of the facilities visited is not necessarily identical to the percent distribution of facilities in the initial sample due to inclusion of back-up facilities during fieldwork.

${ }^{3}$ Nairobi was treated both as a province and a district. Health facilities were selected from throughout the province.

\section{Selection of Health Workers}

Using data from a recent health sector assessment (Ministry of Health and Department for International Development 2005), the study team estimated the distribution of professional health workers in the public sector nationwide to be: doctors ( 5 percent), clinical officers (9 percent), nurses (68 percent), laboratory staff ( 9 percent), and social workers/VCT counselors ( 9 percent). This distribution was used to determine the proportion of health workers in each cadre to be selected in the KHWS. However, the survey over-sampled doctors and clinical officers, since they are the main cadres involved in requesting HIV testing for patients. The sample was weighted during data analysis to mirror the national distribution of health care workers by cadre. All results presented in this report are based on weighted data, unless otherwise specified.

Most health facilities in Kenya are understaffed. For example, dispensaries, which make up over three-fourths of the facilities, are mostly run by one or two nurses. In order to achieve the desired sample size and have an adequate cross-section of health workers, quotas were established for each cadre and for each type of facility. For example, research teams aimed to target at least 45 respondents in hospitals (7 doctors, 11 clinical officers, 20 nurses, 3 laboratory staff, 2 social workers, and 2 VCT counselors). Similar quotas were established for health centers, maternity homes, and dispensaries.

At each selected health facility, the required number of health workers in each cadre was randomly selected from the duty roster and included in the study after giving informed consent. Back-up health facilities were identified and included in the survey sample where there were shortfalls in the requisite sample. Because hospitals have many health care providers, they contributed a larger number of respondents to the sample. And because dispensaries have only one or two health workers at any one time, even though efforts were made to interview both workers when possible, they contributed only a small proportion of the respondents interviewed. 


\section{Data Collection Tools and Procedures}

\section{Survey}

Data were collected using a structured questionnaire (Appendix 3). The questionnaire collected information on:

- Sociodemographic characteristics of respondents

- Occupational exposure to HIV

- HIV testing and counseling of patients

- Care for HIV-positive persons

- Perceptions about people living with HIV/AIDS

- Attitudes toward ways to prevent HIV infection

- Personal experience with HIV/AIDS

- Health workers awareness of their own HIV status

- Alcohol and substance use

\section{Focus group discussion}

24 focus group discussions (FGDs) were conducted with health workers and District Health Management Teams (DHMT). Three FGDs were conducted in each province: two with health workers and one with the DHMT. Discussions were conducted at a pre-selected district or provincial hospital. Trained interviewers used a FGD guide (Appendix 4). Participants in the health worker FGDs were of the same cadre as those who completed the questionnaire (doctors, clinical officers, nurses, laboratory staff, VCT counselors, and social workers). Participants in the DHMT FGDs comprised the District Medical Officer of Health, District Health Records and Information Officer, District Public Health Nurse, Hospital Matron, District Clinical Officer, District Health Education Officer, District AIDS and STDs Coordinator (DASCO), and District Laboratory Officer. The FGDs were tape-recorded, and the recordings were supplemented by notes from the study's notetakers.

\section{Pilot Test}

The questionnaire and FGD guides were pre-tested twice, first in Narok and Kirinyaga districts, then in Nyandarua and Koibatek districts. While initially designed as a self-administered questionnaire, the high error rate associated with this method ${ }^{1}$, as well as respondents' personal preferences, led to a decision to collect the data using face-to-face method. Further discussions with health workers and the research team generated a modified format called "guided self-administration method." This procedure entailed the interviewer reading the items in the questionnaire to the provider, but laying the questionnaire on a table in a way that allowed the respondent to see the items as well. This allowed the respondents to see the possible responses and make their choices. Because the respondents were literate, and because most questions were not sensitive, this method of data collection proved more efficient. It was also deemed superior to purely self-administered data collection because it enabled the interviewer to promptly clarify responses and correct mistakes, especially those associated with skip patterns. On average each questionnaire took 20-30 minutes to complete.

\footnotetext{
${ }^{1}$ During the pretest, 39 percent of self-administered questionnaires had an error rate of over 5 percent compared to 0 percent for questionnaires administered using the face-to-face method.
} 


\section{Training of Data Collection Teams}

Prior to data collection, 45 research assistants were recruited and taken through a five-day training. The training comprised of a comprehensive review of the questionnaires, FGD guides, and interviewing techniques. It also included training in specialized topics such as HIV counseling and testing, PEP, and the structure of health care facilities. Both lecture and role-play methods were used. Class-based training was supplemented by a fieldwork practicum in local health care facilities. A screening quiz was used to evaluate interviewer performance, and 35 research assistants were retained as interviewers and supervisors for the study (Appendix 2). Special sessions were held with supervisors, with emphasis on quality control.

Data were collected in May and June 2005. Seven teams of researchers, each with 3-4 members and a supervisor, conducted the fieldwork. The teams worked closely with the respective District AIDS and STD Coordinators (DASCOs) to gain entry and cooperation from participating health facilities. On average, research teams took 3-4 days to complete data collection in a district and all of the fieldwork was completed in three weeks.

\section{Data Management and Analysis}

Quantitative data were double-entered using EPIDATA, and internal consistency corrections made. Analysis was conducted using STATA. All FGDs were transcribed after the two note takers in each session reconciled their notes. FGD transcripts were analyzed using NUD*IST (N6).

\section{Ethical Procedures}

NASCOP secured the relevant approvals and authorization for the survey from the National Council for Science and Technology (NCST), the government agency that regulates research in Kenya. The study protocol also underwent ethical review and approval by Population Council/Horizons and the Centers for Disease Control and Prevention (CDC).

Prior to completing the questionnaire or participating in the FGD, each willing participant completed a consent form (Appendices 3 and 4). During the pretest of the data collection tools, health care providers had expressed great discomfort about signing a consent form and the signature requirement was dropped. It was replaced by a tick indicating that the respondent understood that completion of the questionnaire was voluntary and all the respondent's questions had been answered prior to participation in the survey.

All questionnaires and FGDs were anonymous, and no identifiers linking an individual to a specific answer were available. All data collected as part of this project - including questionnaires, notes, and tape recordings - were kept in a stored room only accessible to authorized research personnel.

\section{Study Limitations}

Several limitations should be born in mind when reviewing this study. First, the KHWS was based on self-reports from the health workers, and did not include verification strategies such as facility observations or patient interviews. Neither could it verify responses to questions about the personal behaviors of health workers. Given the nature of the topics being explored, it is feasible that there were elements of social desirability bias in the answers. Second, the study did not investigate other aspects of HIV/AIDS service delivery, such as equipment and supplies. Therefore, the assessment of 
"preparedness for HIV/AIDS service delivery" was based largely on the health workers' perception. Thirdly, the team collected data from only one district in the NEP (i.e. Garissa district), due to logistical, financial and security considerations. Therefore the findings are less generalizable to the entire NEP. Fourthly, the study's sample was designed in such a way that a province was treated as a unit, and the requisite number of participating facilities sampled from across the districts selected within the province (see Appendix 1). Thus the results should not be used to draw conclusions at the district level, but rather at the provincial level. Finally, some of the study categories are rather small, even though this is a reflection of staffing realities on the ground. For example, the country has only a handful of social workers, and most facilities do not have this cadre of health worker. Therefore the reader is alerted to keep these sample sizes in mind and weigh the study's findings in light of these shortcomings. 


\section{Findings}

\section{Sociodemographic Characteristics}

The study interviewed 1,897 health workers nationwide; Table 2 presents their weighted and unweighted distribution. All subsequent results are based on weighted data. The table shows that slightly more than 60 percent of the sample was female. Enrolled nurses comprised the largest group of health workers, suggesting that the bulk of health care in Kenya is delivered by nurses and, specifically, enrolled nurses ${ }^{2}$. Rift Valley, the province with the most health facilities, also had the greatest number of respondents (26 percent). Just over 70 percent of the respondents worked in hospitals and about 80 percent worked in public health facilities.

Table 2 Sociodemographic characteristics of respondents

\begin{tabular}{|c|c|c|c|}
\hline \multirow[t]{2}{*}{ Characteristic } & \multicolumn{2}{|c|}{ Number of respondents } & \multirow{2}{*}{$\begin{array}{c}\text { Percent } \\
\text { (weighted) }\end{array}$} \\
\hline & Unweighted & Weighted & \\
\hline \multicolumn{4}{|l|}{ Sex } \\
\hline Male & 826 & 712 & 37.7 \\
\hline Female & 1,058 & 1,175 & 62.3 \\
\hline \multicolumn{4}{|l|}{ Cadre } \\
\hline Doctor & 179 & 86 & 4.5 \\
\hline Clinical officer & 394 & 171 & 9.0 \\
\hline Registered nurse & 326 & 397 & 20.9 \\
\hline Enrolled nurse & 691 & 841 & 44.4 \\
\hline Laboratory staff & 137 & 167 & 8.8 \\
\hline Social worker & 22 & 33 & 1.8 \\
\hline VCT counselor & 94 & 131 & 6.9 \\
\hline Other & 52 & 70 & 3.7 \\
\hline \multicolumn{4}{|l|}{ Province } \\
\hline Central & 214 & 214 & 11.3 \\
\hline Coast & 201 & 211 & 11.1 \\
\hline Eastern & 388 & 385 & 20.3 \\
\hline Nairobi & 127 & 116 & 6.1 \\
\hline North Eastern & 103 & 102 & 5.4 \\
\hline Nyanza & 257 & 249 & 13.1 \\
\hline Rift Valley & 477 & 497 & 26.2 \\
\hline Western & 130 & 123 & 6.5 \\
\hline \multicolumn{4}{|l|}{ Type of facility } \\
\hline Hospital & 1,369 & 1,338 & 72.0 \\
\hline Health center & 263 & 274 & 14.8 \\
\hline Dispensary & 152 & 182 & 9.8 \\
\hline Maternity home & 65 & 63 & 3.4 \\
\hline \multicolumn{4}{|c|}{ Operating organization } \\
\hline Public & 1,522 & 1,522 & 80.3 \\
\hline Faith-based & 157 & 157 & 8.2 \\
\hline Private & 218 & 218 & 11.5 \\
\hline All health workers & 1,897 & 1,897 & 100 \\
\hline
\end{tabular}

\footnotetext{
${ }^{2}$ In Kenya, there are two types of nursing cadres: registered and enrolled. Registered nurses receive more advanced training and are accorded greater management responsibility in a health care facility. Registered nurses are awarded a diploma upon completion of their 3.5 years of training, while enrolled nurses receive a certificate and are trained for three years. The academic requirements for admission if one desires to be a registered nurse are also higher than that of enrolled nurses.
} 
The mean age of the respondents was 38 years, 75 percent were currently married, and 21 percent had never been married (data not shown). Among those married, 12 percent of males and 6 percent of females were in a polygamous marriage. About 63 percent of respondents were Protestants, 28 percent were Catholics, and 8 percent were Muslims. Respondents had worked in their current health facility for a median of six years.

Table 3 presents selected demographic characteristics by gender, and shows that in this sample, 82 percent of Kenya's doctors are males, as are 70 percent of laboratory staff and 66 percent of clinical officers. On the other hand, females predominate in the nursing, social work, and VCT counselor professions. When examined by provinces, NEP is the most male-dominated province, where men make up 73 percent of the health staff. Nairobi Province, on the other hand, is the most femaledominated, where females comprise 80 percent of the health staff. Females outnumber males in hospitals, health centers, dispensaries, and maternity homes as well as in public, faith-based, and other NGO facilities.

Table 3 Percent distribution of selected respondent characteristics by sex

\begin{tabular}{|c|c|c|c|c|}
\hline Characteristic & Males & Females & Total & $\begin{array}{c}\text { Number of } \\
\text { health } \\
\text { workers }\end{array}$ \\
\hline \multicolumn{5}{|l|}{ Cadre } \\
\hline Doctor & 81.5 & 18.5 & 100 & 86 \\
\hline Clinical officer & 65.6 & 34.6 & 100 & 169 \\
\hline Registered nurses & 27.8 & 72.2 & 100 & 394 \\
\hline Enrolled nurses & 24.4 & 75.7 & 100 & 837 \\
\hline Laboratory staff & 70.4 & 29.6 & 100 & 165 \\
\hline Social worker & 40.9 & 59.1 & 100 & 33 \\
\hline VCT Counselor & 38.9 & 61.1 & 100 & 131 \\
\hline Others & 52.3 & 47.7 & 100 & 70 \\
\hline \multicolumn{5}{|l|}{ Province } \\
\hline Central & 28.7 & 71.3 & 100 & 214 \\
\hline Coast & 54.6 & 45.4 & 100 & 210 \\
\hline Eastern & 34.8 & 65.2 & 100 & 382 \\
\hline Nairobi & 19.6 & 80.4 & 100 & 114 \\
\hline North Eastern & 72.5 & 27.5 & 100 & 102 \\
\hline Nyanza & 34.3 & 65.7 & 100 & 245 \\
\hline Rift Valley & 33.5 & 66.5 & 100 & 497 \\
\hline Western & 44.8 & 55.2 & 100 & 123 \\
\hline \multicolumn{5}{|l|}{ Type of facility } \\
\hline Hospital & 37.9 & 62.1 & 100 & 1,382 \\
\hline Health Center & 36.7 & 63.3 & 100 & 254 \\
\hline Dispensary & 35.7 & 64.3 & 100 & 186 \\
\hline Maternity Home & 42.5 & 57.5 & 100 & 64 \\
\hline \multicolumn{5}{|c|}{ Operating organization } \\
\hline Public & 37.5 & 62.5 & 100 & 1,514 \\
\hline Faith-based & 31.4 & 68.6 & 100 & 215 \\
\hline Private & 43.3 & 56.7 & 100 & 156 \\
\hline All & 37.7 & 62.3 & 100 & 1,886 \\
\hline
\end{tabular}




\section{HIV Testing in Clinical Settings: Knowledge, Attitudes, and Practices}

Health workers were asked a series of questions to document how HIV testing is conducted in their facility. They were also asked about their own experiences providing HIV testing and counseling and couple counseling, as well as testing of adult and pediatric patients. They were also asked their opinion about management's support for HIV testing in their facility.

\section{Availability of HIV testing and who conducts it}

Most providers reported that HIV testing was available in their facility; only 12 percent worked in facilities that did not have HIV testing. Two-thirds of survey respondents said that HIV testing was conducted at the facility's VCT site, 64 percent said it was conducted in the laboratory, and 32 percent in the ANC clinic (Figure 1; multiple responses possible). This suggests that HIV testing as part of DTC would be feasible in the facilities where the vast majority of respondents worked. Figure 1 Percent of health workers reporting various locations for HIV testing in their
facilities ${ }^{1}$

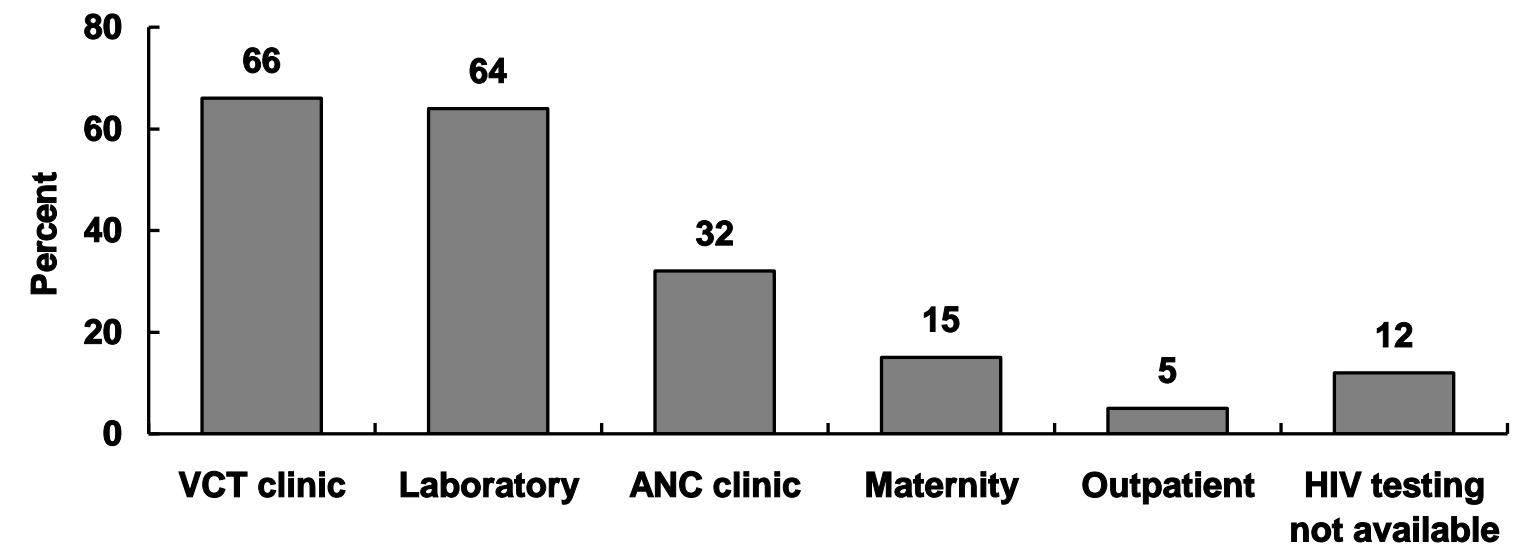

Where HIV testing is conducted

${ }^{1} n=1,897$ health workers

Respondents were asked whether they themselves "conduct HIV testing or counseling." The question was worded in that manner because in a health facility, providers may provide counseling but the actual execution of the test is done in the laboratory. Therefore the survey wanted to capture respondents who conducted either activity. About half (49 percent) of all respondents said they conduct HIV counseling or testing. Those who responded affirmatively were asked whether they had been trained in counseling or testing, and 72 percent said they had. Thus, the remainder - or a quarter of health workers who conduct HIV testing or counseling - were doing so without the benefit of relevant training. The data also show that 45 percent of the doctors who conduct HIV counseling or testing said they had not been trained, as did 40 percent of their clinical counterparts, 29 percent of the registered nurses, 30 percent of the enrolled nurses, 28 percent of laboratory staff, 17 percent of the social workers and 5 percent of VCT counselors. Thus doctors and clinical officers, who provide the bulk of counseling or testing, were the least likely to have been trained. Those who had received training were asked what kind of training they had received, and half (50 percent) said they had received training in PMCT HIV counseling and testing, while 36 percent had received training in VCT (see Figure 2). About 18 percent had received training in DTC, which had only been recently introduced. 
Figure 2 Percent of health workers who conduct HIV testing and counseling and who
have been trained by type of training they have received ${ }^{1}$

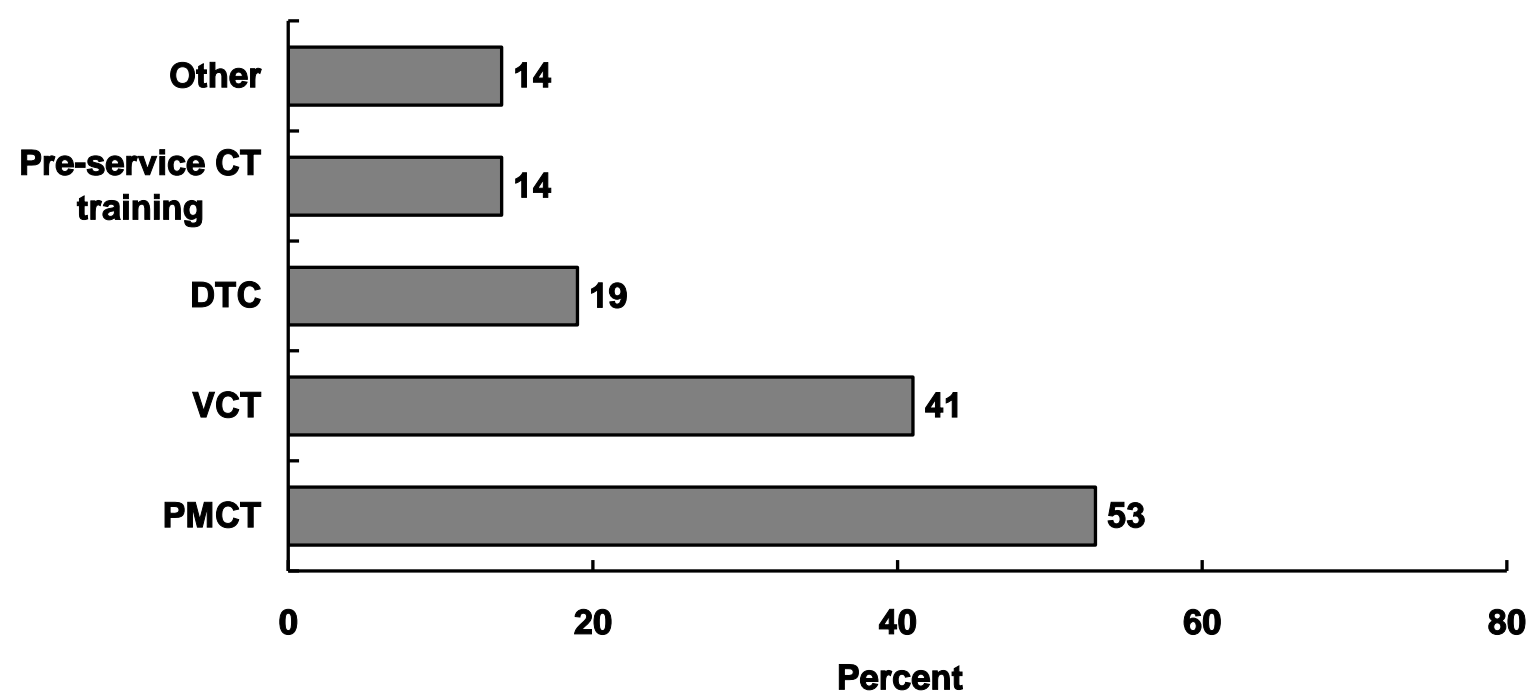

${ }^{1} n=891$ health workers who conduct HIV counseling or testing and who have been trained in this service. Multiple responses possible.

FGDs provided an opportunity to find out more about how HIV testing and counseling is conducted in clinical settings, and the role of training in facilitating DTC. The discussions suggest that lack of training is a barrier to DTC, as indicated by both the health workers and by the DHMTs. FGD participants expressed concern that health workers who lacked training and confidence in HIV testing and counseling may provide inadequate services to patients and miss important opportunities to inform patients of their HIV status:

... a patient may be seen to have symptoms but since one [i.e., health worker] isn't trained, he neglects it or pushes it to VCT.

DHMT member, Rift Valley Province

Health workers sometimes lack confidence in testing and counseling.

Female nurse, Rift Valley Province

Some health workers don't know how to counsel. At times clients' results are released secretly; this brings conflict and tension to the client.

Female nurse, Western Province

A large majority of health workers participating in FGDs felt that all health workers should be trained in HIV counseling and testing:

Training should be done for all health workers so that all of them can do the job of counseling and testing when the need arises.

Female nurse, Eastern Province

All staff should be trained [in HIV counseling and testing], as this will reduce the inconvenience of referring clients to other health workers....

Male doctor, Rift Valley Province

At the same time, it was recognized that not all health workers were suited for the task: 
...doctors should do that [HIV testing and counseling] but when it comes to handling patients emotionally, they are poor.

Female nurse, Coast Province

Clinicians are reluctant to be trained, yet they are the ones who do a lot of mistakes.

Female nurse, Western Province

FGDs also revealed that in addition to training, other barriers hindered the ability of health workers to conduct DTC, especially lack of time and shortage of test kits. Many providers indicated they had to borrow test kits from other departments when they ran out. Providers also reported that some of their colleagues had counterproductive attitudes toward HIV testing, discouraging many patients from accepting DTC:

The staff may sometimes say to patients: 'You are healthy. Why should you test [for HIV]?'

DHMT member, North Eastern Province

Many health workers do not keep confidentiality because they are not trained.

DHMT member, Eastern Province

Some staff are moody and they scare away patients.

Female nurse, Eastern Province

\section{HIV testing of adult patients}

In order to assess the extent to which providers initiate HIV testing, all respondents were asked whether they had "ever ordered an HIV test on an adult patient," and 41 percent said they had done so (Figure 3). Nearly all doctors and clinical officers had ever ordered an HIV test on an adult patient. The results also show that nearly one in five laboratory staff also ordered HIV testing.

Figure 3 Percent of health workers who had ever ordered an HIV test for an adult patient by cadre ${ }^{1}$

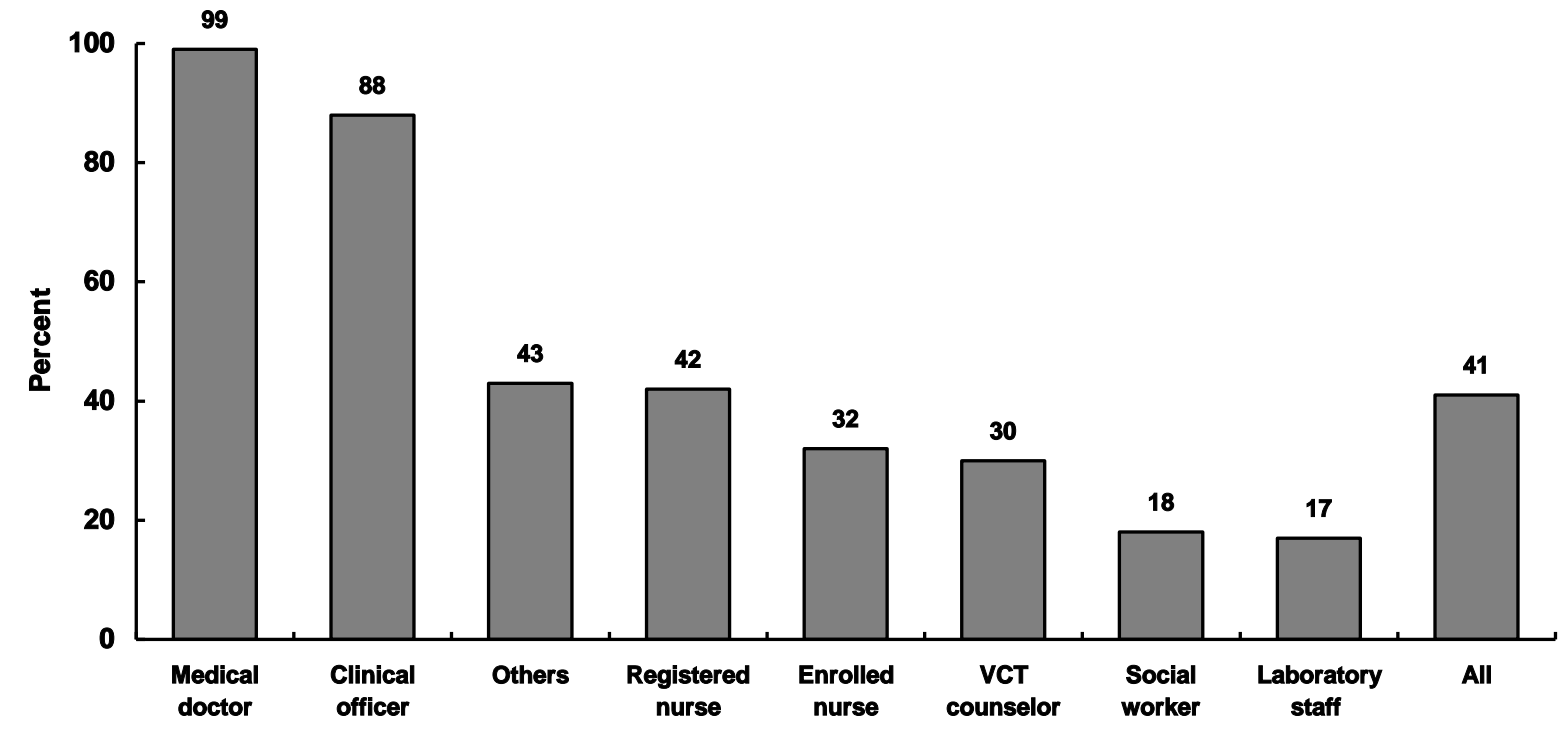

${ }^{1} n=1,894$ health workers 
To assess how testing was done, the 776 providers who said they had ordered a test on an adult patient were asked whether they obtained informed consent and availed pre and post-test counseling on their most recent test. Figure 4 shows that 91 percent informed their most recent patient themselves before the test was conducted, 92 percent made pre-test counseling available either by conducting it themselves (58 percent) or arranging for it to be done by someone else ( 34 percent), and a similar percentage made post-test counseling available ( 46 percent conducted it themselves; 43 percent made arrangements it be done by someone else). Thus providers appear to follow the DTC guidelines fairly closely.

\section{Figure 4 Percent of health workers who followed recommended procedures in their last adult HIV test ${ }^{1}$}

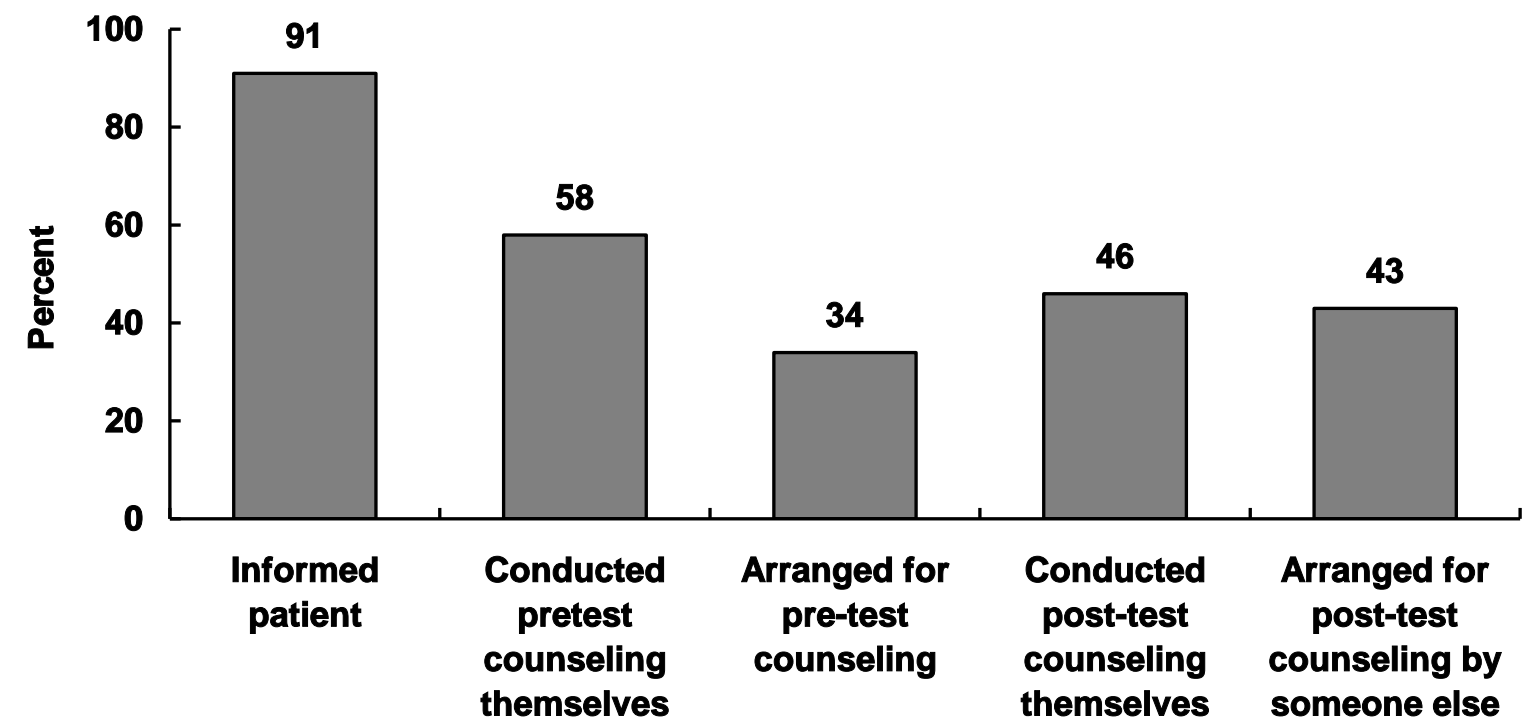

${ }^{1} n=776$ health workers who had ever ordered a test for an adult patient

When asked who initiated the last HIV test on an adult patient, 63 percent of health workers who had ever ordered an HIV test on an adult said they initiated it themselves or on request from another health worker, 32 percent said the patient requested the test himself/herself, and five percent said the patient's family requested it. But in some cases, relatives object to the patient being tested, as FGDs showed:

Sometimes families are reluctant. We sometimes have bed-ridden patients and when we ask relatives whether they can be tested, they refuse.

Female nurse, Central Province

Sometimes it is the wife who is bed-ridden. We talk to the husband and they discourage testing. Male doctor, Central Province

\section{HIV testing of pediatric patients}

About 17 percent of health workers $(n=313)$ had ever requested an HIV test for a pediatric patient. When asked who initiated the last pediatric test, 69 percent said they or another provider did, while 30 percent said the parent or guardian requested it. Figure 5 shows that 90 percent of the health workers 
who had ever ordered an HIV test on a pediatric patient informed the patient's parents or guardians before conducting the most recent test. Ninety percent of all providers who had ever ordered a pediatric HIV test said they sought verbal (80 percent) or written (10 percent) permission from the parents or guardians to conduct the test on the child. Only 10 percent did not seek either verbal or written permission. After the test, 90 percent provided post-test counseling themselves or arranged for it to be done by someone else. These figures are similar to those observed in the adult HIV testing data, suggesting that when DTC is done, guidelines for pediatric patients are followed fairly closely.

\section{Figure 5 Percent of health workers who followed recommended procedures in their last pediatric HIV test ${ }^{1}$}

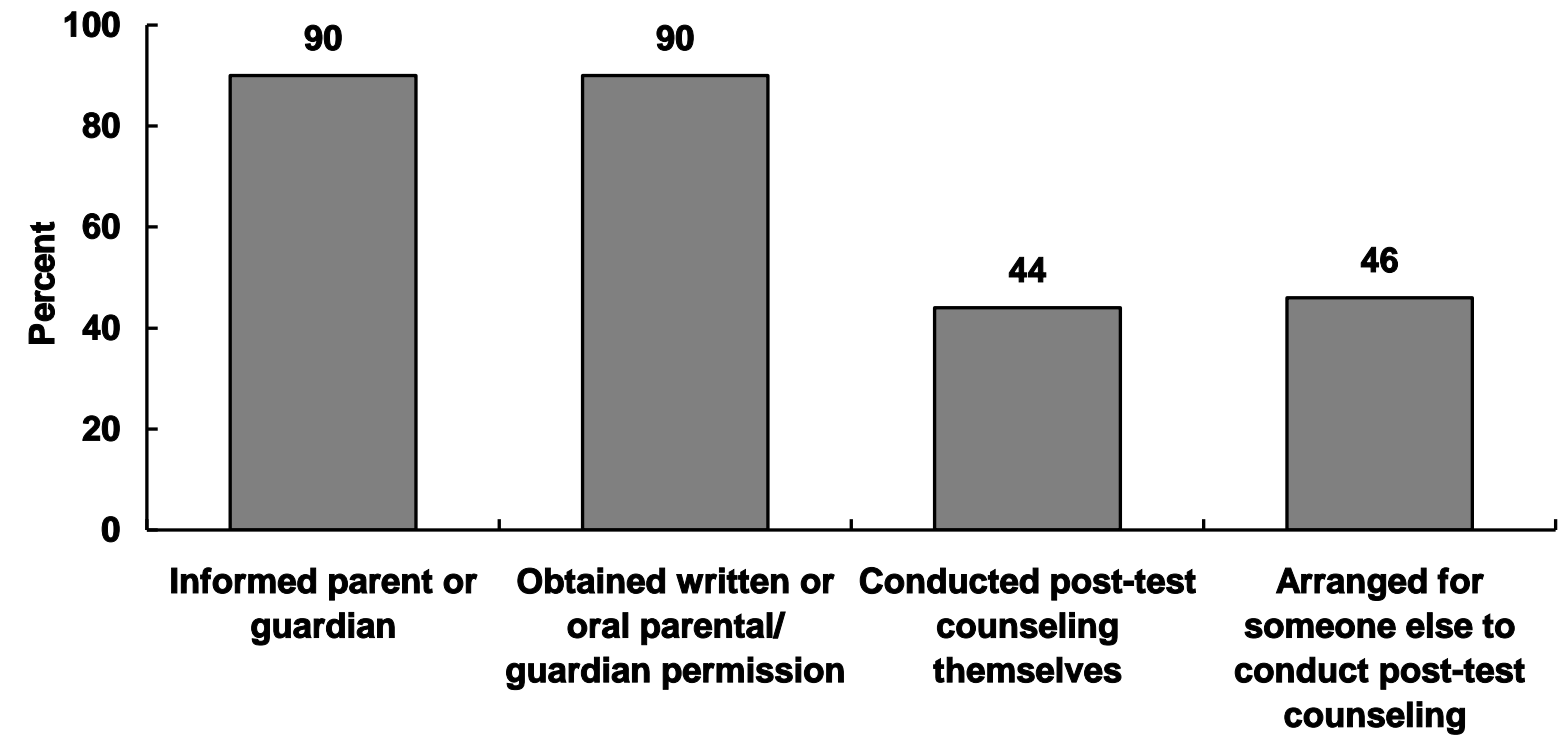

${ }^{1} n=313$ health workers who had ever ordered a test on a pediatric patient.

\section{Couple counseling and testing}

The DTC guidelines recommend couple counseling and partner disclosure. In order to determine the preparedness of providers to counsel and test couples, respondents were asked whether they knew what "couple counseling" was, and whether it would be appropriate for four categories of patients and their partners namely:

1. Patients who test HIV positive

2. STI patients

3. TB patients

4. Pregnant women

Table 4 shows that just over three quarters ( 78 percent) of respondents were aware of the term "couple counseling." VCT counselors were the most likely to know this term (99 percent), and enrolled nurses the least likely (74 percent). The data suggest that couple counseling is unfamiliar to a considerable proportion of health care workers in certain provinces: for example, a quarter or more of respondents in Central, Coast, Eastern, and Western provinces did not know the term "couple counseling." Thus there is need to educate these health workers about this term and what it entails.

Respondents who said they did not know what couple counseling was were read a brief description and then asked about its appropriateness for the four patient groups. Health workers were quite 
supportive of couple counseling for married couples; nearly all (including those who were not initially aware of the term) felt that this procedure should be provided to all the different groups asked about. For example, 98 percent recommended couple counseling for married patients who test HIV-positive, 98 percent recommended it for married patients with a sexually transmitted infection (STI), 96 percent recommended it for married tuberculosis (TB) patients, and 96 percent recommended it for married pregnant women (data not shown). Thus health workers in Kenya readily recognize the value of couple counseling within the context of HIV testing in clinical settings.

Table 4 Percent of health workers who know what "couple counseling" is

\begin{tabular}{lcr}
\hline Characteristics & Percent & $\begin{array}{c}\text { Number of health } \\
\text { workers }\end{array}$ \\
\hline Sex & 78.3 & 705 \\
Male & 78.4 & 1,170 \\
Female & & \\
Cadre & 81.5 & 84 \\
Doctor & 82.3 & 168 \\
Clinical officer & 80.4 & 397 \\
Registered nurse & 74.2 & 837 \\
Enrolled nurse & 76.8 & 167 \\
Laboratory staff & 83.3 & 33 \\
Social worker & 98.9 & 129 \\
VCT counselor & 77.8 & 70 \\
Others & & \\
Province & 72.7 & 211 \\
Central & 74.3 & 210 \\
Coast & 75.6 & 384 \\
Eastern & 84.6 & 115 \\
Nairobi & 83.5 & 102 \\
North Eastern & 87.5 & 248 \\
Nyanza & 78.0 & 494 \\
Rift Valley & 75.4 & 123 \\
Western & & \\
Type of facility & & 1,384 \\
Hospital & 78.7 & 253 \\
Health center & 77.1 & 186 \\
Dispensary & 74.9 & 64 \\
Maternity home & 85.5 & 156 \\
Operating organization & & 1,886 \\
Public & 77.1 & \\
Private & 83.4 & \\
Faith-based & 83.2 & \\
All respondents & 78.3 & \\
\hline & & \\
\hline
\end{tabular}

\section{Testing patients without their knowledge}

Respondents were asked whether it was appropriate "for a health worker to test a patient for HIV without the patient's knowledge," and the results are presented in Table 5. About 20 percent of health workers felt that it was appropriate for a health care provider to test a patient for HIV without the patient's knowledge. While there was little difference by sex, there were significant differences by occupational group - nearly 40 percent of medical doctors felt that testing a patient without their knowledge was appropriate, while less than 6 percent of VCT counselors and social workers agreed. 
Providers in maternity homes were nearly twice as likely as other providers to feel that testing patients without their knowledge was appropriate.

Table 5 Health workers who feel it is acceptable to test a patient for HIV without their knowledge

\begin{tabular}{|c|c|c|}
\hline Characteristics & Percent & $\begin{array}{c}\text { Number of health } \\
\text { workers }\end{array}$ \\
\hline \multicolumn{3}{|l|}{ Sex } \\
\hline $\begin{array}{l}\text { Male } \\
\text { Female }\end{array}$ & $\begin{array}{l}21.3 \\
18.6\end{array}$ & $\begin{array}{r}710 \\
1,172\end{array}$ \\
\hline \multicolumn{3}{|l|}{ Cadre } \\
\hline Doctor & 39.8 & 86 \\
\hline Clinical officer & 21.2 & 170 \\
\hline Registered nurse & 24.0 & 399 \\
\hline Enrolled nurse & 18.2 & 839 \\
\hline Laboratory staff & 17.6 & 167 \\
\hline Social worker & 4.2 & 33 \\
\hline VCT counselor & 5.9 & 131 \\
\hline Others & 23.8 & 70 \\
\hline \multicolumn{3}{|l|}{ Province } \\
\hline Central & 26.9 & 212 \\
\hline Coast & 18.8 & 211 \\
\hline Eastern & 18.5 & 384 \\
\hline Nairobi & 25.9 & 116 \\
\hline North Eastern & 11.6 & 102 \\
\hline Nyanza & 20.4 & 248 \\
\hline Rift Valley & 17.9 & 497 \\
\hline Western & 18.2 & 123 \\
\hline \multicolumn{3}{|l|}{ Type of facility } \\
\hline Hospital & 20.0 & 1,388 \\
\hline Health center & 18.2 & 255 \\
\hline Dispensary & 14.2 & 186 \\
\hline Maternity home & 32.4 & 66 \\
\hline \multicolumn{3}{|c|}{ Operating organization } \\
\hline Public & 18.6 & 1,519 \\
\hline Private & 24.9 & 218 \\
\hline Faith-based & 22.5 & 157 \\
\hline All respondents & 19.6 & 1,894 \\
\hline
\end{tabular}

Those who said it was acceptable to test patients without their knowledge were asked to give their reasons. The main explanations and scenarios given included the need to obtain a more accurate diagnosis, to know how to medically manage the patient, situations when patients could not give consent (e.g., comatose patients, children etc.), or when a health worker has been potentially exposed to HIV through contact with a patient's blood and post-exposure prophylaxis may be necessary.

\section{Management's support of HIV testing at health facility}

Respondents were asked whether "management is encouraging, discouraging, or neutral in promoting HIV testing" among specified groups of individuals, specifically: medical patients, pregnant women, 
STI patients, TB patients, and mothers of HIV-positive children. The results, presented in Figure 6, suggest that health facility management is largely seen to be supportive of HIV testing of all groups of patients.

\section{Figure 6 Percent of health workers who say management encourages HIV testing ${ }^{1}$ of listed categories of individuals}

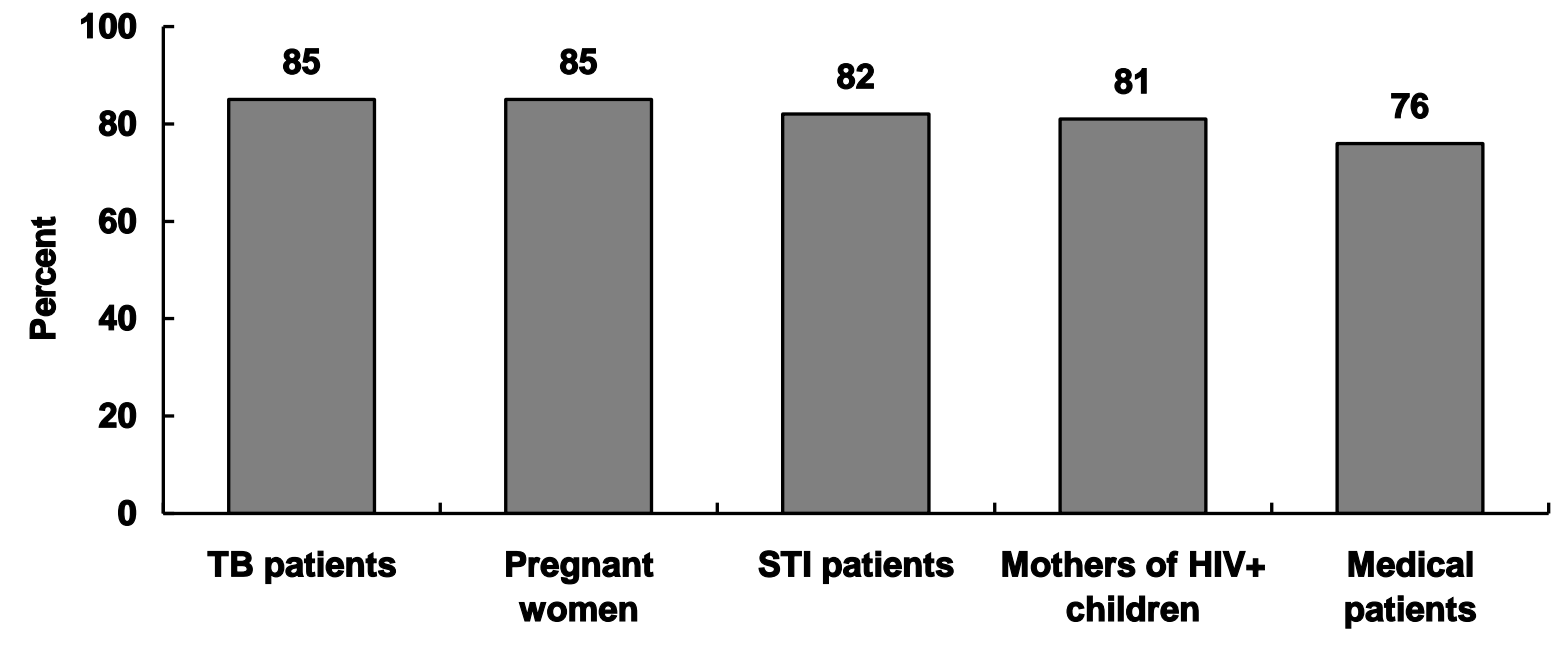

${ }^{1} n=1,897$ health workers

Over three quarters of respondents said that management encouraged testing each of the five categories of individuals, suggesting that HIV testing is well supported by management in Kenya's health facilities. This was the case across the board, regardless of the sex of the respondent, province, cadre of health worker, and funding affiliation (data not shown). However, there were differences by type of facility - respondents in dispensaries were considerably less likely to report that management was supportive (65-70 percent). Thus managers of dispensaries may need additional support and education regarding DTC, even if for purposes of referral.

The FGDs revealed the ways in which management supports HIV testing and counseling. Some of the examples given include provision of staff, equipment, and space for clients to be tested and counseled. Health workers also cited provision of staff training, updates to the DHMT, and additional information on topics such as ARVs and supportive supervision by the counselors.

The management is placing staff in strategic points so as to gain easy access to the clients.

Female nurse, Nyanza Province

The management organizes seminars and workshops and encourages HIV testing of medical patients.

Male clinical officer, Eastern Province

However, some respondents voiced concern that even though management supported HIV testing and counseling, there sometimes crept inequity in how training opportunities were allocated and whether or not trained personnel were optimally utilized:

The wrong people are [sent] for courses that were not meant for them.

Female nurse, Nairobi Province 
There is some bias in training allocation like some specific people are always picked to go for trainings all the time.

Female nurse, Eastern Province

The health workers who are trained are not utilized.

Male doctor, Nairobi Province

\section{Perceived confidence in HIV testing and counseling and training needs}

All respondents were asked how confident they were in conducting specific activities involved in DTC, and whether they would like further training in these areas (see Table 6). Respondents could rank themselves as being "highly confident" in undertaking the task, being "moderately confident," or having "low confidence." The question was asked of all health workers in the study, because they presumably interact with patients who could benefit from DTC, and whom they may need to advise.

The results are shown on Table 6. The second column shows the percent who report low confidence in the areas explored and shows that less than 10 percent of health workers self-report low confidence in recommending an HIV test and counseling individual patients. This suggests that over 90 percent felt at least moderately confident in these areas. Couple counseling was the most problematic; 12 percent reported low confidence in this task.

Table 6 Percent of health workers who report low confidence in specific aspects of HIV testing and percent of health workers who request additional training

\begin{tabular}{lcc}
\hline HIV testing activity & $\begin{array}{c}\text { Report “low } \\
\text { confidence" }\end{array}$ & $\begin{array}{c}\text { Request } \\
\text { training }\end{array}$ \\
\hline Recommending an HIV test to a patient & 5.9 & 80.6 \\
Counseling a patient who has agreed to test & 5.4 & 79.7 \\
Counseling a patient whose HIV test is positive & 9.1 & 80.4 \\
Counseling a patient who is HIV-negative & 4.5 & 71.8 \\
Couple counseling & 12.1 & 86.9 \\
Number of health workers & 1,895 & 1,888 \\
\hline
\end{tabular}

All respondents were also asked whether they would like further training in the competence areas assessed, and at least 70 percent felt they would like training in each area (Table 6). The greatest demand was on training for couple counseling, requested by 87 percent of the respondents. Thus while health workers overall felt confident that they can conduct most aspects of DTC, the vast majority still felt that they needed further training.

\section{HIV Testing Among Health Workers}

\section{Knowledge of own status and that of partner}

Because health workers are at risk for HIV due to occupational and personal factors, respondents were asked whether they had ever been tested for HIV. The results, presented in Table 7, show that nearly two thirds (64 percent) have been tested. There were no differences between males and females. When examined by cadre, the data show that VCT counselors were the most likely to have been 
tested, and social workers the least. Health workers in Nairobi Province were the most likely to report having been tested, while those in Eastern Province were the least likely. In addition, respondents in dispensaries were the least likely to have been tested.

Table 7 also shows that about 43 percent of the study sample had their most recent test during the previous 12 months. Thus even though around two thirds of the health workers have been tested for HIV, over half were tested more than 12 months ago. VCT counselors, doctors, and laboratory staff were the most likely to have tested in the past 12 months, while social workers and enrolled nurses were the least likely.

Table 7 Percent of health workers who have ever been tested for HIV, who tested in the past year, and whose partner has been tested

\begin{tabular}{|c|c|c|c|}
\hline & $\begin{array}{l}\text { Ever tested } \\
\text { for } \mathrm{HIV}^{1}\end{array}$ & $\begin{array}{c}\text { Tested in the } \\
\text { last } 12 \\
\text { months }\end{array}$ & $\begin{array}{c}\text { Partner tested for } \\
\text { HIV }^{2}\end{array}$ \\
\hline \multicolumn{4}{|l|}{ Sex } \\
\hline Male & 65.9 & 44.7 & 50.7 \\
\hline Female & 63.1 & 41.6 & 47.3 \\
\hline \multicolumn{4}{|l|}{ Cadre } \\
\hline Doctor & 78.6 & 54.2 & 67.5 \\
\hline Clinical officer & 66.7 & 40.9 & 51.8 \\
\hline Registered nurse & 68.9 & 44.5 & 54.1 \\
\hline Enrolled nurse & 54.9 & 35.2 & 38.6 \\
\hline Laboratory staff & 75.9 & 54.0 & 57.5 \\
\hline Social worker & 54.2 & 27.3 & 47.4 \\
\hline VCT counselor & 88.9 & 69.2 & 69.9 \\
\hline Others & 59.5 & 42.7 & 46.5 \\
\hline \multicolumn{4}{|l|}{ Province } \\
\hline Central & 57.7 & 38.9 & 64.1 \\
\hline Coast & 73.7 & 48.7 & 52.7 \\
\hline Eastern & 53.7 & 34.5 & 40.2 \\
\hline Nairobi & 81.2 & 55.2 & 64.1 \\
\hline North Eastern & 71.7 & 51.6 & 51.7 \\
\hline Nyanza & 70.3 & 40.8 & 54.1 \\
\hline Rift Valley & 62.4 & 43.1 & 47.7 \\
\hline Western & 61.8 & 46.9 & 52.4 \\
\hline \multicolumn{4}{|l|}{ Type of facility } \\
\hline Hospital & 66.5 & 44.3 & 48.5 \\
\hline Health center & 59.8 & 41.2 & 54.9 \\
\hline Dispensary & 47.3 & 25.9 & 34.8 \\
\hline Maternity home & 75.0 & 61.9 & 64.7 \\
\hline \multicolumn{4}{|l|}{ Operating organization } \\
\hline Public & 61.0 & 40.2 & 46.0 \\
\hline Private & 77.1 & 55.6 & 63.0 \\
\hline Faith-based & 75.1 & 50.4 & 60.8 \\
\hline All respondents & 64.0 & 42.7 & 48.6 \\
\hline Number of health workers & 1892 & 1897 & 1688 \\
\hline
\end{tabular}

${ }^{1}$ Among all health workers; ${ }^{2}$ Among health workers with a partner 
Further analysis showed that having been tested was associated with higher levels of confidence in undertaking various tasks associated with HIV testing and counseling of patients in clinical settings. For example, 68 percent of health workers who reported feeling "highly confident" about being able to recommend HIV testing to a patient had been tested, compared to 52 percent of their counterparts who reported "low confidence" $\left(X^{2}=15.3 ; \mathrm{p}<.001\right)$. Likewise, 70 percent of those who reported "high confidence" in their ability to provide pretest counseling had been tested, compared to 53 percent of their counterparts who reported feeling "low confidence" $\left(X^{2}=27.6 ; p<.001\right)$. The same pattern was observed with other aspects of DTC including post-test counseling of an HIV-positive patient, post-test counseling an HIV-negative patient, and couple counseling. As an FGD participant commented,

You will find that health workers who have been tested know the procedures better. I encourage all health workers to be tested.

Male clinical officer, Rift Valley Province

Respondents were asked whether their sex partners had ever been tested for HIV and the results, also shown in Table 7, suggest that many health workers do not know their partners' HIV status. Only 49 percent of the respondents who had a partner said this individual had been tested for HIV. There were minimal differences between males and females. However, VCT counselors and medical doctors were the most likely to say their partner had been tested, with about two thirds stating their partner had been tested. The least likely to report partner testing were enrolled nurses, with only 39 percent stating that their partner had been tested.

\section{Reasons for not testing}

The 661 respondents who said they had not been tested for HIV were asked their main reasons for not testing. The results, presented in Figure 7, suggest that most health workers who were not aware of their HIV status said they had "no particular reason" for not getting tested (42 percent), while a third did not feel at risk, and a third planned to test "in the future." Nearly a quarter of health workers who have not been tested expressed fear of results however, and a small minority cited fears that other people would find out their results.

Figure 7 Health workers' reasons for never having been tested for HIV ${ }^{1}$

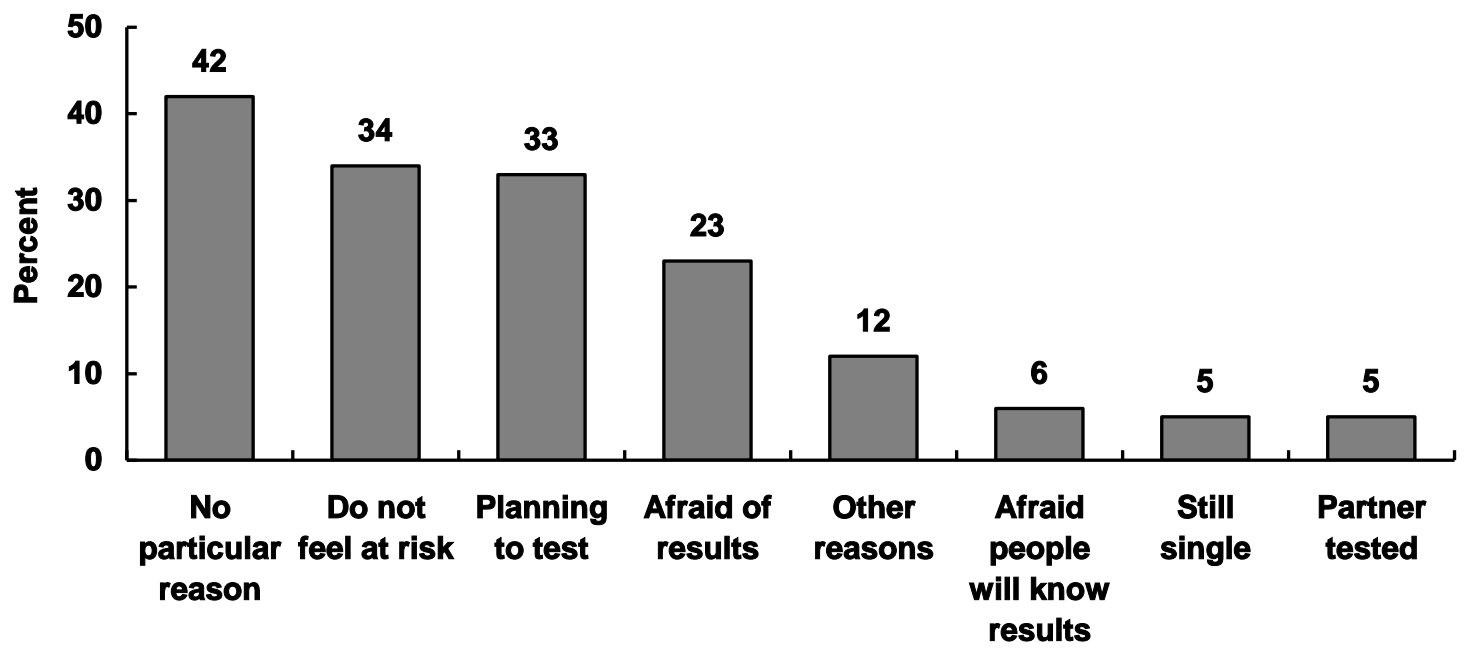

Reasons for never having tested

${ }^{1} n=661$ health workers who said they had not been tested. Multiple responses allowed 


\section{Interest in self-testing}

All respondents were asked whether they would be interested in self-testing if such an option were available in Kenya. The results, presented in Table 8, suggest appreciable interest - nearly three quarters of the health workers said they would be interested. The level of interest was greater among those who had never been tested, with 77 percent expressing interest compared to 71 percent among those who had ever been tested. In general, medical doctors were the most likely to express interest in self-testing, and VCT counselors the least. More respondents from Nyanza, the province with the highest HIV prevalence in the country, expressed interest in the procedure compared to other provinces. Because health workers are at frequent risk of HIV exposure, the practicality of routine self-testing, even among those who have ever tested, may be an important priority for this population.

Table 8 Percent of health workers who would be interested in self-testing among all respondents and by past HIV testing status

\begin{tabular}{lccc}
\hline & $\begin{array}{c}\text { Among all } \\
\text { respondents }\end{array}$ & $\begin{array}{c}\text { Among those } \\
\text { ever tested }\end{array}$ & $\begin{array}{c}\text { Among those } \\
\text { never tested }\end{array}$ \\
\hline Sex & & & \\
Male & 73.9 & 71.9 & 77.8 \\
$\quad$ Female & 72.4 & 69.8 & 76.8 \\
Cadre & & & \\
$\quad$ Doctor & 80.5 & 80.1 & 81.6 \\
Clinical officer & 79.2 & 78.9 & 80.0 \\
Registered nurse & 77.2 & 75.5 & 81.0 \\
Enrolled nurse & 76.2 & 74.5 & 78.1 \\
Laboratory staff & 75.6 & 77.2 & 70.6 \\
Social worker & 63.6 & 58.3 & 70.0 \\
VCT counselor & 32.2 & 31.1 & 41.3 \\
Others & 62.1 & 55.3 & 72.6 \\
Province & & & \\
Central & 66.9 & 61.4 & 74.5 \\
Coast & 71.5 & 69.3 & 77.7 \\
Eastern & 76.7 & 72.6 & 81.4 \\
Nairobi & 76.5 & 79.4 & 64.0 \\
North Eastern & 62.9 & 60.4 & 69.3 \\
Nyanza & 81.0 & 80.3 & 82.9 \\
Rift Valley & 71.9 & 69.5 & 75.7 \\
Western & 68.5 & 65.1 & 74.1 \\
Type of facility & & & \\
Hospital & 72.1 & 70.4 & 75.9 \\
Health center & 73.5 & 71.3 & 77.0 \\
Dispensary & 77.4 & 71.6 & 82.6 \\
Maternity home & 80.1 & 79.3 & 82.5 \\
Operating organization & & & \\
Public & 73.2 & 70.2 & 78.0 \\
Private & 73.1 & 72.9 & 73.8 \\
Faith-based & 71.1 & 71.6 & 69.6 \\
All respondents & 73.0 & 70.7 & 77.2 \\
Number of health workers & 1,892 & 1,212 & 681 \\
\hline
\end{tabular}


Focus group discussions with health workers revealed that many already test themselves, as illustrated in the following exchange:

Moderator: Do you think health workers would be interested in self-testing?

Chorus: Yes (laughter).

Female VCT counselor: Most have done it.

Health workers, Central Province

Several reasons were given for self-testing including that it eliminated a possible breach of confidentiality, eliminated stigma and suspicion (since other colleagues would not learn that the health worker had sought testing), and was a "do it yourself option" that eliminated mistrust the "test had been tampered with".

As a health worker what we fear most is stigmatization (laughter). I do it [testing] myself.

Male laboratory staff, Central Province

Some health workers felt the availability of self-testing kits would offer immediate benefits, such as greater acceptability of HIV testing or opportunities to learn the HIV status of their family members:

It will be a breakthrough because stigma would die out.

Male doctor, Rift Valley Province

Yes it's good because I can go home and test my family members.

Health worker, Eastern Province

I would test my children at home.

DHMT member, Central Province

It would be good because not even my husband would know my results (laughing).

DHMT member, Eastern Province

However, self-testing was not necessarily seen as a trouble-free option, and some FGD participants expressed reservations, with many feeling that lack of counseling and follow up was a drawback:

Moderator: Do you think health workers would be interested in self-testing if such a kit were available?

Reply: Yes, I would be interested but the problem is when the result turns positive.

DHMT member, Nairobi Province

Moderator: Do you think health workers who turn out to be HIV positive would act irrationally or do you think health workers can handle it?

Replies:

Some even end up in committing suicide.

Male clinical officer, Nyanza Province

Unless you have been counseled, self-testing is not good.

DHMT member, Eastern Province

They [health workers] would behave the same way as other patients.

DHMT member, Rift Valley Province 
The issue of support is important because people will collapse or will go infecting others if they know their status.

DHMT member, Coast Province

Some health workers really go down and become worse after being tested positive to a point of committing suicide.

DHMT member, Western Province

I would be scared if I do it alone.... I fear to know my status if I am alone.

Female nurse, Coast Province

\section{Confidential testing at work}

Respondents were asked whether they thought they could get a confidential HIV test at work. About 11 percent of respondents worked in facilities where there were no HIV testing facilities, and they are omitted from this analysis. Thus the sample is based on the 1,691 respondents who said that HIV testing services were available at their facility. Table 9 presents the results.

The data show that that respondents have considerable trust in their health facilities: 73 percent said a health worker could get a confidential test at their index facility, with little difference between males and females. VCT counselors ( 90 percent) and laboratory staff ( 84 percent) were the most likely to feel one could get a confidential HIV test, but medical doctors (66 percent) and social workers (67 percent) were less likely to exude such confidence. When examined by province, respondents from Western Province (88 percent) were the most likely to feel that health workers could be tested for HIV confidentially at their health care facility, and North Eastern Province (68 percent) the least. There were sharp differences by type of facility. While over three quarters of respondents from maternity homes, health centers, and hospitals felt that a health worker in their facility could be tested confidentially, only half their counterparts from dispensaries felt that this could happen in their facility.

FGDs painted a less optimistic picture though, with many health workers expressing anxiety that confidentiality would not be maintained, or fearing stigma if colleagues learned that a health worker had sought testing.

Health workers are shy [to be tested at their facility] because of stigma from other health workers.

DHMT member, Eastern Province

Health workers fear being tested by someone they know.

Male medical doctor, Rift Valley Province

In some cases, VCT counselors were seen to be reluctant to test other health workers.

The VCT counselor refuses to test health workers. She says some of them are her friends and someone else should do it.

Male clinical officer, Eastern Province

Thus while many health workers felt they could receive a confidential HIV test in their facilities, others had strong fears about stigma and potential breaches in confidentiality. 
Table 9 Percent of health workers who feel they can get a confidential HIV test at work among those who say testing available at their facility

\begin{tabular}{lcc}
\hline & Percent & Number of health workers \\
\hline Sex & & \\
Male & 76.0 & 637 \\
Female & 71.8 & 1,043 \\
Cadre & & \\
Doctor & 65.7 & 86 \\
Clinical officer & 70.8 & 162 \\
Registered nurse & 70.9 & 373 \\
Enrolled nurse & 70.4 & 693 \\
Laboratory staff & 84.3 & 155 \\
Social worker & 66.7 & 32 \\
VCT counselor & 90.2 & 124 \\
Others & 80.3 & 65 \\
Province & & \\
Central & 73.5 & 198 \\
Coast & 78.5 & 198 \\
Eastern & 70.5 & 323 \\
Nairobi & 69.3 & 111 \\
North Eastern & 68.4 & 98 \\
Nyanza & 74.6 & 239 \\
Rift Valley & 70.9 & 419 \\
Western & 88.3 & 106 \\
Type of facility & & \\
Hospital & 73.1 & 1,378 \\
Health center & 78.3 & 193 \\
Dispensary & 53.5 & 63 \\
Maternity home & 85.4 & 57 \\
Operating organization & & \\
Public & 72.3 & 1,345 \\
Private & 77.1 & 199 \\
Faith-based & 78.8 & 148 \\
All respondents & 73.4 & 691 \\
\hline & & \\
\hline
\end{tabular}

\section{Care and Treatment of People Living with HIV/AIDS}

\section{Perceptions about people living with HIV/AIDS}

Stigma and discrimination of PLHIV remains a major challenge in Kenya's fight against HIV/AIDS. This survey examined health workers' perceptions of PLHIV and the extent to which PLHIV are stigmatized in the health facilities. For example, health workers were asked whether they felt that PLHIV were treated better, worse, or the same as other patients. Half of the respondents (51 percent) felt that PLHIV received the same treatment as other patients, 42 percent felt they got better treatment and only 7 percent felt their treatment was worse. Some health workers noted that HIV/AIDS was well funded compared to other health conditions, and thus AIDS-related sections of the health facilities received greater attention and had access to equipment, supplies, entertainment (e.g., TV sets in PMCT/ANC clinics), and food supplementation that were not available for other types of patients: 
[HIV] patients are treated well especially PTB [pulmonary tuberculosis], their diet is even better - we give them a packet of milk to supplement their diet. They are discriminated in a better way I would say.

DHMT member, Coast Province

In other cases, providers felt that HIV-positive patients received greater attention from the health workers because of their conditions:

Moderator: During clinical rounds are HIV-positive patients reviewed with the same level of attention given to other patients?

Answer: It is higher. It is higher than other patients. You have to take more time with them because they have numerous ailments. The only problem is the unavailability of drugs.

Female nurse, Nyanza Province

Respondents were asked questions to further gauge stigma toward PLHIV. Interviewers read the following statements, and the respondents could agree or disagree with them:

- Health workers have a right to refuse to care for an HIV/AIDS patient.

- Patients with HIV should be kept separately from other patients.

Most health workers seemed to hold empathetic attitudes toward PLHIV. For example, 92 percent disagreed that health workers have a right to refuse to care for an HIV-positive patient. But at the same time, a minority of respondents harbored troubling attitudes toward PLHIV. For example 15 percent of doctors, 12 percent of clinical officers, and 9 percent of registered nurses felt that health workers have a right to refuse to care for PLHIV. There were minimal differences in the responses when examined by geographic region, type of facility, or funding affiliation. However, 18 percent of both health workers in North Eastern Province and health workers working in maternity homes felt that health workers had a right to refuse to care for HIV-positive inpatients. Focus group discussions revealed some of the stigmatizing actions carried out by health workers, such as reluctance to treat infected patients, inappropriate use of gloves, and lack of confidentiality:

Knowingly when a mum says they have taken Nevirapine, midwives do not want to deliver them. They give excuses like 'she is not ready to deliver' so that the mum can deliver when [the midwife] is away. The stigma is there.

Female nurse, Coast Province

A health worker when attending to an [infected] patient takes more precautions by wearing two gloves as if they are handling a dead body.

Male doctor, Nairobi Province

...our health workers are confident when they don't know the [HIV] status of the client they are handling. They may not use gloves.... When they are told the client is HIV-positive they .... shy away....

DHMT member, North Eastern Province

Health workers have a bad attitude which causes stigma and they do not have confidentiality. DHMT member, Eastern Province

Another way stigma toward PLHIV was assessed was by asking whether HIV-positive patients were separated from other patients in the wards. Around 92 percent disagreed that HIV-positive patients should be isolated. It was noted as well that isolating a patient is not by itself necessarily a reflection 
of stigma - it could be for the benefit of the patient, who may be severely immuno-compromised and should be kept away from others to minimize contact with germs.

Among facilities that had inpatient wards, most health workers (83 percent) reported that PLHIV inpatients were mixed with other patients. About one in ten health workers (11 percent) said HIVpositive patients in their facilities were separated when clinically necessary, and only 3 percent said such patients were isolated for non-medical reasons. However, FGDs revealed evidence of physical separation or special placement of PLHIV without any clinical need:

Moderator: How are HIV-positive patients treated at this facility?

Male clinical officer: They are treated differently and put near sluice rooms. They are discriminated. I feel they should mix."

FGD respondent, Rift Valley Province

The way they are kept and placed in the wards everybody knows they are HIV-positive.

DHMT member, Eastern Province

Comments about stigma frequently came after the end of the FGDs, when individual health workers would approach the research team quietly and express concern. Thus many health workers did not feel comfortable discussing stigma in the context of the FGDs but preferred a more confidential setting. The favorable picture presented by the survey about stigma was thus sometimes at odds with the private discussions providers had with the research team members. This suggests that stigma may be a concern in Kenya's health care facilities, and further assessment may be warranted.

\section{Perceptions about HIV-positive health workers}

Because health workers in Kenya may also be HIV-positive, respondents were asked whether they thought that such colleagues should continue working. The data suggest that providers are quite accepting of HIV-positive colleagues, and 95 percent felt that these staff members should continue to work with patients. During FGDs, most discussants suggested the need to provide infected health workers with appropriate duties, free medication, psychosocial support, and posting in their home areas. However, participants felt it was difficult to know whether a colleague was HIV-positive, as disclosure is rare because of stigma.

Moderator: What happens to HIV-positive health workers?

Answer: Nothing. Nobody knows they are HIV-positive.

Female nurse, Coast Province

\section{Knowledge and Perceived Competence in the Care and Management of HIV-positive Patients}

\section{Preparedness for management of AIDS patients}

The rapidly changing knowledge and skills required to manage AIDS patients pose major in-service training challenges for the health sector. The KHWS examined health workers' training and perceived competence in the provision of basic HIV/AIDS services. This analysis is restricted to respondents who are likely to provide direct clinical management of HIV-infected patients, specifically doctors, clinical officers, and nurses $(n=1,494)$. Nearly 80 percent of these respondents had ever taken care of 
an AIDS patient at their current post, and doctors (97 percent) were the most likely to have done so while enrolled nurses (75 percent) the least likely (Table 10).

Providers who care for AIDS patients were also asked whether they make referrals in cases where services are not available at their facility, and a third said they have (Table 10). As expected, most of the health workers who made referrals were those working in dispensaries, health centers, and maternity homes.

Table 10 Percent of doctors, clinical officers and nurses who provide AIDS care and referral, percent who have been trained in AIDS patient management, and percent feel adequately prepared among those trained

\begin{tabular}{|c|c|c|c|c|c|}
\hline \multirow[b]{2}{*}{ Characteristics } & \multicolumn{5}{|c|}{ Percent who have: } \\
\hline & $\begin{array}{l}\text { Ever cared for } \\
\text { AIDS } \\
\text { patient at } \\
\text { current post }{ }^{1}\end{array}$ & $\begin{array}{l}\text { Ever } \\
\text { referred } \\
\text { AIDS } \\
\text { patient from } \\
\text { current post }^{1}\end{array}$ & $\begin{array}{c}\text { Ever } \\
\text { received any } \\
\text { training in } \\
\text { AIDS patient } \\
\text { management }{ }^{1}\end{array}$ & $\begin{array}{c}\text { Feel } \\
\text { adequately } \\
\text { trained in AIDS } \\
\text { patient } \\
\text { management }^{1}\end{array}$ & $\begin{array}{l}\text { Been trained in } \\
\text { AIDS patient } \\
\text { management } \\
\text { and feel } \\
\text { adequately } \\
\text { prepared }^{2}\end{array}$ \\
\hline \multicolumn{6}{|l|}{$\overline{\operatorname{Sex}}$} \\
\hline Male & 77.8 & 45.0 & 37.4 & 41.8 & 63.0 \\
\hline Female & 79.9 & 27.1 & 31.3 & 37.3 & 57.0 \\
\hline \multicolumn{6}{|l|}{ Cadre } \\
\hline Medical doctor & 96.6 & 56.0 & 63.2 & 61.7 & 77.3 \\
\hline Clinical officer & 79.3 & 53.4 & 43.4 & 40.2 & 62.4 \\
\hline Registered nurse & 85.3 & 28.8 & 37.1 & 39.0 & 58.8 \\
\hline Enrolled nurse & 74.6 & 28.8 & 26.2 & 36.1 & 54.2 \\
\hline \multicolumn{6}{|l|}{ Province } \\
\hline Central & 85.0 & 25.4 & 41.1 & 37.0 & 62.6 \\
\hline Coast & 81.3 & 31.7 & 24.5 & 29.5 & 48.2 \\
\hline Eastern & 80.7 & 29.7 & 25.0 & 30.4 & 51.3 \\
\hline Nairobi & 83.7 & 35.3 & 46.8 & 58.2 & 61.6 \\
\hline North Eastern & 66.6 & 21.5 & 25.3 & 47.7 & 71.2 \\
\hline Nyanza & 91.9 & 35.1 & 42.1 & 46.6 & 64.6 \\
\hline Rift Valley & 69.9 & 37.4 & 32.4 & 38.9 & 58.0 \\
\hline Western & 80.2 & 43.2 & 40.7 & 43.9 & 66.8 \\
\hline \multicolumn{6}{|l|}{ Type of facility } \\
\hline Hospital & 88.9 & 23.4 & 34.3 & 40.1 & 60.2 \\
\hline Health center & 53.2 & 79.0 & 30.1 & 33.9 & 52.3 \\
\hline Dispensary & 42.4 & 81.3 & 24.8 & 31.3 & 52.9 \\
\hline Maternity home & 97.0 & 63.5 & 52.0 & 58.1 & 75.5 \\
\hline \multicolumn{6}{|l|}{$\begin{array}{l}\text { Operating } \\
\text { organization }\end{array}$} \\
\hline Public & 77.3 & 31.8 & 30.4 & 34.5 & 55.5 \\
\hline Private & 83.2 & 43.3 & 44.3 & 59.2 & 70.6 \\
\hline Faith-based & 92.5 & 30.8 & 45.7 & 54.7 & 70.1 \\
\hline All & 79.2 & 32.9 & 33.2 & 38.8 & 59.3 \\
\hline $\begin{array}{l}\text { Number of } \\
\text { respondents }\end{array}$ & 1,494 & 1,494 & 1,494 & 1,494 & 489 \\
\hline
\end{tabular}

${ }^{1}$ Among all doctors, clinical officers and nurses; ${ }^{2}$ Among doctors, clinical officers and nurses who said they had ever been trained in AIDS patient management.

Doctors, clinical officers and nurses in the study were asked whether they had ever been trained in AIDS patient management, and only a third answered affirmatively. Doctors (63 percent) were again 
the most likely to have received such training, enrolled nurses (26 percent) the least. This implies that the remaining 37 percent of doctors and 74 percent of enrolled nurses who provide AIDS patient care and management had not received any specialized training in this area. Regional analysis shows that in all eight provinces the majority of health care providers specifically tasked with the management of AIDS patients had not been trained in the management of HIV disease. Indeed in no province had even half of the providers been trained.

When examined by type of facility, providers in maternity homes (52 percent) were more likely than all the others to have received training, and those in dispensaries ( 25 percent) the least likely. Public sector providers ( 30 percent) were the least likely to have received training compared to private sector providers (44 percent) and faith-based (46 percent).

When asked whether they felt adequately trained to manage AIDS patients, only 39 percent of respondents tasked with this job answered affirmatively, implying that the remaining 61 percent did not feel they had enough training (Table 10). This suggests a substantial deficiency in capacity building. Again, physicians ( 62 percent) were the most likely to feel adequately trained, while enrolled nurses (36 percent) the least likely. Nevertheless, it is still noteworthy that 38 percent of physicians did not feel prepared for this task. There were sharp geographic differences, with less than 40 percent of health care professionals who manage AIDS patients in Coast, Eastern, Central, and Rift Valley provinces feeling adequately prepared to do so. The last column on Table 10 further illustrates the training gap: only 59 percent of the trained respondents tasked with AIDS patient management felt adequately prepared for this task, suggesting that the training they have received may not have been sufficient and that refresher trainings are necessary.

Trained respondents were asked whether they had been trained in specific areas involving management of AIDS patients. The results, presented in Figure 8, show that less than two thirds of trained doctors, clinical officers, and nurses had received training in basic counseling of AIDS patients, and less than 40 percent had been trained on how to manage patients on ARVs.

\section{Figure 8 Percent of doctors, clinical officers, and nurses who have been trained in the specified area ${ }^{1}$}

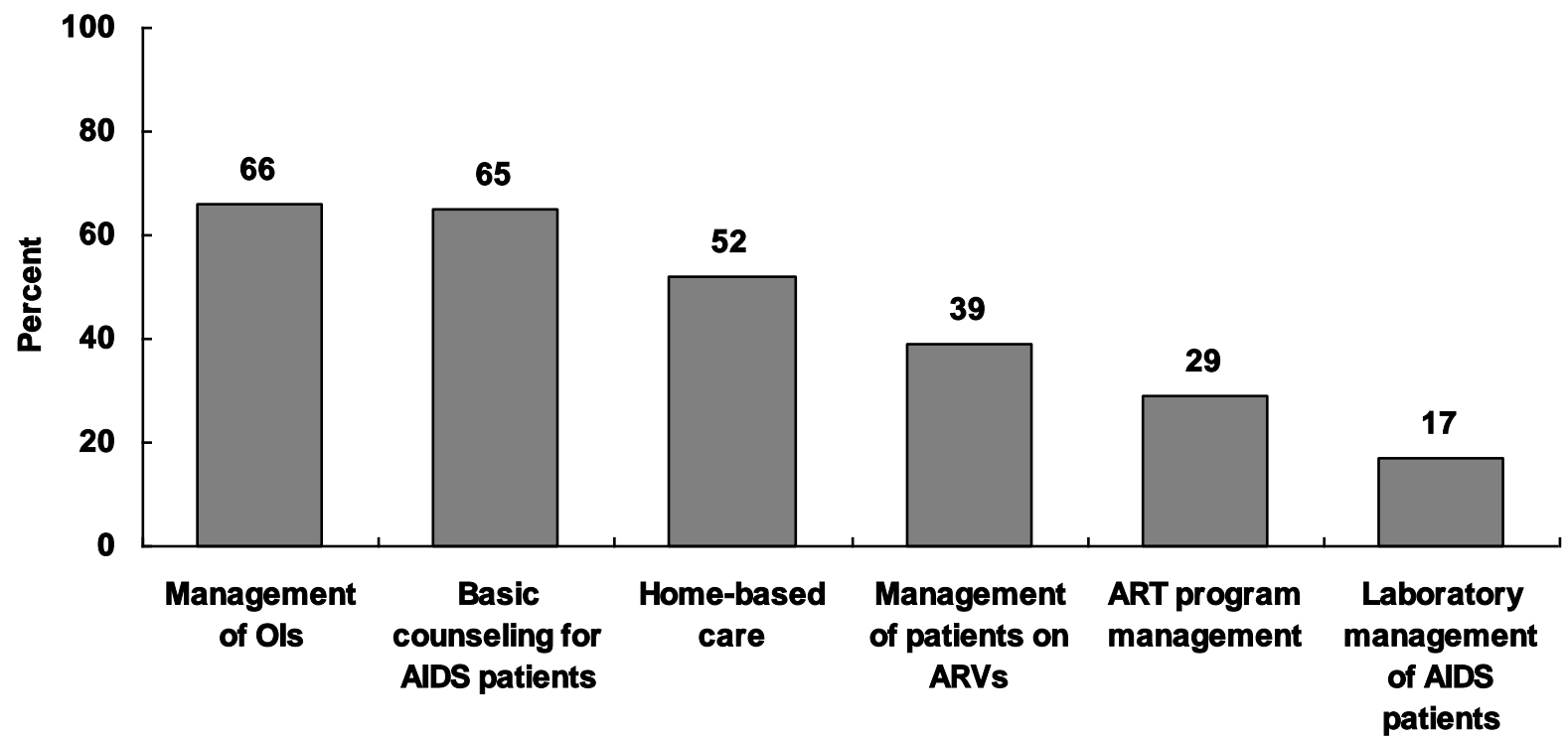

Area of training

${ }^{1}$ Among those who said they have been trained in AIDS patient management, $n=489$ 
Regardless of whether they had been trained, all doctors, clinical officers and nurses $(n=1,494)$ were also asked whether ARVs were available at their facility and 66 percent said they were (data not shown). Those who said that ARVs were available were asked whether they ever prescribed them, and 16 percent said they did. These comprised 75 percent of doctors, 40 percent of their clinical officer counterparts, and 6 percent of registered and enrolled nurses each. Thus when they are available, ARVs are predominantly prescribed by medical doctors.

\section{Perceived competence in the delivery of HIV/AIDS services}

Health workers were asked to rate their competence as high, moderate, or low in selected aspects of care and management of HIV/AIDS patients. Figure 9 presents the results. The analysis was restricted to doctors, clinical officers, and nurses, since these are the cadres designated to conduct the tasks assessed. The results show that many clinicians self-report low competence in key areas, but especially in aspects that involve ARV management such as laboratory monitoring of AIDS patients, adherence counseling, and assessing patient readiness for ART.

\section{Figure 9 Percent distribution of doctors, clinical officers and nurses who report feeling "low competence" in the listed areas"}

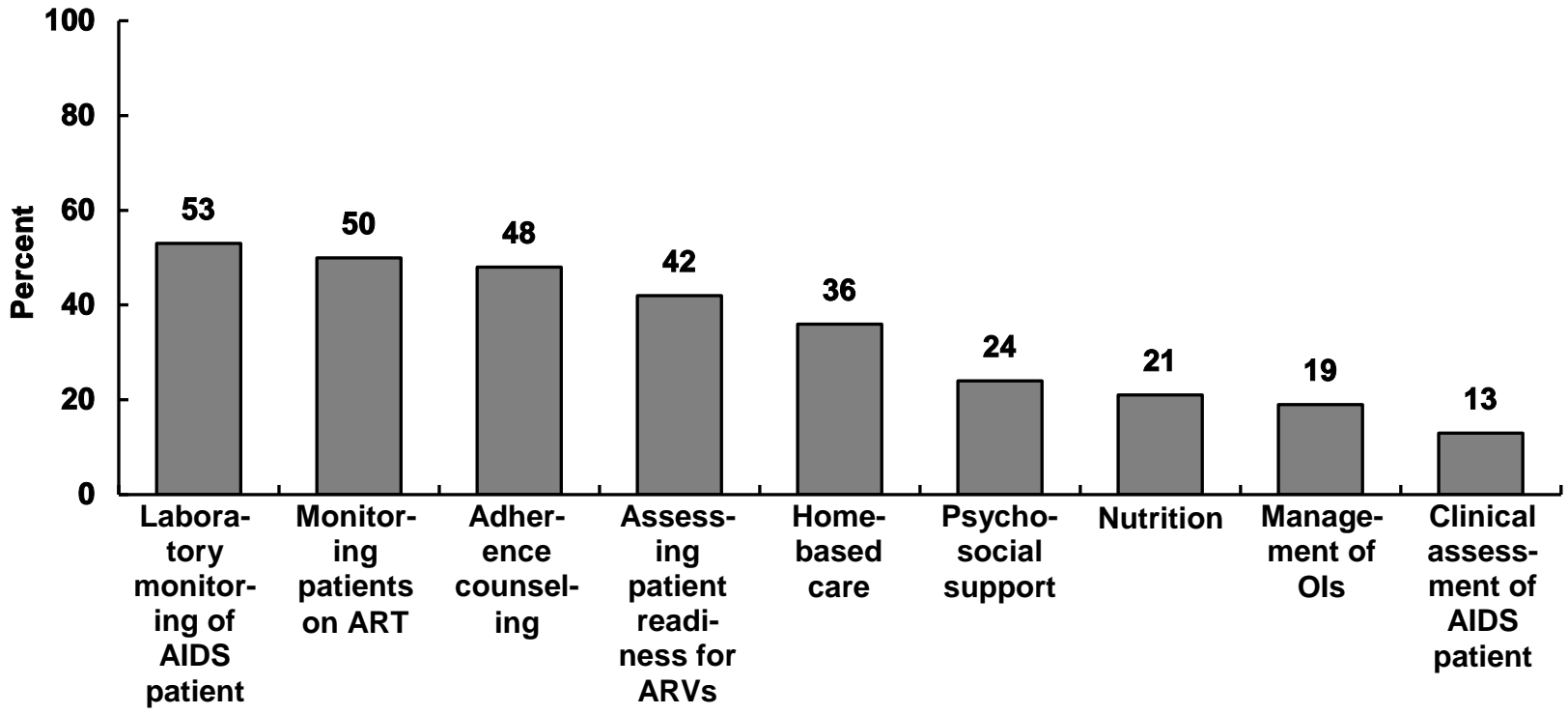

Aspects of AIDS patient management assessed

${ }^{1} \mathrm{n}=1,494$ doctors, clinical officers and nurses

\section{Infection Control, Occupational HIV Exposure and PEP}

\section{Perceptions about availability of infection control items}

In order to assess the availability of infection control supplies, all health workers $(n=1,897)$ were asked whether their facilities had access to several items, specifically, gloves, protective gowns, disposable containers for sharps, bleach solution (disinfectant), soap, and running water. The specific question was: "Would you say the supply of [item] is adequate, inadequate, or not available at this facility?" Table 11 shows the percent who said that the supply was adequate. About three quarters of 
providers reported that their facilities had an adequate supply of sharps disposal equipment and gloves, while around two thirds felt there was an adequate supply of disinfectant and soap. Less than 60 percent reported having an adequate supply of running water and only 27 percent had protective gowns. Table 11 also shows the mean number of infection control items deemed adequately available and suggests that of the six products inquired about, the respondents felt that 3.6 were in adequate supply. Doctors reported the highest availability of items (4.3), while clinical officers and enrolled nurses (3.5 each) reported the least. Providers in Nairobi and Central provinces reported the most number of items (4.0), while those in Western Province reported the least (2.6). When examined by type of facility, maternity homes and faith-based institutions reported the highest number of items (5.4).

Table 11 Percent of health workers who say the supply of selected infection control items is adequate, mean number of items available, and percent of health workers who are aware of written infection guidelines in their facility

\begin{tabular}{|c|c|c|c|c|c|c|c|c|}
\hline & \multicolumn{7}{|c|}{ Infection control item } & \multirow{2}{*}{$\begin{array}{c}\text { Aware of } \\
\text { written } \\
\text { guidelines } \\
\text { in facility }\end{array}$} \\
\hline & Gloves & Gowns & $\begin{array}{c}\text { Sharps } \\
\text { disposal } \\
\text { containers }\end{array}$ & $\begin{array}{l}\text { Disin- } \\
\text { fectant }\end{array}$ & Soap & $\begin{array}{c}\text { Running } \\
\text { water }\end{array}$ & $\begin{array}{c}\text { Mean } \\
\text { number } \\
\text { of items }\end{array}$ & \\
\hline $\begin{array}{l}\text { Sex } \\
\quad \text { Male } \\
\text { Female }\end{array}$ & $\begin{array}{l}76.4 \\
72.6\end{array}$ & $\begin{array}{l}27.5 \\
26.5\end{array}$ & $\begin{array}{l}75.3 \\
75.8\end{array}$ & $\begin{array}{l}68.6 \\
66.4\end{array}$ & $\begin{array}{l}62.3 \\
42.7\end{array}$ & $\begin{array}{l}57.5 \\
56.2\end{array}$ & $\begin{array}{l}3.6 \\
3.7\end{array}$ & $\begin{array}{l}31.6 \\
38.7\end{array}$ \\
\hline $\begin{array}{l}\text { Cadre } \\
\text { Doctor } \\
\text { Clinical officer } \\
\text { Registered nurse } \\
\text { Enrolled nurse } \\
\text { Laboratory staff } \\
\text { Social worker } \\
\text { VCT counselor } \\
\text { Other }\end{array}$ & $\begin{array}{l}77.1 \\
72.6 \\
74.2 \\
73.5 \\
79.6 \\
63.6 \\
78.6 \\
64.9\end{array}$ & $\begin{array}{l}59.2 \\
27.0 \\
28.3 \\
21.4 \\
34.1 \\
23.8 \\
27.8 \\
31.8\end{array}$ & $\begin{array}{l}80.5 \\
73.3 \\
74.2 \\
74.8 \\
75.2 \\
77.3 \\
81.4 \\
80.2\end{array}$ & $\begin{array}{l}71.9 \\
62.2 \\
65.3 \\
66.7 \\
74.5 \\
61.9 \\
71.1 \\
72.6\end{array}$ & $\begin{array}{l}75.4 \\
59.3 \\
62.9 \\
58.5 \\
70.8 \\
63.6 \\
65.7 \\
76.9\end{array}$ & $\begin{array}{l}63.7 \\
51.5 \\
57.4 \\
53.7 \\
64.0 \\
81.8 \\
63.5 \\
54.1\end{array}$ & $\begin{array}{l}4.3 \\
3.5 \\
3.6 \\
3.5 \\
4.0 \\
3.7 \\
3.8 \\
3.8\end{array}$ & $\begin{array}{l}48.6 \\
38.9 \\
43.3 \\
27.4 \\
30.7 \\
68.2 \\
55.4 \\
34.7\end{array}$ \\
\hline $\begin{array}{l}\text { Province } \\
\text { Central } \\
\text { Coast } \\
\text { Eastern } \\
\text { Nairobi } \\
\text { North Eastern } \\
\text { Nyanza } \\
\text { Rift Valley } \\
\text { Western }\end{array}$ & $\begin{array}{l}81.5 \\
87.0 \\
70.0 \\
84.6 \\
85.4 \\
59.2 \\
77.2 \\
50.7\end{array}$ & $\begin{array}{l}37.7 \\
23.3 \\
24.6 \\
52.2 \\
16.9 \\
28.1 \\
24.2 \\
18.0\end{array}$ & $\begin{array}{l}72.4 \\
75.1 \\
79.3 \\
81.5 \\
90.9 \\
59.0 \\
81.0 \\
62.3\end{array}$ & $\begin{array}{l}68.7 \\
72.2 \\
72.3 \\
71.9 \\
77.2 \\
58.8 \\
67.8 \\
45.0\end{array}$ & $\begin{array}{l}71.8 \\
58.3 \\
65.0 \\
62.2 \\
73.4 \\
54.0 \\
64.9 \\
46.3\end{array}$ & $\begin{array}{l}60.0 \\
55.5 \\
49.8 \\
56.2 \\
49.5 \\
61.2 \\
67.1 \\
32.1\end{array}$ & $\begin{array}{l}4.0 \\
3.7 \\
3.6 \\
4.0 \\
3.9 \\
3.2 \\
3.9 \\
2.6\end{array}$ & $\begin{array}{l}35.3 \\
23.6 \\
23.9 \\
70.7 \\
20.7 \\
58.1 \\
35.4 \\
32.7\end{array}$ \\
\hline $\begin{array}{l}\text { Type of facility } \\
\text { Hospital } \\
\text { Health center } \\
\text { Dispensary } \\
\text { Maternity home }\end{array}$ & $\begin{array}{l}72.0 \\
72.0 \\
86.0 \\
93.7\end{array}$ & $\begin{array}{l}28.3 \\
16.4 \\
15.9 \\
76.1\end{array}$ & $\begin{array}{l}74.7 \\
73.5 \\
78.1 \\
91.9\end{array}$ & $\begin{array}{l}66.2 \\
60.7 \\
76.4 \\
92.6\end{array}$ & $\begin{array}{l}65.0 \\
50.2 \\
49.8 \\
95.6\end{array}$ & $\begin{array}{l}54.6 \\
60.4 \\
57.3 \\
90.0\end{array}$ & $\begin{array}{l}3.6 \\
3.4 \\
3.6 \\
5.4\end{array}$ & $\begin{array}{l}42.3 \\
19.1 \\
11.7 \\
35.0\end{array}$ \\
\hline $\begin{array}{l}\text { Operating } \\
\text { organization } \\
\text { Public } \\
\text { Private } \\
\text { Faith-based }\end{array}$ & $\begin{array}{l}69.4 \\
92.3 \\
95.1\end{array}$ & $\begin{array}{l}17.9 \\
66.3 \\
61.8\end{array}$ & $\begin{array}{l}71.2 \\
95.7 \\
89.2\end{array}$ & $\begin{array}{l}61.3 \\
90.6 \\
93.7\end{array}$ & $\begin{array}{l}54.4 \\
94.7 \\
97.4\end{array}$ & $\begin{array}{l}47.7 \\
92.0 \\
96.8\end{array}$ & $\begin{array}{l}3.2 \\
5.4 \\
5.4\end{array}$ & $\begin{array}{l}31.2 \\
51.3 \\
59.8\end{array}$ \\
\hline All respondents & 74.1 & 27.1 & 75.5 & 67.4 & 62.6 & 56.8 & 3.6 & 35.9 \\
\hline $\begin{array}{l}\text { Number of health } \\
\text { workers }\end{array}$ & 1,896 & 1,888 & 1,895 & 1,890 & 1,893 & 1,893 & 1,897 & 1,895 \\
\hline
\end{tabular}


Respondents were asked whether there were any written guidelines about infection control at their facility, and only 36 percent said there were. This suggests that the remaining 64 percent were not aware of any such written guidelines. When examined by cadre, social workers were the most likely to report awareness of the guidelines (68 percent), and enrolled nurses the least ( 27 percent). Again, these results raise concern: enrolled nurses, who are one of the cadres most involved with patient care, were the least likely to be aware of any written guidelines on infection control. On the other hand, social workers and VCT counselors, whose work involves less invasive procedures, were more likely to be aware of infection control guidelines. An analysis of the findings by geographic region indicates large disparities - whereas 71 percent of health workers in Nairobi Province said they had infection control guidelines, only around a third or less of health workers in other provinces except Nyanza reported the existence of written guidelines.

Respondents were also asked how concerned they were about getting infected with HIV at work. The overwhelming majority of health workers (94 percent) said they were "very concerned," with little difference between men ( 93 percent) and women (96 percent, data not shown). When examined by cadre, over 90 percent of clinical officers, registered nurses, enrolled nurses, laboratory staff, VCT counselors, and social workers, and 80 percent of medical doctors, were "very concerned" about occupational exposure to HIV. This level of concern was evident among health workers in all provinces and facility type (90 percent or more, 97 percent for dispensaries).

\section{Post-exposure prophylaxis}

All health workers were asked whether they knew what post-exposure prophylaxis (PEP) was. Those who said they did were asked to describe it. The interviewers determined whether their definition was correct, based on detailed training sessions they had received prior to data collection.

The results are presented in Table 12. Six out of ten health care providers said they knew what PEP was, and among these, 83 percent could correctly define it as assessed by the interviewer. This translates to about half (51 percent) of the study universe who are both aware of PEP and can correctly describe it (defined as possessing functional knowledge about PEP). Males were more likely to have functional knowledge compared to females; medical doctors were the most likely to have functional knowledge and enrolled nurses the least. Respondents from dispensaries were the least likely to have functional knowledge about PEP, and those from hospitals the most likely.

Respondents who said they knew what PEP was, regardless of whether they could define it correctly, were asked whether it was available for use by health workers (as opposed to its availability for patient use) in their health care facility, or was available at another site. The results are presented for the total sample in order to demonstrate the proportion of health workers who would access PEP were they to need it. The data, presented on Table 12, show that 42 percent of health workers say PEP is available in their facility or somewhere else nearby. Put another way, were they to need it (regardless of their ability to describe it correctly), 42 percent of all health workers feel they could access PEP. However, this suggests that the majority of health workers, nearly 60 percent, do not feel they have access. There were no substantial differences between males and females. The low level of perceived access is spread throughout the provinces, but health workers in North Eastern, Eastern, and Western provinces were the least likely to report access to PEP, at only a third or less. In addition, a quarter or less of health workers in health centers or dispensaries believe they have access to PEP. 
Table 12 Percent of health workers who claim to know what PEP is, who accurately know what it is, who believe PEP is available at their facility, and who have experienced possible occupational exposure to HIV

\begin{tabular}{|c|c|c|c|c|}
\hline & $\begin{array}{l}\text { Say they know } \\
\text { what PEP is }{ }^{1}\end{array}$ & $\begin{array}{l}\text { Accurately know } \\
\text { what PEP is }\end{array}$ & $\begin{array}{l}\text { Say PEP is } \\
\text { available at the } \\
\text { health facility }\end{array}$ & $\begin{array}{c}\text { Experienced } \\
\text { possible HIV } \\
\text { exposure past } 12 \\
\text { months }^{1}\end{array}$ \\
\hline \multicolumn{5}{|l|}{$\overline{\operatorname{Sex}}$} \\
\hline Male & 66.8 & 55.7 & 41.8 & 17.9 \\
\hline Female & 57.7 & 47.4 & 41.7 & 16.4 \\
\hline \multicolumn{5}{|l|}{ Cadre } \\
\hline Doctor & 98.3 & 88.2 & 72.1 & 23.6 \\
\hline Clinical officer & 78.6 & 67.8 & 51.3 & 15.6 \\
\hline Registered nurse & 67.8 & 58.9 & 46.3 & 17.0 \\
\hline Enrolled nurse & 48.9 & 36.2 & 31.7 & 16.9 \\
\hline Laboratory staff & 53.2 & 41.9 & 37.2 & 19.0 \\
\hline Social worker & 66.7 & 57.1 & 54.6 & 12.5 \\
\hline VCT counselor & 86.7 & 75.5 & 60.4 & 9.0 \\
\hline Others & 67.3 & 57.3 & 46.4 & 14.4 \\
\hline \multicolumn{5}{|l|}{ Province } \\
\hline Central & 65.1 & 50.8 & 51.7 & 19.6 \\
\hline Coast & 70.8 & 62.8 & 37.2 & 16.3 \\
\hline Eastern & 51.2 & 43.1 & 31.3 & 20.3 \\
\hline Nairobi & 66.5 & 54.7 & 52.8 & 17.2 \\
\hline North Eastern & 53.5 & 40.7 & 23.9 & 11.2 \\
\hline Nyanza & 69.3 & 58.7 & 58.0 & 15.9 \\
\hline Rift Valley & 58.7 & 46.9 & 43.0 & 13.6 \\
\hline Western & 63.3 & 54.4 & 32.4 & 23.0 \\
\hline \multicolumn{5}{|l|}{ Type of facility } \\
\hline Hospital & 65.4 & 55.7 & 47.3 & 18.0 \\
\hline Health center & 52.1 & 40.9 & 25.1 & 17.9 \\
\hline Dispensary & 40.6 & 25.8 & 19.4 & 9.2 \\
\hline Maternity home & 63.3 & 48.7 & 39.7 & 12.9 \\
\hline \multicolumn{5}{|l|}{ Operating organization } \\
\hline Public & 59.3 & 48.8 & 39.6 & 17.2 \\
\hline Private & 63.4 & 52.1 & 45.5 & 13.4 \\
\hline Faith-based & 76.0 & 64.7 & 57.8 & 19.0 \\
\hline All respondents & 61.1 & 50.5 & 41.8 & 16.9 \\
\hline Number of health workers & 1,896 & 1,882 & 1,897 & 1,877 \\
\hline
\end{tabular}

${ }^{1}$ Among all respondents; ${ }^{2}$ i.e. can correctly describe PEP

In order to assess the need for and utilization of PEP, all respondents, regardless of whether they knew what PEP was or not, were asked whether they had had an experience in which they thought they could have been infected with HIV at work in the 12 months preceding the study. About 17 percent of all health workers reported being potentially exposed to HIV in the past 12 months (Table 12). When examined by cadre, doctors were the most likely to report such an event. Among the regions, health workers from Western Province were also most likely to report an incident of potential exposure. Among those who reported experiencing a possible exposure, close to half (47 percent) had multiple exposures during that time (data not shown). 
Those who reported potential occupational exposure to HIV were asked whether they sought PEP. This analysis is limited to those who had functional knowledge of PEP, and said it was accessible either at their facility or nearby $(n=661)$. The data show that among this subgroup, 13 percent had experienced an incident where they feared they could have been infected with HIV at work but only 46 percent of these sought PEP. The main reasons for not seeking PEP were lack of sufficient information (40 percent), followed by fear of the process (28 percent), PEP not available on that day (19 percent), not knowing where exactly to access it (9 percent), and not wanting to be tested for HIV (7 percent). These results suggest that many providers may not be utilizing PEP even if they could benefit from it and say it is accessible. Therefore there is need to educate them about this service and to get to the heart of why many remain reluctant to use it. FGDs pointed out some of these barriers:

Moderator: Why do you think some health workers do not seek PEP?

Male doctor: There is a lot of stigma whenever a health worker is suspected to be HIV-positive.

Female nurse: There is completely no confidentiality on HIV for health workers.

Clinical officer: Some health workers do not have information on PEP.

FGD, Eastern Province

Moderator: Do health workers seek PEP when they need it?

Female nurse: Yes they go, but the idea of being tested is fearful to them.

FGD, Coast Province

Health workers are not sensitized about PEP.

Male doctor, Nyanza Province

I do not know [whether PEP is available at the hospital].

Male doctor, North Eastern Province

We as staff know what PEP is but the drugs are not available.

Female doctor, Rift Valley Province

\section{Utilization of National HIV/AIDS Guidelines}

The Government of Kenya (GOK) has developed several national guidelines on HIV/AIDS, covering a range of topics from condoms to blood safety. There are eight ${ }^{3}$ guidelines that pertain to the prevention and management of HIV disease in a clinical setting, specifically guidelines on VCT, ARVs, PMCT, condoms, DTC, management of OIs, TB and leprosy, and home-based care. The KHWS provided an opportunity to assess the extent to which health workers had read these guidelines, not merely heard of them. Analysis here is limited to doctors, clinical officers, and nurses $(\mathrm{n}=1,494)$, who are supposed to be familiar with all eight guidelines. The results are presented in Figure 10 .

On average, respondents had read four of the eight guidelines, with physicians and clinical officers having read the most and enrolled nurses the least. There were slight variations by geographic region - on average, clinicians in Nairobi, Nyanza, Western, and North Eastern provinces had read more than four guidelines, while those in the remaining provinces had read fewer. When examined by type of facility, respondents in hospitals and maternity homes had read the most, an average of four each; those in health centers and dispensaries had read an average of three. Data by funding affiliation suggests that respondents in public facilities had read fewer guidelines (average 3-4) compared to those in faith-based or "other NGO" facilities (4-5).

\footnotetext{
${ }^{3}$ Nine guidelines were included in the questionnaire. However, one of these, blood safety, is relevant to only a specialized group of health workers and was dropped from the analysis.
} 
Figure 10 Average number of GOK HIV/AIDS guidelines read by cadre ${ }^{1}$

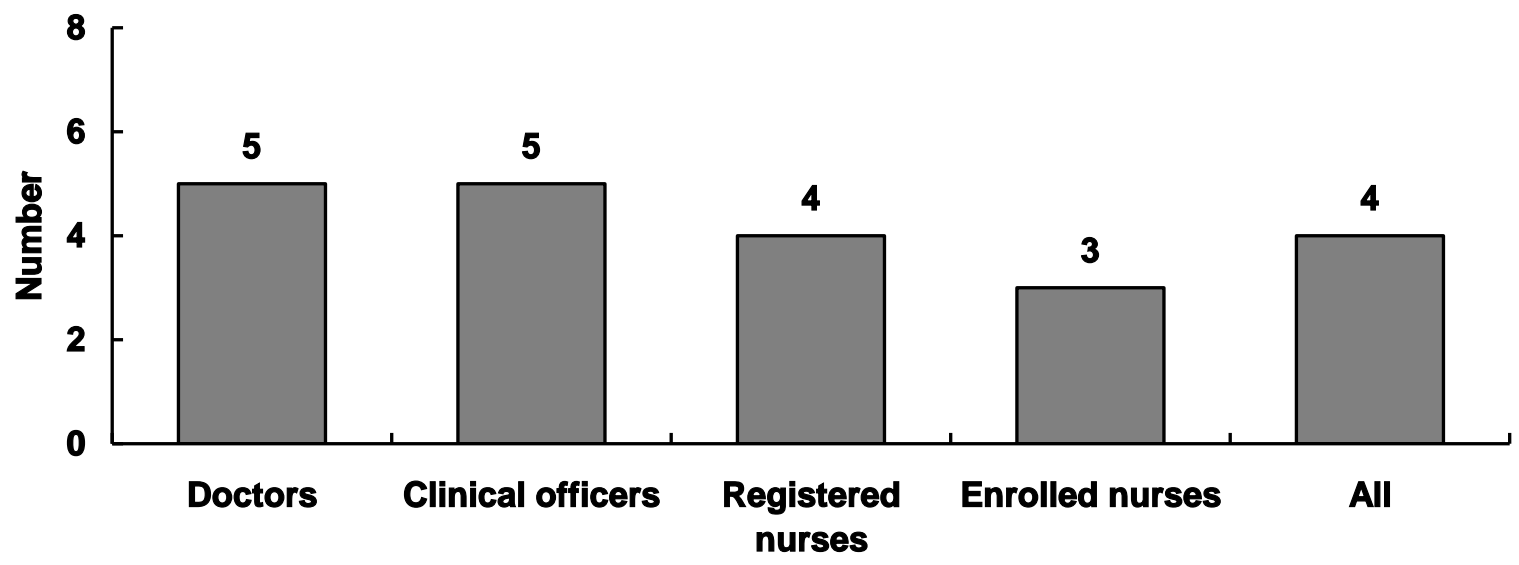

\section{Cadre}

${ }^{1}$ Among doctors, clinical officers and nurses, $n=1,494$

Only 7 percent of clinicians had read all eight guidelines, while 15 percent had not read any (data not shown). The most widely read publications were the PMCT guidelines, followed by condoms and opportunistic infections guidelines, each read by more than half of the respondents. The least read were the DTC and the ARV guidelines; indeed 74 percent of respondents were yet to read the DTC guidelines (see Figure 11).

Figure 11 Percent who have read specific GOK HIV/AIDS guidelines ${ }^{1}$

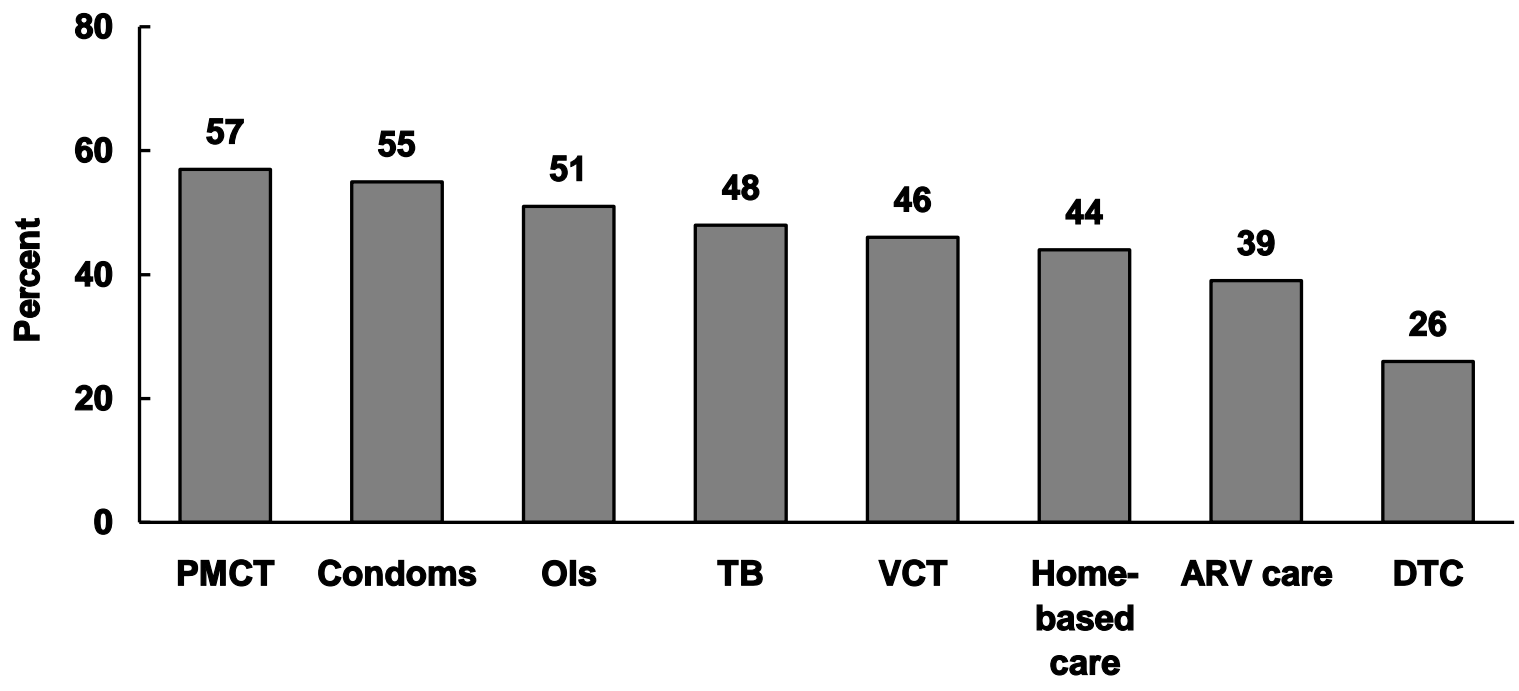

GOK HIVIAIDS guideline

${ }^{1}$ Among doctors, clinical officers and nurses; $n=1,494$ 
In general, health workers felt the guidelines were not well distributed at their facility, as an FGD with a group of health workers in North Eastern Province illustrates:

Female nurse: Guidelines are not accessible for health workers.

Male doctor: We know they [the guidelines] exist, the problem is disseminating them.

\section{Perception of HIV Prevention Messages and Knowledge of HIV Transmission}

\section{HIV prevention: ABC messages}

The thrust of HIV prevention efforts in Kenya revolve around promoting the "ABCs," which stand for Abstain, Be faithful, use Condoms correctly and consistently. Recent activities have added "D", to describe the need for "Diagnosis and disclosure", i.e., awareness of one's HIV status and disclosure to sexual partners. Providers are urged to promote these behaviors, and to advise their patients accordingly. However, it is known that the opinions of health workers greatly influence the options they offer patients. For example, health workers who harbor skepticism about condoms may be lukewarm when recommending them to clients. In order to assess the attitudes of health workers toward ABC messages, a series of agree/disagree questions were asked:

- Abstinence is effective in preventing the transmission of HIV

- Faithfulness to one uninfected partner is effective in preventing the transmission of HIV

- Consistent and correct use of male condoms is effective in preventing transmission of HIV

- Consistent and correct use of female condoms is effective in preventing transmission of HIV (the agree/disagree option also had a third choice, "never heard of female condoms")

The results show that providers are convinced about the role abstinence and faithfulness play in preventing HIV infection-93 percent of all health workers agreed that abstinence is effective in preventing HIV transmission, and a similarly high proportion (96 percent) agreed that faithfulness was also effective (data not shown). However, while 79 percent of health workers agreed that male condoms were effective in preventing HIV transmission, it implies that a sizable proportion (21 percent) did not seem convinced (see Table 13). This represents nearly a quarter of female health workers, a quarter of enrolled nurses, nearly 30 percent of respondents from Nairobi Province, and 37 percent of health workers employed in faith-based hospitals. That such a substantial proportion of health worker are skeptical of male condoms as a deterrent to HIV transmission identifies an important gap that should be addressed.

Most providers (96 percent) had heard of the female condom, but only 66 percent of these felt it was an effective method of preventing HIV. This suggests that a third of providers do not yet have confidence in the female condom and more education and sensitization may be needed to convince them of its role in HIV prevention. As was the case with male condoms, female respondents, especially nurses, were least confident about female condoms, and special interventions targeted to them may be appropriate. 
Table 13 Percent of health workers who know that male or female condoms are effective in preventing the transmission of HIV

\begin{tabular}{lcc}
\hline & Male condoms & Female condoms \\
\hline Sex & & \\
Male & 84.5 & 73.1 \\
Female & 74.5 & 62.4 \\
Cadre & & \\
Doctor & 87.8 & 74.1 \\
Clinical officer & 85.4 & 69.5 \\
Registered nurse & 77.8 & 62.3 \\
Enrolled nurse & 74.8 & 62.0 \\
Laboratory staff & 75.2 & 63.4 \\
Social worker & 87.5 & 77.3 \\
VCT counselor & 93.1 & 88.0 \\
Others & 85.8 & 83.0 \\
Province & & \\
Central & 75.0 & 60.0 \\
Coast & 84.9 & 71.6 \\
Eastern & 77.6 & 69.7 \\
Nairobi & 70.7 & 56.3 \\
North Eastern & 84.3 & 70.6 \\
Nyanza & 79.7 & 69.4 \\
Rift Valley & 76.7 & 61.1 \\
Western & 83.1 & 79.2 \\
Type of facility & & \\
Hospital & 77.6 & 65.2 \\
Health center & 81.6 & 71.4 \\
Dispensary & 81.0 & 71.1 \\
Maternity home & 77.1 & 57.7 \\
Operating organization & & \\
Public & 80.7 & 69.3 \\
Private & 73.7 & 59.3 \\
Faith-based & 63.1 & 47.9 \\
All respondents & 78.5 & 66.4 \\
Number of health workers & 1,893 & 1,802 \\
\hline
\end{tabular}

${ }^{1}$ Excludes 82 respondents who said they have not heard of the female condom

\section{Knowledge of HIV transmission}

All respondents in the study were asked two knowledge questions in order to assess whether they are up to date on certain basic information about HIV transmission. They were asked:

1. "Is it true or false that if a married man is HIV-positive, his wife is also definitely HIVpositive?" (to assess awareness of discordance)

2. "Is it true or false that if a pregnant woman is HIV-positive, her unborn child will also be HIV-positive?" (to assess understanding of vertical HIV transmission)

The results, presented in Table 14, show that nearly 90 percent of respondents knew about couple discordance, and 93 percent knew that not all babies born of HIV-positive mothers are HIV-positive. 
Table 14 Percent of health workers who know about couple discordance and vertical transmission of HIV

\begin{tabular}{|c|c|c|}
\hline & Correct kı & wledge about \\
\hline & Couple discordance & $\begin{array}{l}\text { Mother-to-child } \\
\text { transmission of HIV }\end{array}$ \\
\hline Sex & & \\
\hline Male & 88.6 & 92.3 \\
\hline Female & 89.9 & 94.0 \\
\hline Cadre & & \\
\hline Doctor & 96.7 & 98.3 \\
\hline Clinical officer & 94.2 & 96.5 \\
\hline Registered nurse & 92.1 & 95.6 \\
\hline Enrolled nurse & 84.9 & 91.9 \\
\hline Laboratory staff & 90.1 & 88.7 \\
\hline Social worker & 87.5 & 91.7 \\
\hline VCT counselor & 98.1 & 95.0 \\
\hline Others & 96.5 & 91.3 \\
\hline Province & & \\
\hline Central & 94.0 & 94.2 \\
\hline Coast & 90.7 & 96.9 \\
\hline Eastern & 90.6 & 93.4 \\
\hline Nairobi & 95.4 & 94.4 \\
\hline North Eastern & 72.8 & 83.5 \\
\hline Nyanza & 92.6 & 97.0 \\
\hline Rift Valley & 86.6 & 91.1 \\
\hline Western & 88.9 & 95.3 \\
\hline Type of facility & & \\
\hline Hospital & 89.9 & 93.9 \\
\hline Health center & 90.7 & 92.9 \\
\hline Dispensary & 84.0 & 90.6 \\
\hline Maternity home & 88.7 & 93.0 \\
\hline Operating organization & & \\
\hline Public & 90.5 & 93.8 \\
\hline Private & 84.3 & 91.7 \\
\hline Faith-based & 86.4 & 91.6 \\
\hline All respondents & 89.4 & 93.4 \\
\hline Number of health workers & 1,894 & 1,894 \\
\hline
\end{tabular}

\section{Impact of HIV on Health Workers' Lives}

Little is known about the personal psychosocial burden health workers may be enduring as a result of HIV/AIDS. The KHWS provided an opportunity to explore how HIV had affected health workers in their personal lives. Respondents were asked whether any of their immediate family members was currently infected with HIV, or whether any had died of AIDS. "Immediate family member" was defined as a partner, child, parent, or sibling. The results are presented in Table 15. 
Table 15 Percent of health workers who report familial HIV burden

\begin{tabular}{lcc}
\hline & $\begin{array}{c}\text { Has family member infected } \\
\text { with HIV or died of AIDS }\end{array}$ & $\begin{array}{c}\text { Currently caring for relative } \\
\text { living with HIV }\end{array}$ \\
\hline Sex & & \\
Male & 32.4 & 15.9 \\
Female & 40.4 & 17.5 \\
Cadre & & \\
$\quad$ Doctor & 33.0 & 17.9 \\
Clinical officer & 36.1 & 16.3 \\
Registered nurse & 36.5 & 15.7 \\
Enrolled nurse & 39.1 & 16.4 \\
Laboratory staff & 31.6 & 16.7 \\
Social worker & 50.0 & 36.4 \\
VCT counselor & 41.5 & 22.1 \\
Others & 33.8 & 11.3 \\
Province & & \\
Central & 36.1 & 12.5 \\
Coast & 34.8 & 9.6 \\
Eastern & 25.9 & 9.3 \\
Nairobi & 37.5 & 18.6 \\
North Eastern & 14.7 & 7.1 \\
Nyanza & 60.5 & 37.1 \\
Rift Valley & 37.5 & 15.6 \\
Western & 52.3 & 31.5 \\
Type of facility & & \\
Hospital & 37.2 & 17.3 \\
Health center & 38.5 & 14.4 \\
Dispensary & 39.6 & 17.9 \\
Maternity home & 32.8 & 16.2 \\
Operating organization & & \\
Public & 38.9 & 17.2 \\
Private & 30.6 & 14.8 \\
Faith-based & 32.5 & 16.7 \\
All respondents & 37.5 & 16.9 \\
Number of health workers & 1,862 & 1,893 \\
\hline & &
\end{tabular}

'Exclude 30 health workers who said, "don't know".

The data show that nearly 40 percent of health workers had an immediate family member either currently infected with HIV or who had died of AIDS. Females, social workers, and health workers from Nyanza Province were the most likely to report such a situation, while men, medical doctors and laboratory staff, and health workers from North Eastern Province were the least likely. Table 14 also shows that 17 percent of health workers in the study were currently caring for an HIV-positive immediate family member. Nearly 40 percent of health workers from Nyanza Province, and nearly 32 percent of their counterparts from Western Province, were presently caring for such a relative. 
The FGDs among the DHMT in Western Province illustrated the psychosocial impacts of HIV.

\author{
Moderator: What are your perceptions about the impact of HIV on health workers? \\ Clinician 4: It has killed some of us. \\ Clinician 1: It has made some of us poor. \\ Clinician 2: There is job overload. \\ Clinician 3: There is shortage of staff. \\ Moderator: What of personnel? \\ Clinician 2: They have become stressed. \\ Clinician 4: They go home early to take care of patients.
}

In some cases, it was felt that having HIV-positive patients to care for at home impacted health workers and made them less effective at work.

Yes, health workers end up neglecting patients because some of them have HIV-positive relatives at home to care for also.

Female nurse, Eastern Province

\title{
Substance Use
}

Health workers may be more stressed on the job than most other workers, since they see more illness and death during their routine activities. Some may turn to alcohol in order to deal with such stress, which can have implications for their personal and professional lives. The correlation between alcohol use and HIV in Kenya is well documented - for example, the 2003 KDHS found that women who drink alcohol have twice the prevalence of HIV as their non-drinking counterparts (19 percent vs. 9 percent) (CBS, 2004). Although it is anticipated that their answers would under-report the use of these substances, all respondents were nevertheless asked about their alcohol consumption habits, as well as use of other mood-altering substances.

Table 16 shows that four of ten health care workers reported ever drinking alcohol, with men more than twice as likely to report alcohol consumption as women. Medical doctors and laboratory staff were more likely to report ever drinking alcohol compared to other cadres, and enrolled and registered nurses were the least likely. When examined by province, health workers from Coast and North Eastern provinces were the least likely to report ever consuming alcohol, but there were no large variations between the other provinces. This could be partly explained by the religious influenceboth Coast and North Eastern provinces have a large proportion of Muslims in their communities, and alcohol consumption is prohibited in Islam. When examined by type of health facility, respondents in maternity homes were more likely to report ever consuming alcohol than those in the other facilities, and dispensary workers the least. There were sharp differences by funding affiliation, with respondents who work in faith-based hospitals the least likely to have ever consumed alcohol and those in public facilities the most. 
Table 16 Percent of health workers who have ever drunk alcohol and have got "really drunk"1 in the last one month

\begin{tabular}{|c|c|c|c|}
\hline & Ever drunk alcohol ${ }^{1}$ & $\begin{array}{l}\text { Been "really drunk" } \\
\text { in past month" }\end{array}$ & $\begin{array}{c}\text { Ever used Kha } \\
\text { (miraa) }^{1}\end{array}$ \\
\hline \multicolumn{4}{|l|}{ Sex } \\
\hline Male & 65.4 & 25.7 & 20.1 \\
\hline Female & 27.3 & 10.5 & 1.1 \\
\hline \multicolumn{4}{|l|}{ Cadre } \\
\hline Doctor & 74.2 & 19.6 & 12.2 \\
\hline Clinical officer & 54.8 & 24.7 & 15.3 \\
\hline Registered nurse & 40.5 & 18.6 & 8.3 \\
\hline Enrolled nurse & 30.2 & 14.2 & 5.3 \\
\hline Laboratory staff & 61.7 & 27.4 & 13.7 \\
\hline Social worker & 45.8 & 22.2 & 12.5 \\
\hline VCT counselor & 45.9 & 12.2 & 8.2 \\
\hline Others & 59.5 & 32.2 & 6.5 \\
\hline \multicolumn{4}{|l|}{ Province } \\
\hline Central & 44.4 & 19.0 & 3.0 \\
\hline Coast & 37.2 & 18.0 & 20.0 \\
\hline Eastern & 44.2 & 25.8 & 7.5 \\
\hline Nairobi & 46.9 & 17.3 & 3.0 \\
\hline North Eastern & 20.9 & 27.3 & 37.5 \\
\hline Nyanza & 42.1 & 13.3 & 4.5 \\
\hline Rift Valley & 41.8 & 21.6 & 4.1 \\
\hline Western & 47.9 & 20.6 & 5.2 \\
\hline \multicolumn{4}{|l|}{ Type of facility } \\
\hline Hospital & 42.0 & 20.0 & 9.2 \\
\hline Health center & 40.5 & 19.6 & 4.8 \\
\hline Dispensary & 37.8 & 15.68 & 8.0 \\
\hline Maternity home & 51.0 & 16.3 & 3.7 \\
\hline \multicolumn{4}{|l|}{ Operating organization } \\
\hline Public & 42.6 & 20.9 & 8.2 \\
\hline Private & 40.8 & 16.5 & 12.7 \\
\hline Faith-based & 33.9 & 5.6 & 3.2 \\
\hline All respondents & 41.7 & 19.4 & 8.3 \\
\hline Number of health workers & 1,892 & 789 & 1,884 \\
\hline
\end{tabular}

${ }^{1}$ Among all respondents; ${ }^{2}$ Among ever drinkers

Respondents who reported using alcoholic beverages were asked, "How many times in the past month have you had so much alcohol that you were really drunk?" Results show that 19 percent of alcohol consumers had been "really drunk" in the past month, translating into ten percent of the total base sample. Male alcohol consumers were more likely than their female counterparts to consume alcohol to a point of inebriation. When examined by occupation, laboratory staff who use alcohol were the most likely to consume to intoxication, followed by clinical officers. Provincial data show that alcohol users from North Eastern Province were the most likely to have been "really drunk" in the past month, while those from Rift Valley the least likely. There were only minor variations in inebriation status by type of facility, but sharp differences by funding affiliation-21 percent of alcohol consumers employed in public health facilities reported inebriation the month preceding the survey, compared to only six percent of their counterparts from faith-based health facilities. 
Respondents were also asked whether they had ever tried khat (miraa), bhang (cannabis or marijuana), glue, petrol, mandrax, cocaine, or heroine. Apart from khat ( 8 percent) and bhang ( 3 percent), health workers said they had not tried any of the other substances. One in five males had ever tried khat (Table 16). Respondents in male dominated professions such as doctors, clinical officers, and laboratory workers were more likely to have tried khat compared to those in female-dominated professions such as nurses. Respondents from Coast and North Eastern provinces, areas that have large Muslim communities, ${ }^{4}$ were the most likely to have used khat. Due to time constraints, the survey did not inquire about use of other substances such as pharmaceutical drugs, and these would be an important topic for further study.

Analysis was conducted in order to examine the correlation between alcohol consumption and HIV testing behavior. The data show that men who did not consume alcohol were more likely to have been tested for HIV, while the reverse was the case for females. Female drinkers were more likely to have taken the HIV test compared to nondrinkers; indeed females who had been inebriated the month before were the most likely to have been tested (see Figure 12). This may suggest a heightened risk perception among women compared to men, or gender-based differences in health-seeking behaviors, or it may be a spurious association. Further research shedding light to this topic could be useful.

\section{Figure 12 Percent of health workers who have ever been tested for HIV by intoxication preceding month}

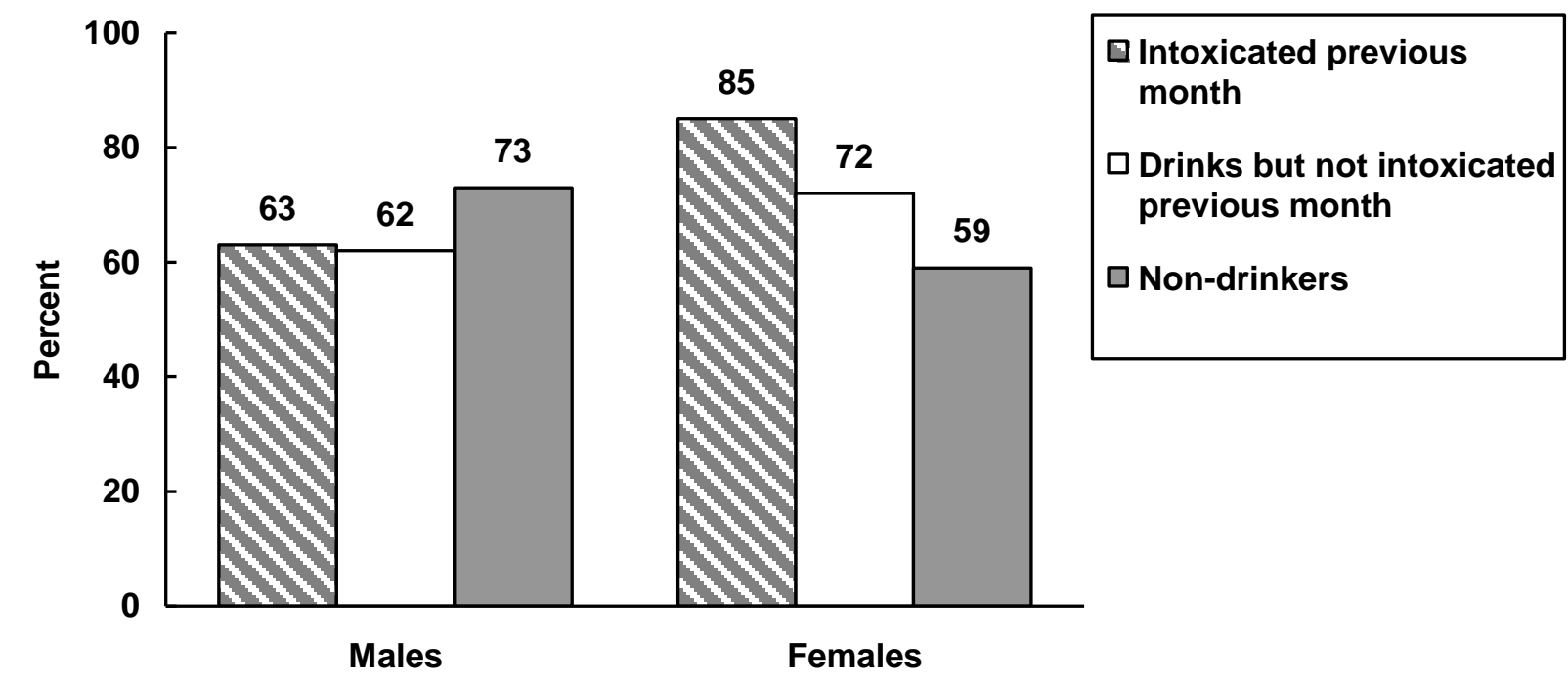

$\mathrm{n}=1,882$

\footnotetext{
${ }^{4}$ Khat is a popular recreational substance among certain Islamic cultures in Kenya.
} 


\section{Summary of Findings and Study Recommendations}

The national 2005 Kenya Health Workers Survey is the first survey of its kind in the country, and assesses the preparedness of health personnel to provide HIV/AIDS services. It was conducted in 247 health facilities including hospitals, health centers, dispensaries, and maternity homes. The facilities were stratified by province and by district, and included those managed by the government, by faithbased institutions, and by other private nongovernmental organizations. The survey sample comprised 1,897 health care providers, specifically doctors, clinical officers, nurses, laboratory staff, VCT counselors, and social workers.

The study provides an important opportunity to assess the health sector's capacity to make providerinitiated HIV testing available, following the recent launch of the government's guidelines on HIV testing in clinical settings (NASCOP/Ministry of Health 2004). In particular, the survey examines the training needs of health workers with regards to HIV counseling and testing. It identifies gaps in AIDS care provision, and assesses the training needs of health workers providing AIDS patient management. It also examines the occupational HIV risks experienced by medical practitioners, and assesses options available to them. Finally, it examines the psychosocial burden of HIV/AIDS on health workers, and the extent to which they too are affected by the disease in their personal capacity.

\section{Key Findings and Recommendations}

\section{Training needs in diagnostic testing and counseling}

Half the health workers in the survey said that they were engaged in diagnostic testing and counseling in their facility. Doctors and clinical officers were the most likely to be involved in DTC. For example, doctors ( 99 percent) and clinical officers ( 88 percent) had ever ordered an HIV test for an adult patient, compared to 42 percent of registered and 32 percent of enrolled nurses. About 73 percent of doctors and 52 percent of clinical officers had also ordered an HIV test for a pediatric patient, compared to 10 percent of registered and nine percent of enrolled nurses. When asked whether they had been trained in HIV testing and counseling, three quarters of the health workers who conduct this procedure said they had been trained in it. Thus the remaining quarter were undertaking HIV testing without appropriate training. Doctors and clinical officers, who provide the bulk of provider-initiated HIV testing, were the least likely to have been trained: 45 percent of physicians and 40 percent of clinical officers respectively who provided counseling or testing said they had not been trained in this procedure. By comparison, 30 percent of nurses, 28 percent of laboratory staff, 17 percent of the social workers and 5 percent of VCT counselors who provided this service also had not been trained. Among those who had received training, most (50 percent) received PMCT training, 37 percent received VCT training, 18 percent received DTC training, and 16 percent received pre-service training.

Where DTC was conducted, it seemed to have been conducted well -90 percent of health workers who reported initiating HIV testing for an adult also informed the patient about the test, obtained informed consent, and arranged for pre- and post-test counseling or conducted it themselves.

Likewise, over 90 percent of those who had conducted pediatric HIV testing also informed the child's parent or guardian, obtained oral or written consent, and made counseling available. Many health workers were highly supportive of DTC, recognized its benefits, and were willing to offer this service to patients. The management of the health facility was also largely seen as supportive of DTC. 
While over 90 percent of health workers considered themselves at least moderately confident in providing DTC, over 70 percent still expressed a need for further capacity building. The area of greatest demand for training was couple counseling, where nearly 90 percent of health workers felt they needed additional skills. Around 80 percent of respondents also felt they needed further training on how to recommend an HIV test to a patient, and how to provide post-test counseling for both HIVpositive and HIV-negative patients.

\section{Recommendations}

There is a need to equip all health workers who conduct HIV testing and counseling in clinical settings with adequate skills. There is also a great need to ensure that the other half of health workers who could conduct DTC but presently do not do so, can undertake this task. As indicated in the Guidelines for HIV Testing in Clinical Settings (NASCOP, 2004), health workers should be trained to routinely offer and appropriately recommend HIV testing for their patients. It may be particularly important to expand the proportion of nurses who can undertake this task, since nurses comprise the majority of health care workers. HIV disease can present with a variety of symptoms, or with rather non-specific symtpoms. Health workers need to be trained to offer HIV testing, so that patients can receive comprehensive care early enough in the disease process when treatment has a higher probability of success. Earlier knowledge of status will also allow HIV-infected persons to modify their behavior sooner, hence avert infection to partners. Refresher training to ensure continuous skills improvement among health workers is necessary, as there is great demand for it by nearly all respondents in the study. Participants for these opportunities should be selected judiciously, since training often comes with material benefits that could attract inappropriate candidates.

As DTC expands, more and more health workers, including laboratory staff, VCT counselors, and social workers, may be increasingly faced with situations where they might be expected or believe it is appropriate for them to order an HIV test. The recently launched DTC guidelines are not clear on which cadres of health workers are "allowed" to order HIV tests. As DTC scales up, there may be a need to clarify which health workers can order a test and which ones cannot.

\section{Perceived competence in care and management of HIV}

Data analysis pertaining to management of AIDS patients was confined to responses from doctors, clinical officers, and nurses $(n=1,494)$. While 80 percent of these had taken care of AIDS patients at their current post, only 33 percent said they had been trained in this aspect, and only 39 percent said they felt adequately prepared to undertake this task. Half or more felt they were not sufficiently trained to undertake laboratory monitoring of AIDS patients or to monitor patients on ART. About 60 percent said that ARVs were available in their facilities but 40 to 50 percent of them did not feel adequately prepared to assess patient readiness for ARVs, or to provide adherence counseling. And over 20 percent felt ill equipped regarding home-based care or psychosocial support. Even among those who had received some training, four out of ten still felt inadequately prepared. These findings suggest a substantial deficiency in capacity building.

\section{Recommendations}

As is the case with HIV testing in clinical settings, there is also a large unmet need for training in AIDS patient management among Kenyan health workers. At present, most training is often conducted in workshops outside the health care facility and frequently with material benefits, a process that often leaves some health workers grumbling about favoritism. Therefore, strategies that build capacity efficiently, equitably, and transparently are greatly needed. 


\section{Availability of and familiarity with Government of Kenya HIV/AIDS guidelines}

Of the eight national HIV/AIDS guidelines that should have been read by all doctors, clinical officers and nurses, and were explored in this survey, these clinicians had read an average of four. In addition, the recently launched DTC guidelines were yet to be read by 74 percent of the clinicians.

\section{Recommendations}

An effective dissemination strategy is required to increase health workers' access to national HIV/AIDS guidelines, including guidelines on DTC. Just as important are seminars, continuing education sessions, mentoring or other opportunities to discuss the guidelines once they arrive at health facilities.

\section{Stigma}

In general, health workers felt that AIDS patients were not stigmatized in their facilities; in fact four out of every ten health workers felt that AIDS patients were treated better than other patients due to increased resources directed at the disease. For the most part, health workers reported that AIDS patients were integrated with other patients within the wards, and appeared not to be isolated except on medical grounds. However, FGDs suggested that there was still underlying discrimination, with AIDS patients being placed at the back of the wards, or in less visible areas. FGDs also suggested some reluctance to manage AIDS patients and/or violations of their rights such as breaching confidentiality. Indeed, 15 percent of medical doctors surveyed felt that health workers should have the right to refuse to care for AIDS patients.

\section{Recommendations}

There is need to address stigma among health workers, and identify its root causes. At the same time, when examined in the context of the poor infection control environment in health facilities (see below), it may not be surprising that a certain amount of fear remains, with health workers apprehensive about being infected. Thus efforts to reduce stigma should be coupled with tangible improvements in infection control. In addition, strong efforts should be made to sensitize health workers about confidentiality, violations of patient rights, and upholding the dignity of patients. There may also be a need to develop supportive structures so that patients and others who identify stigmatizing behavior can seek assistance.

\section{Infection control supplies}

The study showed that Kenyan health workers feel they have an adequate supply of some infection control items but not others. For example, three quarters of the survey respondents said they had an adequate supply of gloves, and the same proportion said they had an adequate supply of sharps disposal containers. However, many said they lacked an adequate supply of running water (57 percent), soap (63 percent) and disinfectant (67 percent). The situation was similar across the various types of facilities, from hospitals to dispensaries. Public sector facilities specifically were less likely to have infection control supplies compared to faith-based or other private facilities. Of six items examined, health workers said that an average of 3.6 were available in sufficient supply. Only a third of participants said there were written guidelines about infection control at their facility. There were large regional differences: 70 percent of health workers in Nairobi Province and 58 percent of those in Nyanza Province reported awareness of guidelines, but the proportions did not reach 40 percent in any of the other provinces. 


\section{Recommendation}

The data suggest a severe need to greatly improve infection control supplies, guidelines, and the general environment in Kenyan health facilities. The problem appears to be widespread, and is particularly urgent in public sector facilities. In addition, wide regional disparities indicate the need to focus more attention on the most problematic provinces.

\section{Knowledge about PEP and experience with HIV exposure}

While 61 percent of Kenya's health workers said they know what PEP is, about 17 percent of these could not accurately describe it. Thus, of the study universe, only half the providers could be said to have functional knowledge about PEP-i.e., have heard of it and can accurately describe it. Medical doctors were the most informed of the sample, and enrolled nurses, who make up nearly half of the sample, were the least informed, with only about a third of this group possessing functional knowledge. Lack of awareness was widespread but was particularly acute in North Eastern, Eastern, and Rift Valley provinces, where level of awareness was below average.

Nearly one in five health workers had had an event in the previous 12 months where they felt they could have been exposed to HIV at work, and half of these had multiple exposures. Doctors (24 percent) were the most likely to report such an incident. Among all health workers who had functional knowledge about PEP, said PEP was available at their facility, and reported an incident of potential HIV exposure in the previous 12 months, only 46 percent sought it. Two thirds of those who did not seek PEP said it was because of a lack of sufficient information and fear of the process.

\section{Recommendations}

There is a compelling need to inform health workers about PEP, so that they are clear on what it is and how it can help them. There is also a need to make it widely available, and to ensure that health workers know when/where it can be found. There is also a need to reduce the social and psychological barriers hindering health workers from seeking it, particularly fear of the PEP provision process (including the HIV test), lack of confidentiality, and fear of stigma should other health workers find out that an employee has sought it.

\section{Personal HIV burden among health workers}

About 40 percent of heath workers surveyed had an immediate family member who was HIV infected or who had died of AIDS. Two out of every ten health workers were caring for an HIV infected immediate family member at the time of the survey. The greatest burden was in Nyanza province, where nearly 60 percent of respondents reported HIV infection among immediate family members, and where 40 percent of respondents were currently caring for an ailing close relative.

\section{Recommendations}

There is need to recognize that health workers are also personally affected by HIV, and the burden of care does not end at their health facility. Resources to help them recognize stresses associated with this burden, and access to coping strategies such as support groups, discounted medical care services, and similar cost-reducing initiatives, can lessen the strain they experience at home. Workplace programs to "care for the caregiver" can begin to address the challenges faced by health workers who are infected or may be dealing with HIV infection among members of their family. 


\section{Health workers' awareness of their own HIV status}

Nearly two thirds of health workers in Kenya said they had been tested for HIV, a considerably high number that indicates their level of alertness to this disease. About 43 percent of all health workers had been tested in the previous 12 months, implying that 57 percent had not been tested at all or had not been tested within that time period. Among all the health workers with a partner, half of these reported that the partner had not been tested, suggesting a large unmet need for couple counseling among health workers themselves. In general, respondents felt that they could take a confidential HIV test at work, although FGDs revealed elements of discomfort and fear that results of those found HIVpositive could be divulged.

When asked why they had never been tested for HIV, four out of ten of untested health workers said "no particular reason," about a third said they did not feel at risk, a third were "planning to go for the test," and a quarter said they were afraid of the results. Those who have tested were more likely to express greater confidence in providing this service to their patients.

There was considerable interest for self-testing among health workers, with 73 percent of respondents saying they would consider this option were it available.

\section{Recommendations}

While many have been tested, there is still a need to continue promoting HIV testing among health workers, particularly those who have not been tested or were tested over a year ago. There is also a need to promote partner HIV status awareness, and to make couple counseling and testing available for health workers. There is a major need to change the apathy toward HIV status awareness particularly among the large proportion of never-testers who state "no particular reason" as the explanation for having never tested. A positive attitude towards knowing their own HIV status appears likely to empower health workers to encourage patients to agree to HIV testing - the study found that health workers who are aware of their HIV status are also better at providing HIV testing services to their patients. Thus HIV testing among health workers could also boost their confidence in delivering this service.

The data also reveal considerable interest in HIV self-testing. Therefore, a feasibility study exploring this option may be useful. Such a study would need to weigh the ethical and psychological costs and benefits of making this new technology available. In addition, the current VCT or DTC guidelines are not clear on self-testing. The findings in this report suggest the need to review these guidelines to provide direction on self-testing.

\section{Attitudes toward HIV behavior change messages}

Overall, providers believed abstinence and be-faithful messages; over 90 percent agreed that these strategies are effective in preventing HIV transmission. However, fewer respondents ( 79 percent) believed the same about male condoms. Health workers were even more skeptical of female condoms, with only 66 percent feeling they were an effective method of preventing HIV. In particular, providers in faith-based facilities were unconvinced about the efficacy of either condom, compared to other health workers.

\section{Recommendations}

As in the rest of Kenyan society, there continues to be a diverse opinion about condoms among health workers. Because provider attitudes and beliefs are likely to affect how they promote condoms, there is a need to educate health workers and to help them disentangle the inconsistent messages about 
these important means of HIV prevention. DTC rollouts may provide an important vehicle for addressing this knowledge deficiency and values conflict.

\begin{abstract}
Alcohol and drug use
The data reveal that four in ten workers had ever drunk alcohol, and 20 percent of ever-drinkers had been intoxicated the month preceding the study. Providers in male-dominated cadres (doctors, clinical officers, laboratory staff) were the most likely to have ever consumed alcohol and also to report inebriation the month before the study. Use of other drugs (including marijuana, khat, Mandrax, cocaine, heroine, petrol, and glue) was explored and found to be low: only 8 percent of the survey respondents had ever used khat, and only 3 percent had ever used marijuana. The study found genderbased differentials regarding alcohol consumption and HIV testing behavior: men who consumed alcohol were less likely to have ever taken an HIV test while women who consumed alcohol were more likely to have been tested, suggesting gender-based risk perceptions or health seeking behavior.
\end{abstract}

\title{
Recommendations
}

Further study of alcohol and substance abuse is needed among health workers, in order to determine whether it is a significant problem, and if so, how it can be addressed. Such a study should include addictive substances available in the health care facilities such as methanol and similar mood-altering products. Such a study should also investigate the gender dynamics of alcohol use and HIV risk perception. 


\section{References}

Central Bureau of Statistics, Ministry of Health, Kenya Medical Research Institute, National Council for Population and Development, ORC Macro, and Centers for Disease Control. 2004. Kenya Demographic and Health Survey, 2003. Nairobi: Central Bureau of Statistics.

Ministry of Health and World Health Organization. 2005. Health sector status report, year 2000 2002. Nairobi: Ministry of Health, Division of Health Management Information Systems.

Ministry of Health. 2005. AIDS in Kenya: trends, interventions and impact. $7^{\text {th }}$ Edition. Nairobi: Ministry of Health.

NASCOP/Ministry of Health. 2004. Guidelines for HIV Testing in Clinical Settings. Nairobi: Ministry of Health.

Ministry of Health and Department for International Development. 2005. MOH human resources validation report. Unpublished report.

National Coordinating Agency for Population and Development (NCPAD), Ministry of Health, Central Bureau of Statistics and ORC-Macro. 2005. Kenya Service Provision Assessment Survey, 2004. Nairobi: NCPAD.

UNAIDS. 2006. 2006 Report on the global AIDS epidemic. Geneva: UNAIDS. 


\section{Appendix 1 \\ Districts and health care facilities in the Kenya Health Worker Survey}

\section{A. Districts}

\begin{tabular}{|c|c|c|c|c|c|c|c|}
\hline \multirow[b]{2}{*}{ Province } & \multirow[b]{2}{*}{ Districts } & \multirow{2}{*}{$\begin{array}{l}\text { Number of } \\
\text { facilities }\end{array}$} & \multicolumn{5}{|c|}{ Number of respondents } \\
\hline & & & Hospitals & $\begin{array}{l}\text { Health } \\
\text { centers }\end{array}$ & Dispensaries & $\begin{array}{l}\text { Maternity } \\
\text { homes }\end{array}$ & All \\
\hline $\begin{array}{l}\text { Nairobi } \\
\text { (12 facilities) }\end{array}$ & 1. Nairobi & 12 & 100 & 14 & 10 & 3 & 127 \\
\hline \multirow{3}{*}{$\begin{array}{l}\text { Central Province } \\
\text { (30 facilities) }\end{array}$} & 1. Nyeri & 11 & 91 & 0 & 10 & 0 & 101 \\
\hline & 2. Thika & 11 & 31 & 10 & 4 & 13 & 58 \\
\hline & 3. Maragua & 8 & 39 & 13 & 3 & 0 & 55 \\
\hline \multirow{3}{*}{$\begin{array}{l}\text { Coast Province } \\
\text { (22 facilities) }\end{array}$} & 1. Lamu & 10 & 55 & 17 & 3 & 0 & $\overline{75}$ \\
\hline & 2. Tana River & 5 & 50 & 6 & 3 & 0 & 59 \\
\hline & 3. Malindi & 7 & 57 & 0 & 4 & 6 & 67 \\
\hline \multirow{4}{*}{$\begin{array}{l}\text { Eastern } \\
\text { Province } \\
\text { (54 facilities) }\end{array}$} & 1. Embu & 15 & 95 & 18 & 12 & 6 & 131 \\
\hline & 2. Isiolo & 10 & 4 & 3 & 12 & 0 & 19 \\
\hline & 3. Makueni & 13 & 57 & 14 & 8 & 0 & 79 \\
\hline & 4. Machakos & 16 & 138 & 5 & 7 & 9 & 159 \\
\hline $\begin{array}{l}\text { North Eastern } \\
\text { Province } \\
\text { (8 facilities) } \\
\end{array}$ & 1. Garissa & 8 & 97 & 2 & 4 & 0 & 103 \\
\hline \multirow{5}{*}{$\begin{array}{l}\text { Nyanza } \\
\text { Province } \\
\text { (23 facilities) }\end{array}$} & 1. Gucha & 5 & 7 & 14 & 4 & 0 & 25 \\
\hline & 2. Homa Bay & 4 & 44 & 10 & 0 & 0 & 54 \\
\hline & 3. Kisumu & 7 & 105 & 0 & 4 & 8 & 117 \\
\hline & 4. Migori & 5 & 43 & 10 & 4 & 0 & 57 \\
\hline & 5. Rachuonyo & 2 & 0 & 0 & 4 & 0 & 4 \\
\hline \multirow{7}{*}{$\begin{array}{l}\text { Rift Valley } \\
\text { Province } \\
\text { (73 facilities) }\end{array}$} & 1. Bomet & 14 & 50 & 11 & 12 & 0 & 73 \\
\hline & 2. Keiyo & 15 & 35 & 17 & 15 & 0 & 67 \\
\hline & 3. Kajiado & 12 & 0 & 19 & 8 & 10 & 37 \\
\hline & 4. Laikipia & 6 & 94 & 10 & 2 & 3 & 109 \\
\hline & 5. Marakwet & 10 & 31 & 19 & 3 & 1 & 53 \\
\hline & 6. Nakuru & 13 & 83 & 14 & 8 & 4 & 109 \\
\hline & 7. Transmara & 3 & 28 & 1 & 0 & 0 & 29 \\
\hline \multirow{3}{*}{$\begin{array}{l}\text { Western } \\
\text { Province } \\
\text { (25 facilities) }\end{array}$} & 1. Busia & 12 & 54 & 12 & 3 & 6 & 75 \\
\hline & 2. Kakamega & 8 & 0 & 10 & 4 & 0 & 14 \\
\hline & 3. Teso & 5 & 37 & 0 & 4 & 0 & 41 \\
\hline Total & 27 & 247 & 1,425 & 249 & 155 & 68 & 1,897 \\
\hline
\end{tabular}


B. Health care facilities

\begin{tabular}{|c|c|c|}
\hline $\begin{array}{l}\text { 1. Nairobi District } \\
\text { G.S.U. Dispensary } \\
\text { Gertrude's Childrens Priv. Hosp } \\
\text { Guru Nanak Priv. Hosp. } \\
\text { J.K.I.A. Disp. } \\
\text { Jericho H.C. } \\
\text { Kabete Disp. } \\
\text { Kahawa H.C. } \\
\text { Kayole H.C. } \\
\text { M.P. Shah Priv. Hosp. } \\
\text { Mathare Lions H.C. } \\
\text { Mbagathi D.H. } \\
\text { Parkroad Priv. Mat. Hosp. }\end{array}$ & $\begin{array}{l}\text { 2. Nyeri District } \\
\text { Amboni Disp. } \\
\text { Gatei Disp. } \\
\text { Gatondo Disp } \\
\text { Karatina D.H. } \\
\text { Karemeno Disp. } \\
\text { Kiganjo Police College Disp } \\
\text { Ndimaini Disp. } \\
\text { Nyeri P.G.H. } \\
\text { Othaya D.H. } \\
\text { Ruruguti Disp. } \\
\text { Tumutumu Mission Hosp. }\end{array}$ & $\begin{array}{l}\text { 3. Thika District } \\
\text { Chania Maternity and Nursing Home } \\
\text { Gachege Disp. } \\
\text { Gakoe Disp. } \\
\text { Gatundu D.H. } \\
\text { Igegania H.C. } \\
\text { Jomo Kenyatta College of Agric. and } \\
\text { Technology Hospital } \\
\text { Kilimambogo Mission Hosp. } \\
\text { Ruiru H.C. } \\
\text { St. Mulumba's Mission Hosp. } \\
\text { Thika Nursing Home Priv. Mat. Hosp. } \\
\text { Thiritha Priv. Mat. Hosp. }\end{array}$ \\
\hline $\begin{array}{l}\text { 4. Maragwa District } \\
\text { Gachanjiru Mission Hosp } \\
\text { Githumu A.I.C. Mission Hosp. } \\
\text { Kaguthi Disp. } \\
\text { Kandara H.C. } \\
\text { Kangari Disp. } \\
\text { Kigumo H.C. } \\
\text { Makuyu H.C. } \\
\text { Maragua D.H. }\end{array}$ & $\begin{array}{l}\text { 5. Lamu District } \\
\text { Baharani H.C } \\
\text { Bargoni H.C. } \\
\text { Kizingitini Disp. } \\
\text { Lake Kenyatta S.D.H. } \\
\text { Lamu D.H. } \\
\text { Langoni Medical Clinic Priv. H.C. } \\
\text { Madodoni H.C. } \\
\text { Makowe H.C. } \\
\text { Mkunumbi Disp. } \\
\text { Naja Medical Clinic Priv. H.C. }\end{array}$ & $\begin{array}{l}\text { 6. Tana River District } \\
\text { Bura H.C. } \\
\text { Hola D.H. } \\
\text { Korati Disp. } \\
\text { Mnazini Disp. } \\
\text { Ngao S.D.H. }\end{array}$ \\
\hline $\begin{array}{l}\text { 7. Malindi District } \\
\text { Galana Private Hosp } \\
\text { Malindi D.H. } \\
\text { Malindi Nursing Home Priv. Hosp. } \\
\text { Marereni Disp } \\
\text { Star Priv. Hosp } \\
\text { Watamu Nursing Home Priv. Mat. } \\
\text { Hosp. } \\
\text { Watamu S.D.A. Mission Disp }\end{array}$ & $\begin{array}{l}\text { 8. Embu District } \\
\text { A.C.K. Kianjokoma Mission H.C } \\
\text { A.C.K. Kiriari Mission Disp } \\
\text { Consolata Kyeni Mission Hosp } \\
\text { Embu P.G.H. } \\
\text { G.K. Prisons (Embu) Disp. } \\
\text { Gatunduri Disp } \\
\text { Joy Kim Nursing Home Priv. Mat. } \\
\text { Hosp. } \\
\text { Kangaru Disp. } \\
\text { Kangaru Priv. Hosp. } \\
\text { Kanja Disp. } \\
\text { Kariari Disp. } \\
\text { Kianjokoma H.C. } \\
\text { Kibugu H/C } \\
\text { Kithunguri Disp. } \\
\text { Maroloni Disp. }\end{array}$ & $\begin{array}{l}\text { 9. Isiolo District } \\
\text { Al-Fallah H.C. } \\
\text { Anti-Poaching Unit Disp. } \\
\text { G.K. Prisons (Isiolo) Disp. } \\
\text { Garbatulla S.D.H. } \\
\text { Garfasa Disp. } \\
\text { Iresaboru Disp. } \\
\text { Isiolo Samburu Complex Disp. } \\
\text { Kulamawe Disp. } \\
\text { Mau Kadera Disp. } \\
\text { School Of Artillery Disp. }\end{array}$ \\
\hline
\end{tabular}




\begin{tabular}{|c|c|c|}
\hline $\begin{array}{l}\text { 10. Makueni District } \\
\text { German Agro-Action Priv. Disp } \\
\text { Kalulini Disp. } \\
\text { Kibwezi H.C } \\
\text { Kibwezi Sisters Mercy Miss. Disp. } \\
\text { Kisau H.C. } \\
\text { Kyuasini Disp. } \\
\text { Machakos D.H. } \\
\text { Makindu S.D.H. } \\
\text { Makueni D.H. } \\
\text { Masumba Disp. } \\
\text { Matiliku H.C. } \\
\text { Mweni Disp. } \\
\text { Tawa H.C. }\end{array}$ & $\begin{array}{l}\text { 11. Machakos District } \\
\text { Bishop Kioko Mission Hosp. } \\
\text { Kangundo S.D.H. } \\
\text { Kathiani S.D.H. } \\
\text { Kimutwa H.C } \\
\text { Kyanzori Disp } \\
\text { Machakos D.H. } \\
\text { Machakos Nursing Home } \\
\text { Mitamboni H.C. } \\
\text { Mutituni Disp. } \\
\text { Ndithi/Kombori Mission Disp. } \\
\text { New Ngei Road Nursing Home } \\
\text { Priv. Mat. H } \\
\text { Ngoleni Disp. } \\
\text { Ol Donyo Sabuk Nursing Home } \\
\text { Priv. Mat. } \\
\text { Sengani Disp. } \\
\text { Shalom Priv. Hosp. } \\
\text { Thinu H.C. }\end{array}$ & $\begin{array}{l}\text { 12. Garissa District } \\
\text { Balambala Disp. } \\
\text { Dagahaley Private Hosp. } \\
\text { Dentu Private H.C. } \\
\text { G.K. Prisons (Garissa) Disp. } \\
\text { Garissa P.G.H. } \\
\text { Hagadera Priv. Hosp. } \\
\text { I.F.O. Priv. Hosp. } \\
\text { Iftin S.D.H. }\end{array}$ \\
\hline $\begin{array}{l}\text { 13. Gucha District } \\
\text { Annex Medical Clinic Priv. Disp. } \\
\text { Etago H.C. } \\
\text { Magena Disp. } \\
\text { Nyamache S.D.H. } \\
\text { Tabaka Mission H.C. }\end{array}$ & $\begin{array}{l}\text { 14. Homa Bay District } \\
\text { Homa Bay D.H. } \\
\text { Mitonyo Clinic Priv. H.C. } \\
\text { Ndhiwa H.C. } \\
\text { St. Paul's Mission H.C. }\end{array}$ & $\begin{array}{l}\text { 15. Kisumu District } \\
\text { Aga Khan Priv. Hosp } \\
\text { Hongo-Ogosa Disp. } \\
\text { Jalaram Maternity Priv. Mat. Hosp } \\
\text { Kisumu D.H. } \\
\text { Marie Stopes Priv. Mat. Hosp. } \\
\text { Nyangande Disp. } \\
\text { Nyanza P.G.H. }\end{array}$ \\
\hline $\begin{array}{l}\text { 16. Migori District } \\
\text { Konywokodalo Disp. } \\
\text { Macalder S.D.H. } \\
\text { Migori D.H. } \\
\text { Ranen S.D.A. Mission Disp. } \\
\text { Rongo H.C. }\end{array}$ & $\begin{array}{l}\text { 17. Rachuonyo District } \\
\text { Adiedo Disp. } \\
\text { C.C.M. Shirikisho Mission Disp. }\end{array}$ & $\begin{array}{l}\text { 18. Bomet District } \\
\text { Chebunyo Disp. } \\
\text { Chepmaner Disp } \\
\text { Gelegele Disp. } \\
\text { Gorgor Disp. } \\
\text { Kapkoros H.C. } \\
\text { Merigi Disp. } \\
\text { Olbutyo H.C. } \\
\text { Olkoyin H.C. } \\
\text { Sigor H.C. } \\
\text { Silibwet Disp. } \\
\text { Siongiroi Disp. } \\
\text { Tarakwa Disp. } \\
\text { Tegat Disp. } \\
\text { Tenwek Mission Hosp. }\end{array}$ \\
\hline
\end{tabular}




\begin{tabular}{|c|c|c|}
\hline $\begin{array}{l}\text { 19. Keiyo District } \\
\text { Chepebo Disp. } \\
\text { Chepkorio H.C. } \\
\text { Emsea Disp } \\
\text { Iten D.H. } \\
\text { Kamuosor H.C. } \\
\text { Kamwosot H.C. } \\
\text { Kapkabus Forest Disp. } \\
\text { Kaptagat Disp. } \\
\text { Kaptarakwa H.C. } \\
\text { Kapteren Disp. } \\
\text { Leilboinet Disp. } \\
\text { Muskut Disp. } \\
\text { N.Y.S. Disp. } \\
\text { Sergoit Disp. } \\
\text { Simotwo Disp. }\end{array}$ & $\begin{array}{l}\text { 20. Kajiado District } \\
\text { Engatatael Disp. } \\
\text { Engatatek Disp. } \\
\text { Eretiti Disp. } \\
\text { Kitengela H.C. } \\
\text { Matasia Nursing Home } \\
\text { Namanga H.C. } \\
\text { Ngong Hills Nursing Home } \\
\text { Oletepesi Disp. } \\
\text { Oloolaiser Secondary School Disp. } \\
\text { Oloyaikalani Disp. } \\
\text { Ongata Rongai Cottage Nursing } \\
\text { Home Priv } \\
\text { Ongata Rongai H.C. }\end{array}$ & $\begin{array}{l}\text { 21. Laikipia District } \\
\text { Doldol H.C. } \\
\text { Engachura Disp. } \\
\text { Medical Reception Station/Air } \\
\text { Base Med. } \\
\text { Nanyuki Cottage Priv. Hosp. } \\
\text { Nanyuki D.H. } \\
\text { Nanyuki Maternity And Nursing }\end{array}$ \\
\hline $\begin{array}{l}\text { 22. Marakwet District } \\
\text { Chesoi Mission H.C. } \\
\text { Kapcherop H.C. } \\
\text { Kapelenge Disp. } \\
\text { Kapsowar A.I.C. Mission Hosp. } \\
\text { Kapsowar D.H. } \\
\text { Kaptalama H.C } \\
\text { Kibigos H.C. } \\
\text { Liter Mission Disp. } \\
\text { Tenden Disp } \\
\text { Tot H.C. }\end{array}$ & $\begin{array}{l}\text { 23. Nakuru District } \\
\text { Bahati H.C. } \\
\text { G.K. Farm Disp. } \\
\text { Industrial Area Disp. } \\
\text { Kabatini Disp. } \\
\text { Longonot Disp. } \\
\text { Maai Mahiu H.C. } \\
\text { Molo S.D.H. } \\
\text { Mulemi Mat \& Nursing Home. } \\
\text { Nakuru Nursing Home } \\
\text { Nakuru P.G.H. } \\
\text { Nakuru Pediatrics Clinic. } \\
\text { Nakuru War Memorial Hospital } \\
\text { Njoro H.C. }\end{array}$ & $\begin{array}{l}\text { 24.Trans Mara District } \\
\text { Kilgoris D.H. } \\
\text { Lolgorian H.C. } \\
\text { Transmara D.H }\end{array}$ \\
\hline $\begin{array}{l}\text { 25. Busia District } \\
\text { Bujumba A.C.K. Mission Disp. } \\
\text { Busia D.H. } \\
\text { Butula Mission H.C. } \\
\text { G.K. Prisons (Busia) Disp. } \\
\text { Khunyangu S.D.H. } \\
\text { Lunga'nyiro Disp. } \\
\text { Matayos H.C } \\
\text { Nambale Cottage Priv. Mat. Hosp. } \\
\text { Nambale H.C. } \\
\text { Port Victoria S.D.H. } \\
\text { Sio-Port H.C. } \\
\text { Tanaka Maternity Nursing Home }\end{array}$ & $\begin{array}{l}\text { 26. Kakamega District } \\
\text { Bushiangala H.C. } \\
\text { Chebwayi Disp. } \\
\text { FPAK Clinic } \\
\text { Ileho H.C. } \\
\text { Lunga'nyiro Disp. } \\
\text { Musaa Medical Clinic } \\
\text { Shibwe H.C. } \\
\text { Sivilie Disp. }\end{array}$ & $\begin{array}{l}\text { 27. Teso District } \\
\text { Akichelesit G.S.U. Disp. } \\
\text { Alupe S.D.H. } \\
\text { Chamasiri Disp. } \\
\text { Kolanya Mission Disp. } \\
\text { St. Marys Chelelemuk Disp }\end{array}$ \\
\hline
\end{tabular}




\title{
Appendix 2 \\ 2005 Kenya Health Worker Survey Data Collection and Management Team
}

\author{
Supervisors \\ John Wanyungu, Eastern Province \\ Daniel Kongai, Nairobi and Central Province \\ Naomi Shiyonga, Rift Valley Province (south) \\ Mary Annuncieta, Western Province \\ Magdalene Cherop, Nyanza Province \\ Patricia Oluoch, Rift Valley Province (north) \\ Sahal Mohammed, North Eastern Province \\ Cornellius Mutangili, Coast Province
}

Interviewers

Eastern Province

Billy Mrema

Rebecca Wafula

Emanuel Mutinda

Nairobi/Central Province

Margaret Njoki

Angela Wamucie

Western Province

Josphat Kibet

Japhet Kubai

Lillian Wangeci

Rift Valley Province (north)

Mercy Mbogoh

Rael Okiya

Vincent Khayeri

\author{
Rift Valley Province (south) \\ Hilda Chebet \\ Beatrice Bariu \\ Chrisantus Khaemba \\ North Eastern Province \\ Daniel Tuitoek \\ Jackson Mulungye \\ Emmanuel Wekesa \\ Kiptum Kosgei \\ Coast Province \\ Olendo Esikokho \\ Peris Mbugua \\ James Kalola \\ Nyanza Province \\ Caroline Mugambi \\ Cleophas Muliro \\ Samuel Gatamo \\ Lance Duda
}

\section{Data entry and management}

Population Council/Horizons

Data entry and management

Technical Advisor: Scott Giebel

Data Manager: George Odingo

\section{NASCOP Data Entry Team}

Wafula Wabwile (Supervisor)

Felix Bukachi

Moses Isaji

Mohammed Abbas

Evelyn Katungu

Mercy Mbogoh

Kenneth Mwangi 


\section{Appendix 3 \\ Kenya Health Workers Survey 2005 Individual Questionnaire}

Date of data collection:

$\frac{1}{\text { Day Month }}$

Province:

\begin{tabular}{|ll|ll|ll|ll|}
\hline Nairobi & 1 & Eastern & 3 & North Eastern & 5 & Nyanza & 7 \\
Western & 2 & Central & 4 & Rift Valley & 6 & Coast & 8 \\
\hline
\end{tabular}

District:

\begin{tabular}{|c|c|c|c|}
\hline Nairobi 01 & Embu 08 & Homa Bay 15 & Laikipia 22 \\
\hline Nyeri 02 & Isiolo 09 & Kisumu 16 & Marakwet 23 \\
\hline Thika 03 & Makueni 10 & Migori 17 & Nakuru 24 \\
\hline Maragua 04 & Machakos 11 & Rachuonyo 18 & Transmara 25 \\
\hline Lamu 05 & Moyale 12 & Bomet 19 & Busia 26 \\
\hline Tana River 06 & Garissa 13 & Keiyo 20 & Kakamega 27 \\
\hline Malindi 07 & Gucha 14 & Kajiado 21 & Teso 28 \\
\hline
\end{tabular}

Name of health facility:

Type of health facility:

Affiliation/funding of health facility:
1....Hospital

2....Health center

3....Dispensary

4....Maternity

5.... Other (specify)
1...Public
2...Private
3...Mission
4...NGO
5...Other (specify): 
Interviewer's name:

Supervisor's name:
Interviewer code:

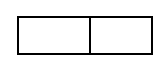

Supervisor code:

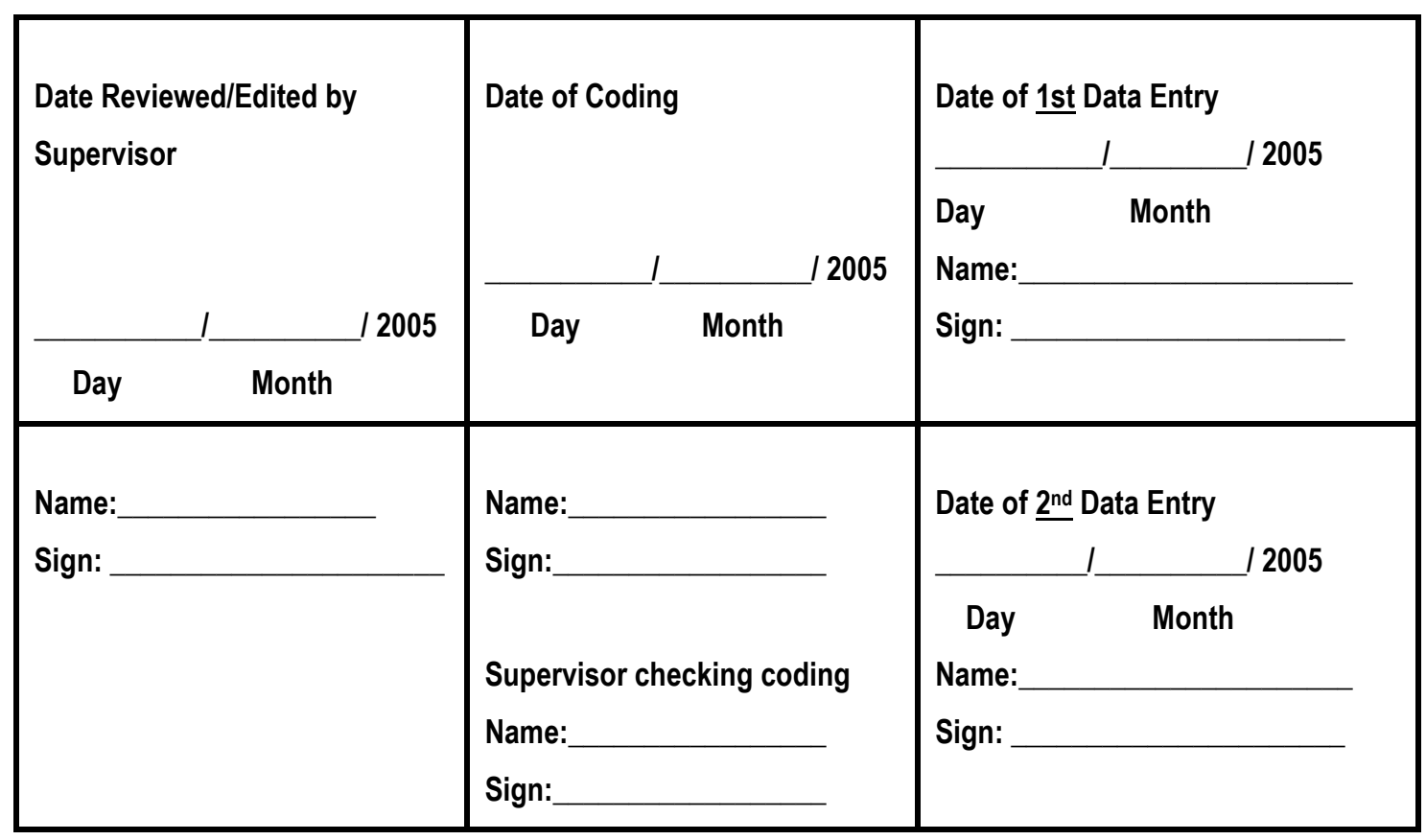




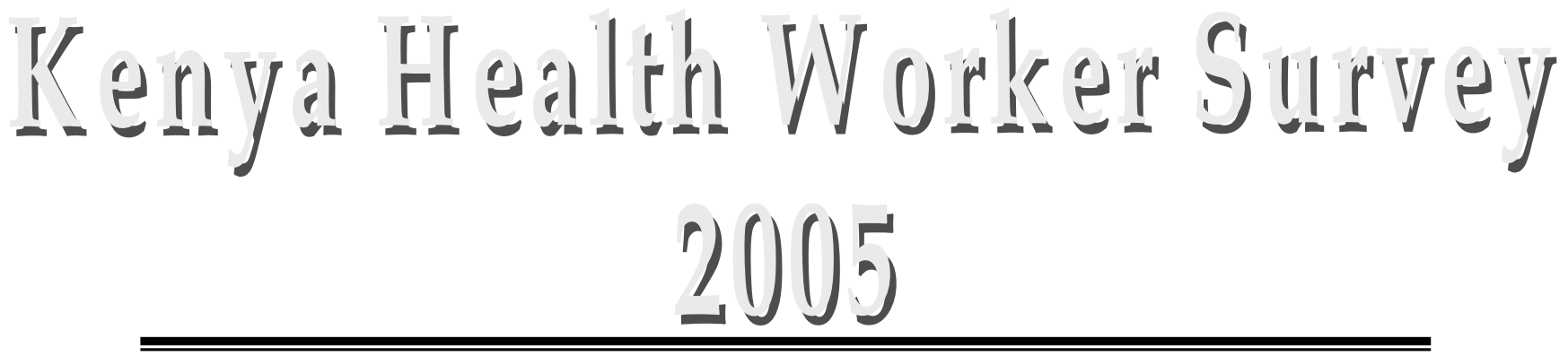

\section{Introduction}

Hello. My name is .I am part of a Ministry of Health study team that is conducting a survey of HIV testing practices among health workers in Kenya. Before we proceed, I am required to seek your consent. May I ask you to please read the consent form below.

\section{Consent Form}

\section{Purpose of the Study}

The Ministry of Health, through the National AIDS and STD Control Program (NASCOP) is conducting a study of the HIV testing practices among health workers in Kenya. This survey is being conducted in several health facilities nationwide. It examines health workers' perceptions and practices pertaining to HIV testing of themselves and their patients. It also examines the HIV risks health workers encounter in and outside their work environment.

\section{Procedures}

Participation in this survey is voluntary. The purpose of this form is to obtain your consent to participate. If you choose to participate, I will guide you to complete a questionnaire. The questionnaires will be stored in a sealed envelope and will not be accessible to anyone else in the hospital. It will take you between 30 and 45 minutes to answer the questions. For most questions, there are no right or wrong answers, and what is important is your opinion. Your name will not appear anywhere on the questionnaire and it will not be possible to know which responses came from any individual.

There are no known risks in participating in this survey. The management in this facility has agreed to cooperate with this study, and allow the staff to take off from work to complete the questionnaire. The study will inform the Ministry of Health, health workers, and other stakeholders on how best to improve HIV testing policies and practices in this country.

If you start the interview and wish to stop at any time, you are free to do so. If you do not wish to participate, please let me know. Your decision to participate or not participate will not affect your standing in this institution. If you have any questions before you proceed, please ask me. If you would like more information about the study or its results, please feel free to contact:

\section{Dr. Isaiah Tanui}

Deputy Head, NASCOP

National AIDS/STD TB and Leprosy Control Program (NASCOP/NTLP)

P.O. Box 19361, Nairobi 00200

Phone: 020-272-9502/49

\section{Please read and circle Yes or No}

I have been informed that completion of this questionnaire is voluntary. $1 \ldots$ Yes Date:

2...No (if "No", please speak to facilitator) 


\section{KENYA HEALTH WORKERS SURVEY, 2005}

\section{SECTION I. BACKGROUND INFORMATION}

1. Sex

2. When were you born?

3a. How long have you been working here in this facility?
1....Female

2....Male

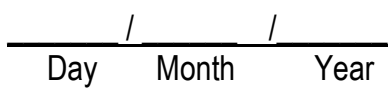

years (if less than 1 year, write 00 )

3b. What is your job? (circle all that apply)
01......Medical doctor
02....Clinical officer
03.....Registered nurse
04....Enrolled nurse
05.....Social worker
06......Lab technician/technologist
07.....VCT counselor
88.... Other (specify)

3c. In which department(s) are you currently working?

4a. What is the highest level of professional education you have attained? (circle only one answer)

01...Certificate

02...Diploma or higher diploma

03...University degree

04...Postgraduate

88... Other (specify)

4b. What is your religion? (circle only one answer)

01...Catholic

02...Protestant

03...Muslim

04.....No religion/None

88.... Other (specify)

5a. What is your marital status? (circle only one answer)

01... Single (never married) (Go to Q6a)

$02 . .$. Currently married

03... Not married but living with partner(Go to $\mathbf{Q 6 a}$ )

04...Divorced/widowed/separated (Go to Q6a) 


\section{5b. Among those who are married only:}

88... Other (specify):

FOR MALES: Do you have more than one wife?

1...Yes How many?

2... No (Go to Q6a)

For FEMALES: Does your husband have more than one wife?

1...Yes How many?

2.... No (Go to Q6a)

\section{SECTION II: OCCUPATIONAL HIV RISK}

6a. Would you say the supply of (gloves....read each item in list) is adequate, inadequate, or not available in this facility? (please circle appropriate response)

$\begin{array}{ll}\text { i. } & \text { Gloves } \\ \text { ii. } & \text { Gowns } \\ \text { iii. } & \text { Disposal container for sharps } \\ \text { iv. } & \text { Bleach solution (disinfectant) } \\ \text { v. } & \text { Soap } \\ \text { vi. } & \text { Running water }\end{array}$

\begin{tabular}{lll}
$\begin{array}{l}\text { Adequate } \\
\text { supply }\end{array}$ & $\begin{array}{l}\text { Inadequate } \\
\text { supply }\end{array}$ & $\begin{array}{l}\text { Not } \\
\text { available }\end{array}$ \\
\hline 1 & 2 & 3
\end{tabular}

6b. In this facility, are there written guidelines about actions a health worker should take if he or she is accidentally exposed to HIV at work?

$1 \ldots$ Yes

2...No

3...Don't know/Not sure

6c. How concerned are you about getting HIVIAIDS at your workplace? (circle only one answer)

1...Very concerned

2...Somewhat concerned

3....Not concerned at all

6d. Do you know what Post-exposure prophylaxis (PEP) is?

1...Yes

2...No (Go to Q7a) 
6e. Could you please describe what it is? (please record verbatim)

\begin{tabular}{|c|c|}
\hline C & W \\
\hline 1 & 2 \\
\hline
\end{tabular}

6f. Is post-exposure prophylaxis available for health workers own use in this facility or elsewhere?

7a. In the last 12 months, have you had a situation at work when you thought you were infected with HIV?

7b. How many times has that happened in the last 12 months?

7c. The last time you felt you might have been exposed to HIV in your work place, did you seek post-exposure prophylaxis?

7d. Why didn't you seek post-exposure prophylaxis? (Do not read list but probe for at least 3 reasons)
1...Yes, available here

2...Yes, available elsewhere

3....No, not available here or elsewhere

4...Don't know/Not sure

1...Yes

2...No (Go to Q8a)
1...Yes (Go to Q8a)
2...No

77....Many times/can't tell

01...Did not have enough information about PEP

02...Did not want to take the HIV test

03...PEP not available

04...Did not know where to go

05...Was afraid of going through the process

06...Did not need it (never had an accident)

88... Other (specify):

\section{SECTION III: HIV TESTING AND COUNSELING}

8a. Where are patients tested for HIV in this facility?

1...Laboratory

2...Antenatal clinic (ANC)

3...Maternity

4...Out -patient department

5...VCT

6. ...Not tested here 
8b. If a health worker wanted to be tested for HIV, do you think he or she can get a confidential HIV test at this facility?

8c. Some people would like to test themselves in private or even at home. If such a kit were available in Kenya, would you yourself be interested in self-testing?

9a. Do you yourself conduct HIV counseling or testing at this facility?

9b. Have you ever received any training in HIV counseling or testing?
1...Yes

2...No

3...HIV test not available at this facility

1...Yes

2...No
1...Yes

2...No

1...Yes

2...No (Go to Q10a) 9c. What kind of HIV training in counseling or testing have you received? (circle all that apply)

10a. Have you ever ordered an HIV test on an adult patient?

10b. The last time you did so, who initiated the request for the HIV test?

10c. Before the test was performed, was the patient informed that you were going to do an HIV test?

10d. Did you provide or arrange for counseling before the patient was tested?
1...VCT training

2...Counseling and testing for PMTCT

3...Pre-service counseling and testing training

4.... Diagnostic counseling and testing (DCT)

5... Other (specify)

1...Yes

2...No (go to Q11a)
01...Patient

02...Patient's family member

03...I requested test

04...Another health worker initiated request

88...Don't know/can't remember

$01 \ldots$ Yes, informed patient

$02 . .$. No, patient not informed about the test

88...Don't know/can't remember
$01 .$. Yes, provided counseling myself before the test

$02 . . . Y e s$, arranged for someone else to counsel the patient

03...No, counseling was not given before the test

88... Don't know/can't remember 
10e. How were test results given to the patient?

11a. Have you ever ordered an HIV test on a young child (under age 6)?

11b. The last time you did so, who initiated the request for the test?

11c. Before the test was performed on the child, was the parent/guardian informed that you were going to do an HIV test on the child?

\section{1d. Was verbal or written permission obtained for the HIV} test?

11e. How were the HIV test results given?
01...Provided counseling myself to give test results $02 . .$. Arranged for someone else to counsel the patient about test results

03...Patient given test results without additional information or counseling

$04 .$. Test results were not given to the patient

88... Don't know/can't remember

1...Yes

2...No (Go to 12)

01...Parent or guardian

02... Other family member

03...I requested test

$04 . .$. Another health worker initiated request

88...Don't know/can't remember

$01 .$. Yes, informed parent/guardian

02....No, parent/guardian not informed about the test

88...Don't know/can't remember

$01 . . . Y e s$, verbal permission was obtained before the test

02... Yes, written permission was obtained from the parents/guardian

03...No, permission for the test was not given

88.... Don't know/can't remember

01...Provided counseling myself to give test results 02...Arranged for someone else to counsel the parent/guardian about test results

03...Patient/guardian given test results without additional information or counseling

04... Test results were not given to the patient

88.... Don't know/can't remember

12a. Would you say you are highly confident, moderately confident or you have low confidence in....(Read each item and circle appropriate response)

\begin{tabular}{llll} 
Highly & Moderately & Low & Not \\
confident & confident & confidence & app \\
\hline
\end{tabular}

i. Recommending HIV testing to a patient?

ii. Counseling a patient who has accepted to test for HIV before testing?

iii. Counseling a patient whose HIV test is positive?

iv. Counseling a patient whose HIV test is negative?

v. Couple counseling?
1
2

2

2

2

2

3

3

3

3 
12b. Do you need training in...(Read each item in list and circle all that apply)

$\begin{array}{lrr}\text { in...(Read each item in list and circle all that apply) } & \text { Yes } & \text { No } \\ \text { 1...Recommending HIV testing to a patient } & 1 & 2 \\ \text { 2... Counseling a patient who has accepted to test for HIV } & 1 & 2 \\ \text { 3...Carrying out an HIV test } & 1 & 2 \\ \text { 4...Counseling a patient whose HIV test is positive } & 1 & 2 \\ \text { 5...Counseling a patient whose HIV test is negative } & 1 & 2 \\ \text { 6...Couple counseling } & 1 & 2\end{array}$

12c. In the last 12 months, how often have you requested an HIV test for.... (Read each item in list and circle appropriate responses)

\begin{tabular}{lcccc} 
& $\begin{array}{c}\text { Always } \\
\text { requests }\end{array}$ & $\begin{array}{c}\text { Sometimes } \\
\text { requests }\end{array}$ & $\begin{array}{c}\text { Never } \\
\text { requests }\end{array}$ & $\begin{array}{c}\text { Not } \\
\text { applicable }\end{array}$ \\
\hline i. Medical patients & 1 & 2 & 3 & 4 \\
ii. Pregnant women & 1 & 2 & 3 & 4 \\
iii. STI patients & 1 & 2 & 3 & 4 \\
iv. TB patients & 1 & 2 & 3 & 4 \\
v. Mothers of HIV-positive children & 1 & 2 & 3 & 4
\end{tabular}

13a. Do you know what couple counseling and testing is?

1.......Yes

2........No (For those who do not know: "Couple counseling and testing is when two people [could be husband and wife, a couple planning to get married, or two sexual partners] learn their HIV status together)".

13b. Would you recommend couple counseling for...(Read items in list and circle appropriate responses):

\begin{tabular}{|c|c|c|}
\hline & & Yes \\
\hline i. & Married patients who test HIV positive & 1 \\
\hline ii. & STI patients & 1 \\
\hline iii. & TB patients & 1 \\
\hline iv. & Pregnant women & 1 \\
\hline
\end{tabular}

13c. Do you feel that it is okay for a health worker to test a

1. Yes patient for HIV without the patient's knowledge?

2. No. (Go to $Q 14$ )

If yes, why? 
14. Have you read the Government of Kenya's national guidelines on... (Read each item on list and circle appropriate response):

Guidelines No

a. Voluntary counseling and testing (VCT) Yes

b. Clinical manual for ARV providers

c. Prevention of mother to child transmission of HIV PMTCT

d. Blood safety

e. Condoms

f. HIV testing in clinical settings (DCT)

g. Management of opportunistic infections (Ols)

h. TB and leprosy guidelines for health workers

i. Home-based care

15. Do you feel that the management in this facility is encouraging, discouraging or neutral in promoting HIV testing among...(Read list and circle appropriate responses)

\section{Encouraging Discouraging}

Neutral
i. Medical patients
ii. Pregnant women
iii. STI patients
iv. TB patients
v. Mothers of HIV-positive children

1

2

3

1

2

3

1

2

3

1

2

3

1

2

3

16a. Is it true or false that ...(Read each item on list and circle appropriate response)

\begin{tabular}{|c|c|c|c|}
\hline & True & False & Don't know \\
\hline i. If a married man is HIV-positive, his wife is definitely also HIV-positive? & 1 & 2 & 3 \\
\hline ii. If a pregnant woman is HIV-positive, her unborn child will also be HIV-positive? & 1 & 2 & 3 \\
\hline $\begin{array}{l}\text { 16b. In Kenya, health providers are required to ask patients who test HIV-negative } \\
\text { to come back for a follow-up HIV test. How soon after the last test should an } \\
\text { HIV-negative client come back for the follow-up test? Is it after... } \\
\text { (read all items and circle one response) }\end{array}$ & & \multicolumn{2}{|c|}{$\begin{array}{l}\text { 1...After one week } \\
\text { 2...After } 3 \text { weeks } \\
\text { 3...After } 3 \text { months } \\
\text { 4...After } 6 \text { months } \\
\text { 5...Don't know/not sur }\end{array}$} \\
\hline
\end{tabular}


17a. In this facility, do you think HIV-positive patients get better, worse or the same kind of care as HIV-negative patients?

17b. In the wards in this facility, are HIV-positive patients isolated from other patients?
1...HIV+ patients get better care

2...HIV+ patients get worse care

3...HIV+ patients get the same care
1 ...Yes, but only when medically necessary

2...Yes, but often for no medical reason

3...No, they are mixed with the others

4...Not applicable (no wards or admission facility)

18. Do you agree or disagree that.... (Read each item in list and circle one response)

Agree Disagree

a. Health care workers have a right to refuse to care for an HIVIAIDS patient

1

b. Health care workers have a right to know whether a patient is HIV-positive 1

c. Patients with HIV should be kept separately from other patients

1

2

d. A husband who tests HIV-positive should be required to inform his wife

2

e. Health workers who are HIV-positive should be allowed to continue working with patients

1

2

\section{SECTION VI: CARE FOR HIV-INFECTED PERSONS}

19a. Do you feel adequately trained to care for AIDS patients? $1 \ldots$ Yes

2...No

3...Not applicable/not part of my job

19b. Have you ever taken care of a confirmed AIDS patient in this facility?

1...Yes

2...No (Go to Q20a)

19c. Are Anti-retroviral drugs (ARVs) available in this facility? $01 \ldots$ Yes

02...No (Go to Q19e)

88...Don't know (Go to Q19e)

19d. In this facility, do you yourself ever prescribe anti-retroviral drugs?

1 ...Yes

2...No 
20a. Have you received any training in the care and management of AIDS patients?

1...Yes

2...No (go to Q21)

20b. Have you received training in .....?

(Read each item in list and Circle all that apply)

1...Basic counseling for HIVIAIDS patients

2...Management of patients on Anti-retroviral drugs

3...Management of opportunistic infections

4...Home-based care for AIDS patients

5...ARV program management

6...Laboratory monitoring of AIDS patients

21. Would you say you are highly competent, moderately competent, or have low competence in...(Read each item in list and circle one response)

\begin{tabular}{|c|c|c|c|}
\hline $\begin{array}{l}\text { Highly } \\
\text { competent }\end{array}$ & $\begin{array}{l}\text { Moderately } \\
\text { competent }\end{array}$ & $\begin{array}{l}\text { Low } \\
\text { competence }\end{array}$ & $\begin{array}{l}\text { Not } \\
\text { applicable }\end{array}$ \\
\hline
\end{tabular}

i. Clinical assessment of an AIDS patient

1

2

3

4

ii. Assessing patient readiness for antiretroviral

therapy (ART)

$\begin{array}{llll}1 & 2 & 3 & 4 \\ 1 & 2 & 3 & 4 \\ 1 & 2 & 3 & 4 \\ 1 & 2 & 3 & 4 \\ 1 & 2 & 3 & 4 \\ 1 & 2 & 3 & 4 \\ 1 & 2 & 3 & 4 \\ 1 & 2 & 3 & 4\end{array}$




\section{SECTION VII: ATTITUDES ABOUT HIV PREVENTION}

22. Do you agree or disagree that ...(Read each item in list and circle only one response)

a. Abstinence is effective in preventing transmission of HIV

\begin{tabular}{cc} 
Agree & Disagree \\
\hline 1 & 2 \\
1 & 2 \\
1 & 2
\end{tabular}

c. Consistent and correct use of male condoms is effective in preventing transmission of HIV

Never heard

d. Consistent and correct use of female condoms is effective in preventing transmission of HIV

(never heard of FC)

\section{SECTION VIII: PERSONAL EXPERIENCE WITH HIVIAIDS}

23a. I do not want to know the name or the relationship to you, but does anyone $01 \ldots$ Yes in your immediate family currently have HIVIAIDS or died of AIDS?

("Immediate family" means your wife/husband/partner, child, father, 88...Don't know/not sure mother, brother, or sister)

23b. Are you currently caring for or helping out with an immediate family 1 ...Yes member who has AIDS?

2...No

\section{SECTION IX: HIV TESTING}

24a. If you had HIVIAIDS and your employer found out, Yes No

do you think...(Read all in list and circle one response)

$\begin{array}{lll}\text { 1...Y You would be fired } & 1 & 2 \\ \text { 2...Your job would be a bit more difficult } & 1 & 2 \\ 3 . . \text { Nothing would happen to your job } & 1 & 2\end{array}$

24b. I don't want to know the results, but has your current sexual

$01 \ldots$ Yes

partner ever been tested to see if she/he has HIV? (if you have more

02...No

than one partner, refer to your "main" partner)

03...No partner/not applicable

88...Don't know/not sure

24c. I don't want to know the results, but have you ever been tested for HIV?

1...Yes

2...No (Go to Q25) 
24d. When was the last time you were tested?

24e. I do not want to know the results of the test, but the last time you were tested for HIV, were you told the results of the test?
1 ...Less than 12 months ago

2 ... 12-23 months ago

$3 . . .2$ or more years ago

1...Yes

2...No

FOR ALL WHO HAVE BEEN TESTED FOR HIV, GO TO question 26a

\section{Only for those who have never been tested for HIV:}

What are the reasons you have never been tested for HIV? (Do not read list but probe for other reasons and circle the first 3 reasons)
$01 . . . \mathrm{I}$ do not feel I am at risk

02...No particular reason/don't know why

03...I do not know where to go for a test

$04 . . . \mathrm{l}$ am afraid of the results

05...I cannot afford the cost of the test

06... I am afraid people would know my

results

07...My partner has already been tested so I

do not need to

08... I am still single

09...I do not trust those HIV tests

$10 . . . I$ am planning to get tested

88... Other (specify)

\section{SECTION XI: ALCOHOL AND SUBSTANCE ABUSE}

26a. Have you ever drunk alcohol?

1 ...Yes

2...No (go to Q26c)

26b. How many times in the past month have you had so much alcohol that you were really drunk? times (if no times, write 0)

26c. Some people have tried a range of different types of drugs. Which of the following, if any, have you tried? (Read each and Circle all that apply)

$\begin{array}{lll} & \text { Yes } & \text { No } \\ \text { Khat/Miraa } & 1 & 2 \\ \text { Bhang } & 1 & 2 \\ \text { Glue } & 1 & 2 \\ \text { Petrol } & 1 & 2 \\ \text { Mandrax } & 1 & 2 \\ \text { Cocaine } & 1 & 2 \\ \text { Heroine } & 1 & 2\end{array}$

27. We are now at the end of our questionnaire. Are there any comments you would like to make?

THANK YOU VERY MUCH. YOUR PARTICIPATION AND THE INFORMATION YOU HAVE PROVIDED IS VERY IMPORTANT. 


\section{Appendix 4 \\ Kenya Health Workers Survey \\ Focus Group Discussion Guide}

\section{Consent Form}

\section{Purpose of the Study}

The Ministry of Health, through the National AIDS and STD Control Program (NASCOP), is undertaking a study of HIV testing in clinical settings. The study will be conducted in severa health facilities nationwide. It examines health workers' perceptions and practices pertaining to HIV testing of themselves and their patients. It also examines the HIV risks health workers encounter in and outside work environment.

\section{Procedures}

Participation in this survey is voluntary. The purpose of this form is to obtain your informed consent to take part in this study. If you choose to participate, the person carrying out the study will invite you and 6-8 other colleagues to take part in a group discussion. The discussion will take 40-60 minutes. The person conducting the study may wish to use a tape recorder to obtain an accurate record of your responses. If you do not wish to have what you say recorded on tape, you are free to say so. What you say and the recorded tapes will be kept confidential. We will not use your name in any report.

There are no known risks of taking part in this study. However, the study will inform the Ministry of Health, health workers, and other stakeholders on how to improve HIV testing policies and practices in this country.

If you choose to participate, we shall ask you to indicate so by circling on the next page. When you circle your consent, it shows that you agree to take part in the discussion. This form will not in any way be linked to what you say. If you choose to participate and wish to withdraw at any time, you are free to do so.

Your decision to participate/not participate/withdraw from the study will in no way affect your position in this facility. If you have additional questions about this study or your rights in this study, please feel free to contact the following

Dr. Isaiah Tanui

Deputy Director

National AIDS/STD TB and Leprosy Control Program (NASCOP/NTLP)

P.O. Box 19361

Nairobi 00200

Phone: 020-272-9502/49 


\section{Your Consent}

\section{Please Circle the Appropriate Number}

1. I GIVE my consent to take part in this discussion. I have read this consent form. I was given a chance to ask questions and all my questions have been answered. I know that taking part in this study is my choice. I know that I may leave the discussion at any time.

Date:

2. I DO NOT give consent to take part in this study (Thank respondent and excuse him/her) 


\section{Focus Group Discussion Guide}

\section{A. ICEBREAKER}

How long have you been working in this hospital?

Where were you working before you came here?

\section{B. HIV TESTING AMONG PATIENTS}

1. What are your views about the current HIV testing practices in the health care settings in general and in your own facility in particular?

Probe:

- Is HIV testing generally available to patients who need to know their status??

- Are testing kits available?

- Do patients have to wait very long before being served?

2. Are there any government or other policies/guidelines that guide HIV testing in this facility?

Probe:

- What does the policy say?

- How is it publicized (how are providers informed about it?

- Where is it placed?

- Is a copy available? (if available, ask to see a copy with you)

3. To what extent does your facility encourage HIV testing among patients suspected to be HIV infected?

Probe:

- Do you encourage the patient to get tested or do you leave it for the patient to decide?

- $\quad$ Do you seek the support of family members in advising a patient to get tested?

4. What are some of the barriers in providing HIV testing to patients in this facility?

Probe:

- Are there cultural barriers (e.g. married women cannot come alone?

- Are there social barriers?

- Is lack of testing supplies a barrier?

- Are the facilities easily accessible or are they scattered?

- Are the hours of operation conducive?

- Is there an adequate number of staff to serve patients?

- Is testing available at different locations in the facility or just in one location? 
5. Do you feel that health workers are sometimes a barrier to HIV testing here at this facility?

Probe:

- $\quad$ They cannot keep confidentialityLack of supplies

- $\quad$ May not be friendly

- $\quad$ May not have time due to work overload

- $\quad$ May not be well trained in HIV testing/have stigma

6a. To what extent does the management of this facility encourage HIV testing of patients who need this service?

Probe:

- Do they communicate clearly about testing here at this facility?

- Do they avail space and equipment?

- Do they avail staff to counsel and test clients?

$6 \mathrm{~b}$. In your opinion, what are some ways that the management of this facility may discourage HIV testing of patients who need this service?

6c. How can the barriers to HIV testing in the clinical setting we have discussed be addressed?

7.In your opinion, who should conduct HIV counseling and testing in the clinical setting and why? (Moderator: Do not probe immediately until participants have given their responses)

Probe:

- Is it nurses, doctors, clinical officers, VCT counselors or who?

- Why?

8.What skills would health workers in this facility require to effectively offer HIV testing to patients who need this service?

Probe:

- Do they need any training?

- If so, in which areas/topics?

- Which departments are most in need of training? 


\section{OCCUPATIONAL EXPOSURE}

1. What are your perceptions about the impact of HIV on health workers/ How has HIV affected health workers?

Probe:

- How has it affected the lives of health workers

- $\quad$ Do you know of health workers who are caring for infected family members at home?

- $\quad$ Do you know of health workers who got infected at work?

- How did they get infected (e.g. during a surgical procedure, lab accident.....)

- Regardless of how they got infected, how are they coping?

2. What measures are in place here to protect health workers from HIV infection?

Probe:

- Are there any policies or guidelines? How are they communicated to staff?

- Is counseling/testing available especially for staff or do they line up with everyone else?

3. Is PEP available for staff in this facility?

Probe: Do you think health workers seek PEP when they need it?

- Why do you think some do not seek PEP?

- $\quad$ Do you think health workers are well informed about PEP?

- $\quad$ Do you think some health workers are hesitant to seek PEP because they have to be tested for HIV first?

- $\quad H o w$ can more health workers be encouraged to seek PEP?

4. In your view, do health workers seeking HIV testing get this service when they need it? If not what are the barriers and how can they be overcome?

Probe:

- Would you seek HIV testing here yourself? Why/why not?

5. Do you think health workers would be interested in self-testing if such a kit were available?

Probe:

- $\quad$ Would you want to test yourself at home?

- Would you test other family members?

- $\quad$ Do you think health workers who turn out to be HIV+ would act irrationally

(e.g., commit suicide) or do you think health workers can "handle it"? 


\section{STIGMA AND DISCRIMINATION OF PLWHA IN THE HEALTH CARE SETTING}

1. How are HIV+ patients treated in this facility?

Probe:

- $\quad$ Do you think HIV+ patients are treated the same way as HIV-patients in this facility?

- Is there a difference in the management of HIV-positive versus HIV-negative patients?

- How do the kitchen staff treat the HIV+ patients?

- How do the cleaners treat the HIV+ patients?

- $\quad H o w$ do the nurses take care of the HIV+ patients e.g. bathing or feeding etc?

- $\quad$ During clinical rounds, are HIV+ patients reviewed with the same level of attention given to other patients?

2. To what extent do health workers in this area contribute to stigma/discrimination of HIV infected patients?

Probe:

- In what way do health workers propagate stigma unknowingly?

- What measures can be taken to reduce stigma?

3. What happens to HIV+ health workers in this facility?

Probe:

Are they allowed to continue working?

Are they assigned other duties?

Are they given less visible roles?

4. In your own opinion, how should HIV+ health workers be handled at the place of work to avoid stigma/discrimination?

Probe:

At early stages of HIV?

When they are having full blown AIDS?

THANK YOU 